\title{
Renata Furia Sanchez
}

\section{Análise acústica não linear da voz pós laringectomia parcial}

Tese de doutorado apresentada ao Programa de Pós-Graduação Interunidades em Bioengenharia da Escola de Engenharia de São Carlos / Instituto de Química de São Carlos / Faculdade de Medicina de Ribeirão Preto da Universidade de São Paulo como parte dos requisitos para obtenção do título de doutor em Ciências.

Área de Concentração: Bioengenharia

Orientadora: $\operatorname{Prof}^{a} \operatorname{Dr}^{a}$ Lídia Cristina da Silva Teles

\section{São Carlos}


AUTORIZO A REPRODUÇÃO TOTAL OU PARCIAL DESTE TRABALHO, POR QUALQUER MEIO ÇONVENCIONAL OU ELETRÔNICO, PARA FINS DE ESTUDO E PESQUISA, DESDE QUE CITADA A FONTE.

1. Voz. 2. Qualidade da voz. 3. Distúrbios da voz. 4. Laringectomia. 5. Acústica da fala. I. Título. 
Renata Furia Sanchez

Título: "Ána ise acústica า ̊̊̊ sinear ce voz pós laringectomia parcial".

TESE APRESENTADA AO PROGRAMA DE POS-GRADUACZĂO INTERUNIDADES EIOENGENHARIA - EESCIFMRPIOSC DÁ UNIVERSIDADE DE SÄO PALLO PARA OBTENGÄO DO TITULO DE DOUTORA EM CIENCIAS NA A ZEA DE BIOENGENHARIA.

s.provado em: $21,03,2014$

Jrofa $\mathrm{Dr}^{2}$. Lid a Cristirla da Silwa Teles (Orientadora) Resultado: Ayrovida

Universidade de Bän Fat.lo - USP

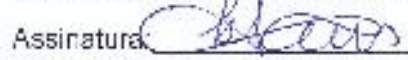

Prof" Dr ${ }^{3}$. Eliarla Maria Gradim Fabbron

Universioade Estadual Paulista Sullio de

Resultato: Qprewodo Mesquita Fi ro: - UNESP

Assinatura Guguelosen

Prorn. Drn I essile Piccolot:o -erreira

Resultado apoworowdos

Pontificia Unversitate Catclica - PUC

Prof? Dr" Lucia Figueiredo Mlourăo

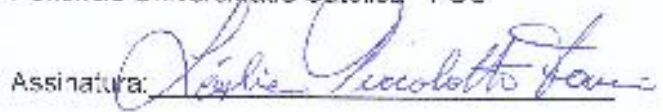

Resultado: Apiocada

Universidade Estadual do Campinas - UN CAMP

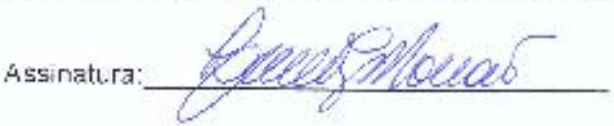

Prof". Dr" Lil an Neto Aguiar Ricz

Universidade de Sāo Paulo - USP

Resultado:
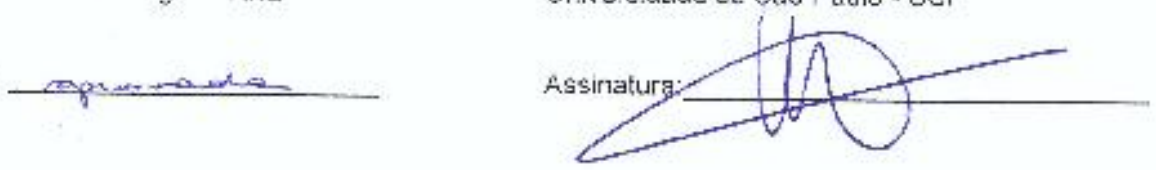

Homologado em: 
"Dedico este trabalho aos meus pacientes oncológícos, que mesmo frente às limitações físicas e emocionaís impostas pela doença se dispuseram a colaborar com a ciêncía." 
Agradecimentos especiais:

$\mathcal{A}$ Deus, pelo Dom da minha vida e pelos Dons e Frutos do Espirito.

Aos meus pais, Antonio Sanchez (in memoriam) e Wanda Furia Sanchez, que com seus exemplos de vida, me conduziram a buscar meus sonhos com força, coragem e determinação, sempre respeitando os conceitos da ética como uma virtude moral.

Agradecimentos:

$\mathcal{A}$ minha querida amiga e orientadora Profa. Dra. Lídia Cristina da Silva Teles, minha eterna gratidão pela amizade, confiança, carinho e incentivo a mim dedicados para que esse trabalho se concretizasse.

Aos Membros da banca examinadora pela dedicação à leitura minuciosa e pela importante contríbuição para a finalização do mesmo.

Aos sujeitos participantes desta pesquisa, aos colegas de trabalho do Departamento de Círurgía de Cabeça e Pescoço e ao Hospital Amaral Carvalho / Jaú, pela disponibilidade de proporcionar uma bem sucedida coleta de dados.

Ao Programa de Pós-Graduação Interunídades Bioengenharia, pela oportunidade concedida para a realização deste trabalho.

A Escola de Engenharía de São Carlos e a Faculdade de Odontología de Bauru da Universidade de São Paulo, unidades imprescindiveis para o desenvolvimento deste trabalho.

À secretáría da Bioengenharia Janete Ferreira Rodrigues dos Santos e sua auxiliar $\mathcal{N a t h a l i a ~ C a m a r g o s ~ D i n i z , ~ p e l a ~ a t e n c ̧ a ̃ o ~ e ~ d i s p o n i b i l i d a d e ~}$ para sempre ajudar.

Agradeço a toda a minha familia, principalmente, ao meu irmão José Antonio Furia Sanchez, meus sobrinhos Giovanni Lima Sanchez e Marcelo Lima Sanchez e a minha querida prima Cristina Lemos Barbosa Furia, que sempre estiveram comigo enchendo minha vida de amizade e alegria. $\mathcal{E}$ aos meus queridos (as) amigos (as) pessoais, pelo incentivo e apoio para a realização deste trabalho. 
$\mathcal{A}$ todos os colegas e amigos da Bioengenharia, em especial as queridas amigas, Débora Galdino, Iara Lorca, Paula Rossi e Maria Eugenia Dajer, que colaboraram de forma direta para a concretização deste trabalho, com verdadeira amizade e companheirismo.

$\mathcal{A}$ todos que diretamente ou indiretamente contribuiram para a realização deste trabalho, o meu sincero: muito obrigada!

Renata Furía Sanchez 


\section{RESUMO}

SANCHEZ, R.F. Análise acústica não linear da voz pós laringectomia parcial. 2014. 80 f. Tese (Doutorado) - Programa de Pós-Graduação Interunidades Bioengenharia, Escola de Engenharia de São Carlos / Instituto de Química de São Carlos / Faculdade de Medicina de Ribeirão Preto, Universidade de São Paulo, São Carlos, 2014.

Disfonia é a principal sequela cirúrgica do paciente submetido à laringectomia parcial vertical (LPV) com presença de ruído glótico intenso o que dificulta a análise acústica convencional. Por esse motivo a análise não linear (ANL), teoria dinâmica de sistemas não lineares aplicada a séries temporais não lineares, tem sido recentemente adotada como uma nova abordagem para avaliação acústica vocal. Objetivo: aplicar a ANL por meio da escala L-IE na análise acústica da voz de pacientes submetidos à LPV. Método: foram analisadas 31 vozes de pacientes submetidos à LPV, denominado de grupo de pacientes (GP) e 31 vozes de indivíduos sem alteração vocal ou laríngea, denominado grupo controle (GC). Os gráficos bidimensionais gerados a partir dos sinais de voz foram avaliados com base na técnica dos padrões visuais da dinâmica vocal (PVDV), por meio da escala de classificação L-IE para os três parâmetros: número de laços (L), irregularidade (I) e espaçamento (E). Para a correlação dos dados da ANL com a avaliação perceptivo-auditiva da voz, as vozes do GP foram avaliadas por meio da escala GRBAS. Resultados: houve correlação significativa $(p<0,05)$ entre os três parâmetros da escala L-IE para a análise total da amostra GP e GC. Os resultados da escala L-IE para a maioria do pacientes do GP se caracterizaram por: número de laços zero; irregularidade e espaçamento dos traçados, ambos com grau 6. O GP teve a maioria de suas vozes avaliadas com grau 3 de disfonia na escala GRBAS. Houve correlação estatisticamente significante $(\mathrm{p}<0,05)$ entre a escala L-IE e a GRBAS nos seguintes parâmetros: o "L" com o grau global da disfonia (G) e com soprosidade (B) e o "I" com a soprosidade (B). Conclusão: o método da ANL por meio da escala L-IE, se mostrou eficiente na avaliação das vozes de pacientes submetidos a LPV.

Palavras-chave: Voz. Qualidade da voz. Distúrbios da voz. Laringectomia. Acústica da fala. 


\begin{abstract}
SANCHEZ, R.F. Nonlinear acoustic voice analysis after partial laryngectomy. 2014. $80 \mathrm{f}$. Tese (Doutorado) - Programa de Pós-Graduação Interunidades Bioengenharia, Escola de Engenharia de São Carlos / Instituto de Química de São Carlos / Faculdade de Medicina de Ribeirão Preto, Universidade de São Paulo, São Carlos, 2014.

Dysphonia is the main surgical sequel in patients who underwent vertical partial laryngectomy (VPL) with the presence of intense glottal noise which makes more difficult conventional acoustic analysis. Therefore the nonlinear analysis, dynamic theory of nonlinear systems applied to nonlinear time series, has recently been adopted as a new approach to acoustic analysis of voice. Objective: apply to ANL by L- IS scale on acoustic voice analysis of patients underwent VPL. Method: 31 voices of patients underwent VPL called patient group (PG) and 31 voices of individuals without vocal or laryngeal disorder were analyzed called control group (CG). Two-dimensional graphs generated from the voice signals the both groups were evaluated based on the technique of VDVP through the rating scale L-IS for the three parameters: number of loops (L), irregularity (I) and spacing (S). For the correlation of data from nonlinear analysis with the perceptual evaluation, the voices of the PG were evaluated by GRBAS scale. Results: significant correlation $(p<0.05)$ between the three parameters of the L-IS scale for the total sample analysis PG and CG. The results of the L-IS scale for the majority of PG patients were characterized by: zero for number of loops; 6 degree for both irregularity and spacing of the traces. The PG had most of their voices evaluated with 3 degree of dysphonia in GRBAS. There was a statistically significant correlation $(p<0.05)$ between L-IS and GRBAS parameters: "L" with the overall grade of dysphonia (G) and breathiness (B) and "I" with breathiness (B). Conclusion: the method of ANL by L-IS scale, is efficient for evaluating the voices of patients underwent VPL.
\end{abstract}

Keywords: Voice. Voice quality. Voice disorders. Laryngectomy. Speech acoustics. 


\section{LISTA DE ILUSTRAÇÕES}

FIGURA 1 - Divisão anatômica da laringe.

FIGURA 2 - "ciclo glótico" com suas fases aberta e fechada

FIGURA 3 - Gráfico bidimensional com classificação do parâmetro do número de laços igual a 0 de um indivíduo do presente estudo.

FIGURA 4 - Gráfico bidimensional com classificação do parâmetro do número de laços igual a 1 de um indivíduo do presente estudo.

FIGURA 5 - Gráfico bidimensional com classificação do parâmetro do número de laços igual a 2 de um indivíduo do presente estudo.

FIGURA 6 - Gráfico bidimensional com classificação do parâmetro do número de laços igual a 3 de um indivíduo do presente estudo.

FIGURA 7 - Gráfico bidimensional com classificação do parâmetro do número de laços igual a 4 ou mais de um indivíduo do presente estudo....

FIGURA 8 - Gráfico bidimensional com classificação do parâmetro da irregularidade igual a 1 de um indivíduo do presente estudo.

FIGURA 9 - Gráfico bidimensional com classificação do parâmetro da irregularidade igual a 2 de um indivíduo do presente estudo

FIGURA 10 - Gráfico bidimensional com classificação do parâmetro da irregularidade igual a 3 de um indivíduo do presente estudo.....

FIGURA 11 - Gráfico bidimensional com classificação do parâmetro da irregularidade igual a 4 de um indivíduo do presente estudo

FIGURA 12 - Gráfico bidimensional com classificação do parâmetro da irregularidade igual a 5 de um indivíduo do presente estudo.

FIGURA 13 - Gráfico bidimensional com classificação do parâmetro da irregularidade igual a 6 de um indivíduo do presente estudo.

FIGURA 14 - Gráfico bidimensional com classificação do parâmetro da irregularidade igual a 7 de um indivíduo do presente estudo.....

FIGURA 15 - Gráfico bidimensional com classificação do parâmetro do espaçamento igual a 1 de um indivíduo do presente estudo.

FIGURA 16 - Gráfico bidimensional com classificação do parâmetro do espaçamento igual a 2 de um indivíduo do presente estudo.....

FIGURA 17 - Gráfico bidimensional com classificação do parâmetro do espaçamento igual a 3 de um indivíduo do presente estudo.

FIGURA 18 - Gráfico bidimensional com classificação do parâmetro do espaçamento igual a 4 de um indivíduo do presente estudo.

FIGURA 19 - Gráfico bidimensional com classificação do parâmetro do espaçamento igual a 5 de um indivíduo do presente estudo.

FIGURA 20 - Gráfico bidimensional com classificação do parâmetro do espaçamento igual a 6 de um indivíduo do presente estudo.

FIGURA 21 - Gráfico bidimensional com classificação do parâmetro do espaçamento igual a 7 de um indivíduo do presente estudo.

FIGURA 22 - Porcentagem do número de laços da escala L-IE dos grupos GP e GC deste estudo.

FIGURA 23 - Porcentagem do parâmetro irregularidade da escala L-IE dos grupos GP e GC deste estudo.

FIGURA 24 - Porcentagem do parâmetro espaçamento da escala L-IE dos grupos GP e GC deste estudo. 


\section{LISTA DE TABELAS}

TABELA 1 - Classificação do número de laços da escala L-IE, considerando a quantidade de laços das órbitas

TABELA 2 - Classificação dos graus do parâmetro irregularidade (I) dos traçados segundo a escala L-IE.

TABELA 3 - Classificação dos graus do parâmetro espaçamento (E) dos traçados segundo a escala L-IE

TABELA 4 - Média, desvio padrão, valores máximos e mínimos e os percentis do número de laços (L) e dos parâmetros irregularidade (I) e espaçamento (E) da escala L-IE dos grupos GP e GC e o resultado da comparação estatística entre os grupos

TABELA 5 - Correlação entre os parâmetros da escala L-IE com dados de ambos os grupos GP e GC deste estudo.

TABELA 6 - Correlação entre os parâmetros da escala L-IE com dados do grupo GP deste estudo.

TABELA 7 - Resultados da correlação de Spearman entre a avaliação e o reteste da avaliação da escala L-IE.

TABELA 8- Ocorrência do grau de desvio dos parâmetros da escala GRBAS para os pacientes do grupo GP

TABELA 9- Resultados do teste de correlação de Spearman entre as escalas L-IE e GRBAS dos dados dos pacientes do grupo GP 


\section{LISTA DE SIGLAS}

ANL Análise não linear

CAPE-V Consensus Auditory - Perceptual Evalution of voice

CHEP Laringectomia supracricóide

$\mathrm{D}_{2} \quad$ Dimensão de correlação

f0 Frequência fundamental

GRBAS grau global da disfonia $(\mathrm{G})$, rugosidade $(\mathrm{R})$, soprosidade $(\mathrm{B})$, astenia (A) e tensão $(\mathrm{S})$

IDV Índice de desvantagem vocal

INCA Instituto Nacional do Câncer

GC Grupo controle

GP Grupo de pacientes

L-IE Laços - Intensidade Espaçamento

LPV Laringectomia parcial vertical

MDVP Multi-Dimensional Voice Program

NHR Proporção harmônico-ruído

PVDV Padrões Visuais da Dinâmica Vocal

SampEn Amostra da entropia

TMF Tempo máximo de fonação

VE Voz esofágica

VN Voz normal

VTE Voz traqeuoesofágica 


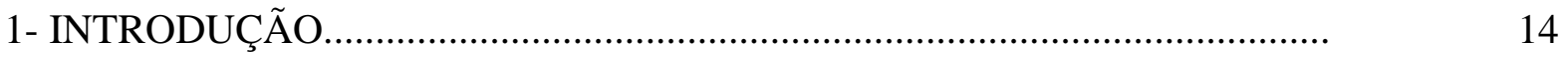

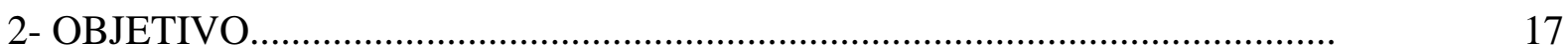

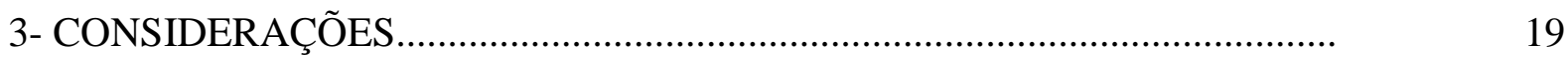

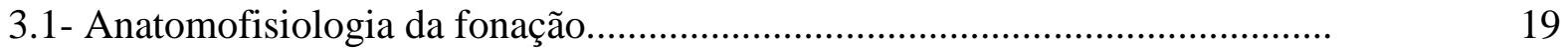

3.2- Câncer da laringe ......................................................................................

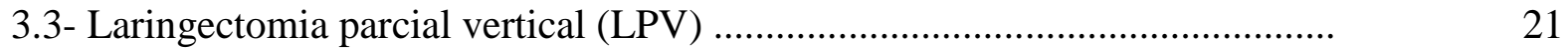

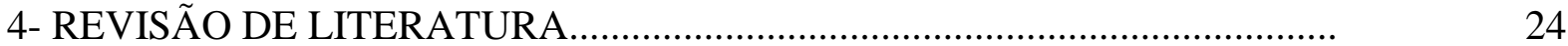

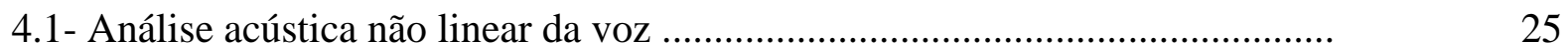

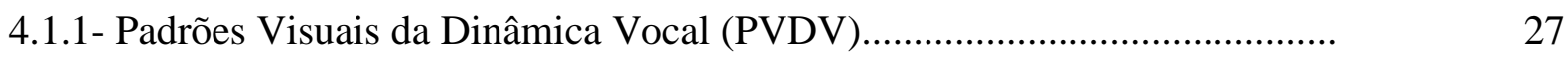

4.2- Análise Perceptivo-auditiva em vozes de pacientes submetidos à LPV .... 33

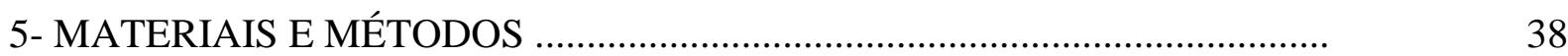

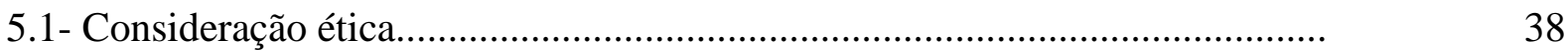

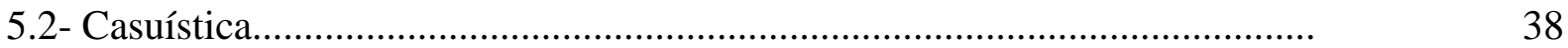

5.2.1- Banco de dados dos sinais de voz....................................................... 38

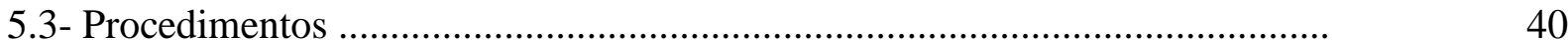

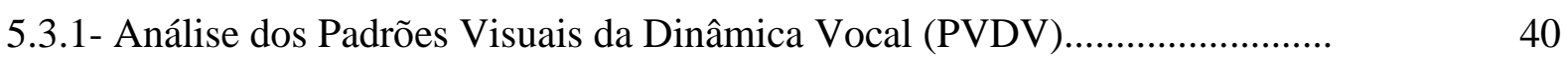

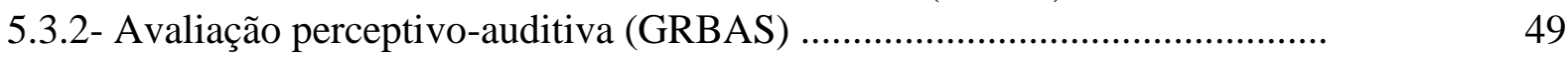

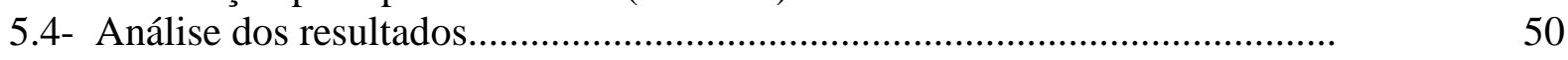

6- RESULTADOS ..............................................................................

6.1- Resultados da análise dos padrões visuais da dinâmica vocal - escala L-IE

6.2- Resultados da avaliação perceptivo-auditiva da escala GRBAS...................

6.3- Correlação entre a escala L-IE e a escala GRBAS.......................................

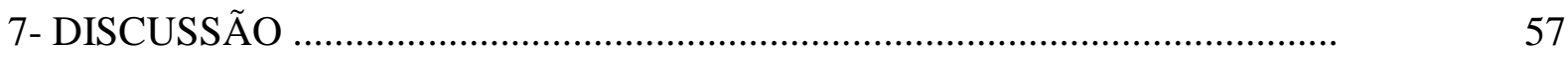

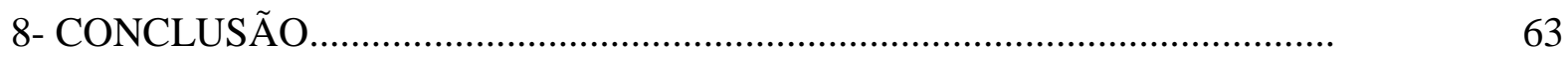

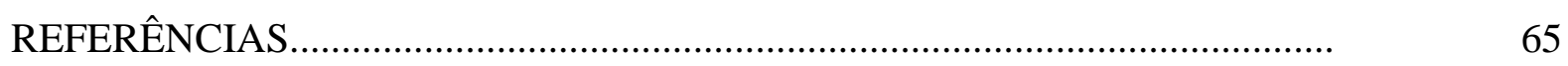

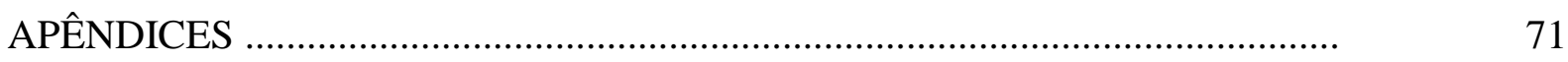

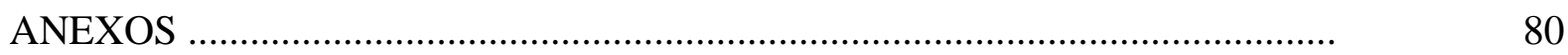


1 Introdução 


\section{INTRODUÇÃO}

A alteração vocal é a principal sequela de pacientes acometidos por câncer de laringe, submetidos à cirurgia de laringectomia parcial vertical (LPV).

$\mathrm{O}$ câncer de laringe ocorre predominantemente em homens e é um dos mais comuns entre os que atingem a região da cabeça e pescoço. A ocorrência pode se dar em uma das três porções da laringe: supraglótica (acima das pregas vocais), glótica (pregas vocais) e subglótica (abaixo das pregas vocais). Aproximadamente 2/3 dos tumores surgem na prega vocal e 1/3 acomete a porção supraglótica. A rouquidão é o primeiro sintoma do câncer de laringe em $83 \%$ dos casos. A estimativa para 2012 foi de 6.110 novos casos (INSTITUTO NACIONAL DO CÂNCER - INCA, 2013).

O tratamento para o câncer de laringe pode ser realizado por radioterapia, quimioterapia ou remoção cirúrgica do tumor de forma isolado ou combinado entre eles. A escolha dependerá da extensão da doença e das condições clínicas do paciente.

As cirurgias de laringe podem ser realizadas por sua remoção total ou parcial. As laringectomias parciais de acordo com o acesso cirúrgico são classificadas como horizontais ou verticais. As LPV são técnicas utilizadas para remoção de tumores localizados na região da glote. As sequelas relacionadas a disfonia relacionadas a esses procedimentos cirúrgicos são as falhas nos mecanismos de controle de fluxo aéreo e/ou ação de vibração por comprometimento das pregas vocais e, consequentemente, alterações na atividade de transdução da energia aerodinâmica em acústica (CAMARGO, 2000).

A voz do paciente submetido à LPV apresenta grande quantidade de ruído devido à rouquidão, aspereza e soprosidade, além da redução de intensidade, alteração de frequência fundamental e incoordenação pneumofonoarticulatória. O ruído é um sinal acústico aperiódico ou caótico, que não permite mensuração, o que interfere diretamente na confiabilidade da análise acústica convencional (frequência fundamental, suas respectivas taxas de perturbação jitter e shimmer e a proporção harmônico-ruído) das vozes desse grupo de pacientes.

Os métodos de análise acústica não lineares (ANL) têm mostrado potencial para quantificar de forma confiável ambos os sinais periódicos e aperiódicos. Estes métodos permitem a avaliação da voz sob uma nova visão, independente dos algoritmos matemáticos convencionais e se apresentam como ferramentas promissoras (STORY e TITZE, 1995). Por meio da ANL as vibrações das pregas vocais podem ser mostradas como trajetórias num 
espaço de fase reconstruído evidenciando a dinâmica do sistema fonatório. A visualização da complexidade da dinâmica do sinal de voz pode ser analisada por meio da técnica dos Padrões Visuais da Dinâmica Vocal (PVDV) (DAJER, 2010).

Vários autores têm se utilizado da ANL para avaliar os sinais de voz em seus estudos tanto na população adulta como pediátrica com vozes normais e disfonicas: Andrade Sobrinho (2011); Butte et al. (2009); Chai et al. (2011); Choi et al. (2012); Costa et al. (2013); Dajer (2009, 2010); Galdino (2012); Lee et al. (2008); Little et al. (2011); Marrara (2010); Meredith et al. (2008); Souza (2011); Tsanas et al. (2011) e Zhang e Jiang (2004). Estudos com a ANL relacionados ao câncer de laringe foram realizados por MacCallum et al., (2009) e Yan et al. (2013) que analisaram vozes alaríngeas em pacientes submetidos à laringectomia total. Com relação à LPV, foi encontrado apenas o estudo de Sanchez et al. (2012) que descreveu um caso de voz pós LPV.

Portanto, este trabalho se justifica pela necessidade da caracterização das vozes de pacientes submetidos à LPV por meio do método da ANL, uma que vez que as análises acústicas convencionais não se mostram confiáveis para esse grupo de pacientes. 
2 Objetivo 


\section{OBJETIVO}

O objetivo deste trabalho foi aplicar a ANL por meio da escala L-IE na análise acústica da voz de pacientes submetidos à LPV. 
3 Considerações 


\section{CONSIDERAÇÕES}

A voz humana resulta da interação de fatores genéticos, anatômicos, características pessoais, como a personalidade, além de fatores sociais, econômicos e culturais, e ainda de aspectos emocionais únicos, próprios de cada indivíduo (TUMA et al., 2005). Ela é um recurso precioso, poderoso e, muitas vezes, desconhecido; inesgotável em possibilidades e como tal, não pode ser vista apenas, como mera vibração das pregas vocais. Essa vibração e o som que dela se origina terão um efeito no ambiente e na nossa relação com o outro (CHUN, 1998).

\subsection{Anatomofisiologia da fonação}

Conhecer a anatomia e a fisiologia da voz humana é um pré-requisito para o diagnóstico e o tratamento dos distúrbios vocais. A voz é uma das três funções da laringe: respiração, proteção da via aérea inferior e fonação.

A laringe está situada na região cervical anterior, logo acima da traqueia. É constituída por um esqueleto cartilaginoso. As cartilagens laríngeas são unidas entre si por articulações e ligamentos, proporcionando movimentos anteroposteriores, laterais e basculantes. A musculatura intrínseca realiza movimentos de precisão, com ajustes tensionais e posturais das pregas vocais. Tais músculos proporcionam os movimentos de abdução, adução e tensão. (TUMA et al., 2005).

A laringe é dividida em três regiões anatômicas: supraglote, glote e subglote (Figura 1).

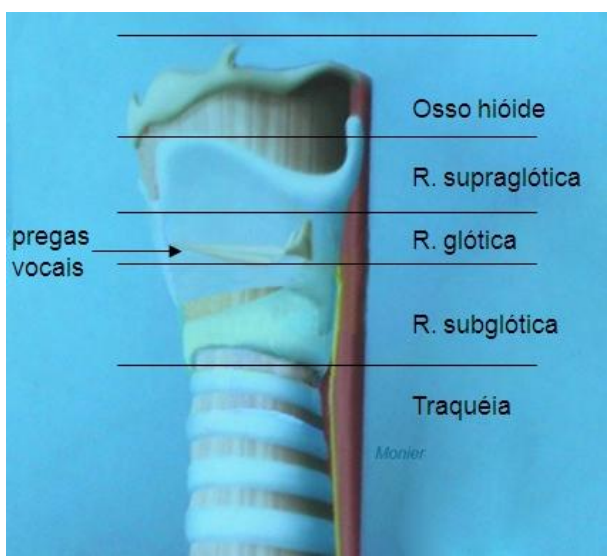

Figura 1- Divisão anatômica da laringe Fonte: Malucelli (2013) 
O mecanismo de produção vocal é complexo e exige interação de diversos sistemas do organismo, desde o trato respiratório até o sistema nervoso central. A compreensão do mecanismo da vibração das pregas vocais exige conhecimento anatômico específico. As pregas vocais são estruturas multilaminadas, com propriedades mecânicas distintas em cada camada, composta por músculo e mucosa. O mecanismo vibratório das pregas vocais originase de ondulações combinadas nos sentidos horizontal, longitudinal e vertical, advindas de forças aerodinâmicas e mioelásticas, determinando o "ciclo glótico" com suas fases aberta e fechada (Figura 2). No controle da frequência, ocorre variação no comprimento das pregas vocais, e no da intensidade a variação se dá principalmente devido ao aumento da pressão subglótica. Em relação a qualidade vocal, há modificação de todo o trato vocal, com aspectos ressonantais envolvidos (TUMA et al., 2005).

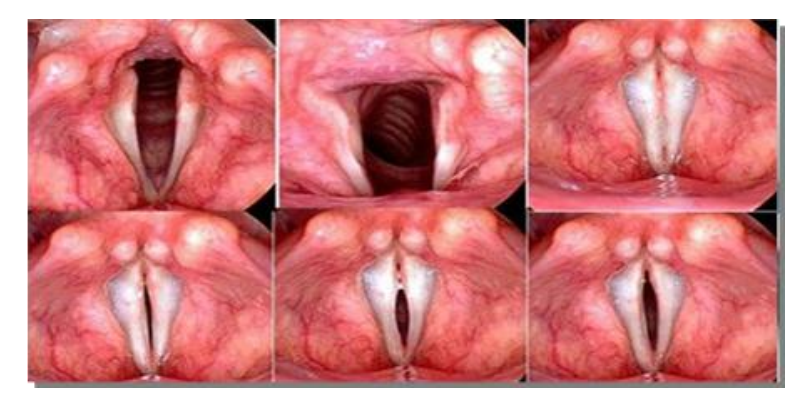

Figura 2 - "ciclo glótico" com suas fases aberta e fechada Fonte: A Voz e as Cordas Vocais (2004)

\subsection{Câncer da laringe}

O câncer de laringe ocorre predominantemente em homens e é um dos mais comuns entre os que atingem a região da cabeça e pescoço. Representa cerca de $25 \%$ dos tumores malignos que acometem essa área e $2 \%$ de todas as doenças malignas. Os sintomas estão diretamente ligados à localização da lesão. Assim, a dor de garganta sugere tumor supraglótico, e rouquidão indica tumor glótico ou subglótico. O câncer supraglótico geralmente é acompanhado de outros sinais, como alteração na qualidade da voz, disfagia leve (dificuldade de engolir) e sensação de "caroço" na garganta. Nas lesões avançadas das cordas vocais, além da rouquidão, podem ocorrer dor na garganta, disfagia e dispneia (dificuldade para respirar ou falta de ar). O álcool e o tabaco são os maiores inimigos da laringe. Fumantes têm 10 vezes mais chances de desenvolver câncer de laringe, no entanto, pessoas que associam o fumo a bebidas alcoólicas, esse número sobe para 43. Pacientes com câncer de 
laringe que continuam a fumar e a beber têm probabilidade de cura reduzida e aumento do risco de aparecimento de um segundo tumor na área de cabeça e pescoço (INCA, 2013).

Atualmente o tratamento do câncer de laringe busca com muito interesse a preservação de suas funções (respiração, deglutição e fonação), as cirurgias de LPV, é um desses tratamentos.

\subsection{Laringectomias parciais verticais (LPV)}

As LPV podem causar sequelas relativas à respiração, deglutição e principalmente à fonação, apesar de o principal objetivo neste tipo de cirurgia ser o de preservar ao máximo as funções vocal e respiratória sem comprometer os índices de cura (MATOS, 2000). Essas cirurgias abrangem desde a remoção da prega vocal - as cordectomias - até cirurgias mais ampliadas, como laringectomia frontal, laringectomia frontolateral (hemilaringectomia), laringectomia frontolateral ampliada, laringectomia quase total (near total). Tais cirurgias ocasionam a redução da coaptação glótica (CARRARA-DE ANGELIS; BARROS, 2000).

Abrahão et al. (2000), descreveram da seguinte forma as LPV e as prováveis alterações vocais:

a) Cordectomia: é realizada por meio de laringofissura constitui o mais antigo tratamento para o câncer de laringe. Consiste na abertura mediana da cartilagem tireoide e membrana cricotiróidea, permitindo abertura da laringe como um livro, ressecando-se a lesão sob visão direta. A cordectomia provoca em curto prazo uma qualidade vocal soprosa, mas após a cicatrização final e por compensação da prega vocal contralateral, ocorre boa coaptação glótica, podendo resultar numa boa qualidade vocal. A qualidade vocal pode permanecer áspera devido à rigidez da mucosa, ou a áspera e soprosa quando a fenda glótica permanece.

b) Laringectomia frontal: tumores primários da comissura anterior são muito raros ( $2 \%$ dos tumores glóticos) e a cirurgia consiste na retirada da fúrcula da cartilagem tireoide, com ressecção da comissura anterior e parte da porção membranácea da prega vocal bilateralmente. Com o fechamento da laringofissura ocorre a diminuição do tamanho e da massa das pregas vocais, com alteração tanto do pitch como do loudness, que podem ser discretas.

c) Laringectomia frontolateral (hemilaringectomia): consiste na retirada da porção membranácea da prega vocal predominantemente acometida, da comissura 
anterior, e parte da porção membranácea da prega vocal contralateral. Essa cirurgia é indicada para tumores que acometem a região glótica envolvendo a comissura anterior, ou tumores que envolvem bilateralmente a região glótica, porém sempre com mobilidade das pregas vocais preservada e sem envolvimento das aritenóides. A ressecção da cartilagem tireoide acompanha a extensão da ressecção glótica. Frequentemente a reconstrução da laringe é realizada pela técnica de Bailey, com excelentes resultados fonatórios e esfincterianos.

d) Laringectomia frontolateral ampliada: traduz o mesmo procedimento de uma hemilaringectomia, porém, com exerese de uma das aritenóides. As hemilaringectomias ampliadas produzem grande impacto sobre as funções fonatória e esfincteriana, o que implica obrigatoriamente na necessidade de reconstruções, para tentar minimizar a disfonia e o nível de aspiração.

e) Laringectomia quase total (near total): é uma técnica de laringectomia parcial proposta por Pearson (1985), sendo mais opção para tumores avançados da laringe. É indicada nos casos em que apesar da grande invasão tumoral, resta uma aritenóide livre. O procedimento preserva uma estreita faixa de mucosa laríngea que conecta a traqueia à faringe, além de uma aritenóide funcional. Esta técnica cria uma fístula natural para fonação e prevenção de aspiração, mantendo o paciente com traqueostomia definitiva. É necessária a oclusão do traqueostoma para que a fonação ocorra. 
4 Revísão da literatura 


\section{REVISÃO DA LITERATURA}

A avaliação completa da voz implica no exame do trato vocal que deve ser realizado pelo médico especialista, na auto avaliação da voz pelo paciente e na avaliação perceptivoauditiva e acústica da voz pelo fonoaudiólogo (LITTLE et al., 2011). As medidas acústicas têm sido muito utilizadas na clínica fonoaudiológica tanto para auxiliar no diagnóstico do distúrbio da voz como para o monitoramento terapêutico.

A história da análise acústica da fala começou neste século com métodos analógicos até chegar aos modernos processos de digitalização. Em 1920 surgiu o oscilograma que se constitui num gráfico da amplitude em relação ao tempo num sinal contínuo. Em 1940, surgiu o analisador de Henrici com análise de Fourier e em 1950 a espectrografia que é a análise da onda complexa em seus componentes de frequência pelo uso de filtros, que mostra a concentração de energia da fala ao longo do tempo. Desde a década de 50, houve um aumento progressivo de estudos voltados à análise objetiva da voz, paralelamente ao aparecimento de teorias que explicam a produção da voz e desenvolvimento de inúmeros laboratórios de voz (FUKUYAMA, 2001). Em 1970, uma nova era se iniciou com a introdução da tecnologia digital (KENT, 1992). Esses avanços tecnológicos tornaram possível analisar a voz com programas simples de computador, aumentando o potencial uso de análise acústica vocal para o ambiente clínico.

Os programas de análise acústica por meio de processamento de sinais e algoritmos são capazes de obter do traçado do formato da onda sonora a análise da frequência fundamental, das medidas de perturbação como jitter e shimmer e das medidas de ruído, que permitem descrever quase completamente a voz humana (ARAÚJO et al., 2002). Tais medidas são importantes porque, sob condições clínicas controladas, uma medida objetiva da voz depende apenas da gravação e dos detalhes do algoritmo e ignora os muitos aspectos subjetivos individuais da percepção e interpretação do clínico. O efeito de uma variedade de distúrbios da voz sobre estas medidas foi testado sob condições experimentais e clínicas, mostrando que diferentes medidas respondem a distúrbios diferentes de formas diferente. (LITTLE et al., 2007, 2011; MACCALLUM et al., 2009).

Nos distúrbios vocais há o aumento da aperiodicidade de vibração das pregas vocais, pela presença do ruído que quando muito intenso interfere na confiabilidade da análise acústica. Titze (1995) definiu três tipos de sinais vocais: Tipo 1, um sinal quase periódico, 
que não apresenta alterações qualitativas no segmento a ser analisado; Tipo 2, um sinal que apresenta alterações qualitativas no segmento a ser analisado e o Tipo 3, um sinal sem estrutura periódica aparente. Segundo Gama e Behlau (2009) o Tipo 1 é encontrado em vozes normais ou levemente alteradas; o Tipo 2 não permite mensurações das medidas acústicas convencionais com confiabilidade, com exceção da análise visual por meio da espectrografia e o Tipo 3 é um sinal aperiódico ou caótico, pela presença intensa de ruído que não permite mensuração acústica convencional confiável .

A partir desta padronização dos tipos de sinais de voz, fica evidente que a análise acústica da voz convencional é confiável para uma pequena parcela dos distúrbios vocais onde, as alterações são discretas. Por esse motivo a análise de sinais de vozes dos Tipos 2 e 3 apenas serão confiáveis por meio das análises acústicas não lineares (ANL).

\subsection{Análise acústica não linear da voz (ANL)}

A teoria do caos, é uma área de teoria dinâmica de sistemas não lineares, aplicada a séries temporais não lineares que permite aos cientistas novas perspectivas sobre a irregularidade de fenômenos da natureza entre elas a das vibrações das pregas vocais (DAJER, 2010; HENRÍQUEZ et al., 2009; JIANG et al., 2001).

A não linearidade na vibração das pregas vocais foi descrita por Titze, Baken e Herzel (1993). O conceito de produção da voz humana como um sistema caótico foi estabelecido nos últimos anos através de modelagem por computador, das experiências com laringe excisadas e da análise de voz humana. Há evidências substanciais de que a vibração das pregas vocais é um processo altamente não linear e que produz efeitos combinados de eventos biomecânicos e aerodinâmicos com ricos comportamentos vibratórios irregulares, tais como bifurcação e caos. Estas evidências têm sido mais frequentemente utilizadas na compreensão dos distúrbios vocais por meio de métodos dinâmicos não lineares (MACCALLUM et al., 2009).

A teoria do caos foi recentemente adotada como uma nova abordagem para processamento de sinal de voz, com o objetivo de alcançar uma melhor compreensão dos fatores que contribuem para as alterações vocais.

As técnicas não lineares de análise acústica do sinal de voz são baseadas em modelos caóticos ou extração de características caóticas. Os ciclos vibratórios das pregas vocais humanas exibem algumas propriedades caóticas inerentes e métodos dinâmicos não lineares 
são úteis para quantificar o grau de irregularidade $\mathrm{e}$ aperiodicidade destes ciclos (MACCALLUM et al., 2009).

As principais características caóticas estudadas são os expoentes de Lyapunov, as dimensões do atrator, a reconstrução de espaço de fase, mapa de Pointcaré, a dimensão fractal, a entropia de Kolmorov e especialmente, a dimensão de correlação $D_{2}$. (DAJER, 2010; HENRÍQUEZ et al., 2009).

Nos trabalhos pesquisados para este estudo encontramos diversos autores utilizando o método da ANL com o objetivo de coletar dados sobre vozes alteradas e normais utilizando as diferentes técnicas citadas acima. No entanto, a dimensão de correlação $D_{2}$ foi o parâmetro mais utilizado pelos seguintes autores na avaliação dos sinais de voz: Meredith et al. (2008) estudou a disfonia infantil; Lee et al. (2008) avaliou sinais de vozes de pacientes com Parkinson; Butte et al. (2009) analisou vozes de cantores; Henríquez et al. (2009) comparou vozes normais com disfonicas; MacCallum et al. (2009) estudou vozes esofágicas; MacCallum et al. (2010) avaliou vozes normais; Little et al. (2011) analisou vozes com paralisia de prega vocal; Chai et al. (2011) avaliou vozes de adultos do sexo masculino fumantes e não fumantes; Choi et al. (2012) estudou vozes saudáveis; Yan et al. (2013) analisou vozes de pacientes laringectomizados totais reabilitados com voz esofágica e traqueoesofágica e comparou com vozes normais e Costa et al. (2013) comparou vozes saudáveis com disfonicas.

$\mathrm{Na}$ literatura são escassos os estudos da análise vocal com método da ANL relacionada ao câncer de laringe. MacCallum et al. (2009) levantaram a hipótese de que a análise dinâmica não linear seria capaz de oferecer uma medição mais confiável da voz esofágica aperiódica do que os parâmetros de perturbação utilizados na análise acústica convencional. A partir dos sinais de voz de 20 sujeitos divididos em dois grupos e pareados por idade, os autores realizaram uma comparação acústica entre vozes esofágicas e vozes normais por meio do método da ANL com as técnicas da dimensão de correlação $D_{2}$ e da entropia de segunda ordem e da análise acústica convencional com as medidas de perturbação (jitter, shimmer) e relação sinal-ruído. Os resultados mostraram que os valores de jitter e shimmer foram significativamente maiores para as vozes esofágicas e que os valores da relação sinal-ruído foram significativamente menores para as vozes esofágicas do que para vozes normais. Valores de contagem de erro, que indicaram a confiabilidade da análise de perturbação, foram significantemente maiores para as vozes esofágicas do que para as vozes normais. $\mathrm{O}$ erro foi atribuído ao sinal aperiódico e demonstrou que a análise de perturbação produziu resultados questionáveis para a voz esofágica. No entanto, as medidas de dinâmica 
não linear analisadas em ambos os grupos se mostrou confiável e indicou que voz esofágica foi significativamente mais caótica do que voz normal. Concluíram que os resultados demonstraram a capacidade dos métodos dinâmicos não lineares para quantificar de forma confiável os sinais aperiódicos e periódicos e diferenciar vozes normais de vozes esofágicas. Sugeriram que a análise dinâmica não linear seja utilizada, preferencialmente, para a caracterização acústica de vozes aperiódicas, como a voz esofágica.

Yan et al. (2013), investigaram as diferenças de características entre vozes normais $(\mathrm{VN})$, vozes esofágicas (VE) e vozes traqueoesofágicas (VTE) pós laringectomia total, por meio da avaliação perceptivo-auditiva e da análise dinâmica não linear por meio da técnica da dimensão de correlação $\left(D_{2}\right)$ e da entropia (SampEn). Participaram deste estudo dez indivíduos com VN, dez com VE e dez com VTE, todos masculinos falantes do cantonês e foram obtidas noventa amostras de vozes. Nas análises perceptivo-auditiva e dinâmica não linear, as VE e as VTE mostraram maior aperiodicidade e com características vocais notoriamente mais difíceis de serem extraídas. Os resultados mostraram que tanto $D_{2}$ como os valores da SampEn foram significativamente maiores para as VTE e as VE em relação as VN. A análise perceptivo-auditiva da qualidade de voz das VE e das VTE foi negativamente correlacionada com as medidas da $D_{2}$ e da SampEn. Os resultados do presente estudo indicaram que a análise dinâmica não linear da voz pode ser uma ferramenta complementar para análise acústica tradicional, especialmente para analisar a qualidade de vozes alaríngeas.

\subsubsection{Padrões Visuais da Dinâmica Vocal (PVDV)}

A análise dos Padrões Visuais da Dinâmica Vocal (PVDV) é uma técnica que descreve qualitativamente a complexidade dos sinais de voz traçados num gráfico gerado pela reconstrução do espaço de fase. A reconstrução do espaço de fase é baseada no método das coordenadas defasadas e tem provado ser uma poderosa ferramenta na análise de sinais biológicos, como os sinais de voz (DAJER, 2010).

O primeiro estudo, que utilizou o método da ANL para a análise de vozes de indivíduos falantes do português brasileiro foi o de Dajer, Pereira e Maciel (2005). Nesse estudo os autores registraram as vogais sustentadas /a/, /e/ e /i/ de 12 sujeitos com vozes adaptadas, sendo 6 homens e 6 mulheres com idade variando entre 19 e 39 anos. A técnica de reconstrução de espaço de fase foi utilizada para descrever as características não lineares dos sinais de voz e foi realizada a correlação com a análise acústica convencional. Os resultados 
mostraram que as trajetórias se convergem e dispersam em momentos diferentes, o que pode sugerir a influência das medidas de perturbação jitter e shimmer na trajetória da dinâmica da voz. Quando os percentuais das medidas de perturbação eram aumentados, faziam com que as trajetórias ficassem com aspecto mais irregular, disperso e caótico. Nos sinais em que shimmer era aumentado, as trajetórias se apresentavam homogeneamente separadas e dispersas entre si, entretanto, nos casos de jitter elevado, as trajetórias se mostravam alternadas em dispersas e concentradas em regiões diferentes do gráfico. Os autores concluíram que os correlatos estatísticos de jitter, shimmer e coeficiente de excesso influenciam as trajetórias das órbitas tornando-as irregulares.

Para avaliar a ferramenta de análise não linear, Dajer (2006) realizou testes com diferentes tipos de sinais de voz simulados e desta forma estabeleceu como se manifestam as mudanças e os efeitos dos parâmetros f0, jitter, shimmer e amplitudes dos harmônicos no traçados das órbitas dos atratores no espaço de fase. Observou-se que em um sinal artificial com a frequência e a amplitude constante, jitter e shimmer iguais a zero, observa-se que o traçado das órbitas se sobrepõem com um espaçamento homogêneo. Em seguida, a autora realizou um teste com aumento de shimmer, de $15 \%$ da amplitude do sinal, e observou-se que os traçados das órbitas se espalharam de forma proporcional. Posteriormente foi incluído um aumento de jitter de 3,15\% que causou contorção e espaçamento nas órbitas, ou seja, as órbitas se convergem e se espalham, de forma alternada no gráfico. A quantidade de harmônicos foi estudada, e observou-se que conforme aumentam os componentes harmônicos, aumenta a quantidade de loops ou laços gerados. Esta variação pôde ser vista nas diferentes vogais emitidas, sendo que a vogal /a/ apresentou mais laços em seu padrão visual em relação com as vogais /e/ e /i/, sendo esta última com apenas um laço. Nos casos em que o shimmer era aumentado e o coeficiente de excesso diminuído, a soprosidade foi mais modificada na avaliação perceptivo-auditiva com diminuição da mesma. Nos casos em que houve aumento nos valores de jitter de sujeito a sujeito, observou-se também pequeno aumento do grau de aspereza na avaliação perceptivo-auditiva e piora da regularidade dos traçados das órbitas. Em relação à f0, sua mudança não influenciou o padrão do gráfico bidimensional.

Nesse período das pesquisas ainda se relacionava o números de laços ao número de harmônicos e com o desenvolvimento das pesquisas relacionadas ao PVDV os estudos demonstraram que o número de laços se correlaciona ao formante.

Com base no comportamento dos traçados das orbitas dos gráficos bidimensionais dos padrões visuais do sinal de voz gerado pela técnica de reconstrução do espaço de fases Dajer 
et al. (2007) descreveram três parâmetros: número de loops, regularidade dos traçados e convergência dos traçados, com objetivo de classificar as características do gráfico bidimensional. Neste estudo os autores aplicaram o método da ANL por meio da técnica da reconstrução do espaço de fase implementado e desenvolvido no MatLAb 7.0 e correlacionaram com a análise acústica convencional nos sinais de voz da vogal /i/ do português brasileiro de 16 indivíduos, sendo 8 cantores e 8 não cantores. A análise acústica tradicional dos parâmetros jitter, shimmer e coeficiente de excesso foi obtida pelo programa “Análise de Voz 5.0" (MONTAGNOLI, 1998). Nos sinais de voz da vogal /i/ ambos os grupos apresentaram um único laço na trajetória dos traçados. Quanto à regularidade dos traçados o grupo de não cantores apresentou traçados irregulares e pequenos laços nas extremidades das trajetórias e o grupo de cantores, traçados regulares, porém também foram encontrados traçados irregulares e complexos.

Scalassara et al. (2009) analisaram os três parâmetros dos gráficos bidimensionais obtidos pela reconstrução do espaço de fase: número de loops, regularidade dos traçados e convergência dos traçados. Os autores investigaram os sinais de voz da vogal /a/ do português brasileiro de 48 indivíduos, sendo 16 vozes normais, 16 com nódulos vocais e 16 com edema de Reinke, não foram descritos as idades e sexo dos indivíduos da amostra. Essas vozes foram analisadas pelo método da ANL com a técnica de reconstrução de espaço de fase implementado e desenvolvido no Matlab 7.0 com o objetivo de caracterizar os sinais de vozes saudáveis e disfonicas. Os resultados da ANL por meio da técnica da reconstrução de espaço de fase mostraram diferentes padrões visuais para cada grupo, sendo que, as vozes saudáveis se caracterizaram por muitos laços concêntricos de diferentes dimensões, regularidade e convergência dos traçados. Os autores correlacionaram a ocorrência de laços com a interação entre a frequência fundamental e as frequências harmônicas do sinal. Para os sinais de vozes com nódulos vocais, os traçados se caracterizaram com a presença de apenas um laço, irregularidade do traçado e em relação a convergência se apresentou dispersa. Os autores justificaram a irregularidade do traçado pela fenda glótica, turbulência do fluxo de ar e vibração assimétrica na presença dos nódulos vocais e a tendência dispersa na convergência pela mudança de volume do fluxo aéreo e pela variação da vibração da mucosa. Quanto aos sinais de voz dos pacientes com edema de Reinke os gráficos apresentaram traçados com muitos laços de diferentes dimensões, semelhantes aos encontrados nas vozes normais, o parâmetro da regularidade apresentou alguns trechos lisos e regulares e outros irregulares e curvos que segundo os autores essa característica do traçado é causada pela turbulência do 
fluxo de ar das pregas vocais e pelo aumento da massa. Em relação à convergência dos traçados os mesmos se apresentaram uma ligeira tendência à dispersão.

A rotina computacional, denominada "PVDV" - Padrão Visual da Dinâmica Vocal foi criada por Dajer (2010) para a análise dos padrões visuais da dinâmica da voz. Baseada na técnica de reconstrução do espaço de fase com a técnica de tempo de atraso (FRAZER; SWINNEY, 1986) foi desenvolvida a partir do pacote Tisean (HEGGER; KANTZ; SCHREIBER, 1999) e utilizou o software Matlab 7.0. Para a avaliação qualitativa dos PVDV Dajer (2010) considerou os três aspectos da configuração descritos em Dajer et al. (2007): número de laços, regularidade dos traçados e convergência dos traçados. Porém, a autora completou a classificação dos três aspectos da configuração com escalas gradativas. Para o número de laços empregou uma escala gradativa decrescente de 4 a 0 e considerou os graus 4 e 3 como normais devido a configuração do trato vocal da vogal /a/ do português brasileiro e o grau 0 como impossível de avaliar. Quanto a regularidade dos traçados foi proposta uma escala gradativa decrescente de 5 a 0 , em que o grau 5 representa o máximo de regularidade e o grau 0 o mínimo de regularidade ou completamente irregular e considerou o 0 esperado em vozes com intensas alterações vocais. A convergência dos traçados foi classificada com uma escala decrescente de 4 a 0 , e segundo a autora esta diretamente relacionada a periodicidade da voz e as perturbações de frequência e amplitude do sinal de voz no tempo sendo que, o grau 4 é usado para maior convergência dos traçados e o grau 0 corresponde a trajetórias com fracas convergências global.

Com essa classificação Dajer (2010) avaliou vozes saudáveis e vozes com distúrbios vocais e aplicou a técnica dos PVDV em conjunto com a análise acústica e análise perceptivoauditiva correlacionando-as. Foram avaliadas 91 sinais de voz da vogal /a/ sustentada de sujeitos de ambos os gêneros com idades entre 21 e 88 anos, divididas em dois grupos: grupo 1 (46 sinais de vozes normais) e grupo 2 (45 sinais de vozes alteradas). O grupo1contava com 16 sinais de vozes de indivíduos adultos jovens sem queixas ou alterações vocais e os outros 30 sinais de voz pertenciam a um único indivíduo com 33 anos de idade e sexo masculino em três posturas corporais diferentes. O grupo 2 era composto por 35 sinais de vozes de indivíduos disfonicos sendo que, 31apresentavam disfonia organofuncional (16 edema de Reinke e 15 nódulos vocais) e 14 disfonias orgânicas de origem neurológica. A avaliação da voz contou com a análise perceptivo-auditiva em que foram avaliados os parâmetros rugosidade, soprosidade, tensão e instabilidade da escala GRBAS, avaliação acústica convencional em que foram obtidos valores de F0, jitter, shimmer e perturbação de amplitude, pelo programa “Análise de Voz 6.0” (MONTAGNOLLI, 1997) e para descrever a dinâmica 
dos sinais de voz dos PVDV foi realizada a técnica de reconstrução do espaço de fase e a partir do gráfico gerado foram analisados qualitativamente os parâmetros laços (loops), regularidade e convergência dos traçados. Os resultados de jitter apresentaram uma correlação negativa com laços, regularidade e convergência dos traçados; e shimmer em correlação negativa com laços e convergência. As características de rugosidade e soprosidade foram correlacionadas negativamente com os três parâmetros dinâmicos.

A técnica da análise dos PVDV foi utilizada no estudo de Marrara (2010) com modificação na classificação da escala gradativa descrita por Dajer (2010) em que o número de laços (loops) foi classificado entre os graus 0 (número indefinido de loops) e 4 (4 ou mais loops), a regularidade dos traçados foi classificada em 5 graus em que, 0 correspondeu a traçados regulares e 4 traçados irregulares e a convergência dos traçados foi classificada com graus entre 1(forte convergência) e 5 (fraca convergência). A pesquisa de Marrara (2010) teve o objetivo de caracterizar a amostra vocal de pacientes disfágicos antes e após a deglutição de $3 \mathrm{ml}$ e $7 \mathrm{ml}$ de consistências pastosa e líquida. $\mathrm{O}$ estudo também realizou análise perceptivoauditiva pela escala GRBAS e a análise acústica convencional. A amostra contou com 31 sujeitos sendo divididos em dois grupos, um grupo de referencia com cinco indivíduos sem alterações neurológicas ( 1 homem e 4 mulheres) com idade média de 28 anos de 25 a 35 anos. No grupo com alterações neurológicas foram incluídos 26 pacientes (16 homens e 10 mulheres) com idade média de 53 anos (de 21 a 77 anos) com alterações neurológicas de diferentes etiologias. Todos os indivíduos de ambos os grupos foram submetidos à videofluoroscopia da deglutição e cinco gravações de amostras de voz de cada sujeito sendo, uma gravação antes da realização da videofluoroscopia e quatro durante o procedimento. As quatro últimas gravações foram realizadas imediatamente após a primeira deglutição de pastoso e de líquido com $3 \mathrm{ml}$ e com $7 \mathrm{ml}$. Os resultados da análise perceptivo-auditiva, da análise acústica convencional e da análise dos PVDV foram comparados aos achados da videofluoroscopia para estabelecer possíveis correlações entre os grupos. Os resultados da análise perceptivo-auditiva indicaram que os parâmetros de tensão e instabilidade foram mais sensíveis quando houve resíduos e penetração laríngea e nos casos de aspiração, o parâmetro mais sensível foi a rugosidade. A análise acústica convencional não apresentou diferenças significativas entre os grupos. Na análise dos PVDV, verificou-se que na presença de resíduo, o parâmetro convergência se mostrou aumentado na maior parte dos pacientes; em casos de penetração laríngea, o número de loops diminuiu e para casos de aspiração laringotraqueal, houve diminuição do número de loops e aumento da convergência. Em relação aos graus encontrados no grupo de referência antes da deglutição, o grau do número de loops foi de 3 e 
4; quanto a regularidade dos traçados $80 \%$ dos indivíduos apresentaram traçados regulares e $20 \%$ deles apresentaram traçado regular com porção irregular. Em relação ao parâmetro convergência $80 \%$ indivíduos foram classificados com forte e média e $20 \%$ dos indivíduos com forte convergência.

Dajer et al. (2011) apresentaram uma modificação na classificação da escala gradativa no parâmetro da regularidade para a análise dos gráficos dos PVDV. A regularidade dos traçados passou a ser classificada com uma escala de variação de grau 4 a 0 onde, o grau 4 corresponde a um traçado completamente regular e o grau 0 a um traçado completamente irregular. Neste estudo Dajer et al. (2011), utilizaram a técnica de análise dos PVDV, medidas de perturbação (jitter e shimmer), F0 e secção de Poincaré para comparar 48 vozes femininas: 23 com vozes adaptadas e com idade média de 33 anos e 25 com edema de Reinke em diferentes estágios de evolução da patologia e com idade média de 37 anos. A análise acústica tradicional apresentou os seguintes resultados: a medida de perturbação jitter e os valores da F0 mostraram diferença significativa $(\mathrm{p}=0,05)$ entre os dois grupos e shimmer não apresentou diferença significativa entre os grupos. Em relação aos resultados da análise dos PVDV, o grupo de mulheres com vozes adaptadas apresentou configurações quanto ao número de laços 4 e 3, regularidade dos traçados com graus 4 e 3 e convergência dos traçados com grau 3. No grupo de mulheres com edema de Reinke a análise dos PVDV apresentou configuração de laços 1 e 2, regularidade dos traçados com graus 1 e 0 e convergência dos traçados com graus 3 e 1 . Os valores da secção de Poincaré apresentaram diferença estatisticamente significante entre os grupos. Este estudo foi capaz de discriminar, por meio dos PVDV, as vozes com edema de Reinke de vozes normais. Os autores concluíram que a associação da análise das medidas de perturbação convencionais, tais como jitter e shimmer, com a técnica de análise dos PVDV podem fornecer mais informações sobre a voz humana.

A classificação de Dajer et al. (2011) foi utilizada no estudo de Sanchez et al. (2012), que avaliaram a aplicabilidade do método da ANL, com a análise dos PVDV na voz de um paciente submetido a LPV. O paciente de 61 anos do sexo masculino apresentou como principal sequela cirúrgica a disfonia. A avaliação perceptivo-auditiva da voz de acordo com os parâmetros e critérios de classificação da escala GRBAS apresentou o seguinte resultado $\mathrm{G}_{2} \mathrm{R}_{2} \mathrm{~B}_{2} \mathrm{~A}_{0} \mathrm{~S}_{0}$ que indicou: rouquidão, aspereza e soprosidade em grau moderado. Para a $\mathrm{ANL}$ por meio da análise qualitativa dos PVDV, obteve os seguintes resultados: laços=2, regularidade $=2$ e convergência dos traçados $=1$. Concluíram que o método de ANL aplicado ao caso se mostrou eficiente para quantificar de forma confiável sinais de voz com alto grau de ruído e permitiu a visualização com maior clareza das características desse tipo voz. 
Devido a complexidade da análise dos PVDV, Galdino (2012) modificou a descrição das classificações dos graus referentes à regularidade dos traçados e foi incluída a opção não avaliável tendo como referência a classificação descrita por Dajer et al. (2011). Neste estudo a autora utilizou à técnica dos padrões visuais da dinâmica vocal (PVDV), com o objetivo de descrever a dinâmica não linear de vozes de homens adultos e sem queixas de voz. Participaram da pesquisa 77 sujeitos do sexo masculino, com idades entre 20 e 40 anos (média 30 anos). Todos os participantes tiveram suas vozes classificadas como normais por meio da análise perceptivo-auditiva (CAPE-V) e da análise acústica convencional (MDVP Kay Pentax). A avaliação do protocolo CAPE-V apresentou média de 18,07 mm, no grau geral da vogal /a/. Na avaliação acústica as médias foram de 125,44 Hz para F0; 0,85\% para jitter; 3,23 para shimmer e 0,13 para NHR. Os resultados do ANL por meio da análise dos PVDV mostrou número de laços com grau 4 (85,71\% com média de 3,84 \pm 0,40), regularidade em graus 3 e 4 (ambos com 40,26\% e média de 3,12 $\pm 0,95$ ) e espaçamento em grau $3(58,44 \%$ e média de 2,95 $\pm 0,76)$. Concluiu-se que os PVDV da vogal /a/ de homens adultos brasileiros com vozes adaptadas dentro da variabilidade normal apresentou padrão visual caracterizado em sua maioria por presença de 4 ou mais laços, traçados regulares ou com discretas irregularidades e com espaçamento entre as linhas de médio a pequeno.

\subsection{Análise perceptivo-auditiva em vozes de pacientes submetidos à laringectomia parcial vertical (LPV)}

Pacientes submetidos à LPV, de forma geral, evoluem com qualidade vocal rouca, tensa, soprosa, com redução da intensidade, alteração da frequência e incoordenação pneumofonoarticulatória (CARRARA-DE ANGELIS; BARROS, 2000).

A avaliação vocal é fundamental para os pacientes submetidos a laringectomia parcial e a análise perceptivo-auditiva é principal ferramenta utilizada tanto na clínica como em pesquisas.

A técnica da análise perceptivo-auditiva é subjetiva e se baseia especialmente na impressão do avaliador sobre a emissão vocal do indivíduo, sofrendo influência do nível de experiência do mesmo neste tipo de avaliação, do material de voz analisado, do tipo de apresentação, do grau de desvio da qualidade vocal, além do tipo de escala utilizada nessa tarefa. Embora sejam feitas críticas à subjetividade e à imprecisão terminológica envolvida nesse procedimento, ela é considerada padrão ouro para avaliação da qualidade vocal. Esta 
avaliação permite a inferência de dados importantes da anatomofisiologia e pode fornecer informações sobre os aspectos psicossociais da voz (GAMA et al., 2011).

Para se obter uma melhor descrição das vozes, vários protocolos de avaliação perceptivo-auditiva foram desenvolvidos, entre eles, a escala GRBAS que é a mais utilizada e difundida no meio científico.

Nos estudos das vozes dos pacientes submetidos à laringectomia parcial, que utilizaram a análise perceptivo-auditiva, a escala GRBAS foi a mais utilizada.

Ricz et al. (2004), avaliaram as funções laríngeas de pacientes submetidos à cordectomia completa (tipo IV), reconstruídos com retalho de prega vestibular. Participaram da amostra dez pacientes, nove do sexo masculino e um do sexo feminino, com idades entre 45 e 75 anos, e média de 64,5 anos. Todos os indivíduos foram submetidos à videolaringoestroboscopia, em que se avaliou a permeabilidade laríngea, o posicionamento do retalho, o fechamento laríngeo, a movimentação das aritenóides e a característica da fonte sonora: vibrátil ou friccional, e quando vibrátil a localização e as estruturas que a compunham. A qualidade vocal foi avaliada pela análise perceptivo-auditiva (GRBAS) e acústica computadorizada. A função de proteção das vias aéreas durante a deglutição foi checada pela avaliação endoscópica da deglutição. Os resultados evidenciaram que não houve necessidade de manter a traqueostomia no pós-operatório tardio, pois a luz laríngea reconstruída se mantinha aberta. A função de proteção estava mantida em todos os casos, a coaptação completa em $30 \%$ e somente um paciente teve a movimentação da aritenóide limitada devido à imobilidade do lado operado. Evidenciaram, também, que havia fonte sonora vibrátil em $90 \%$ dos casos e que em todos os casos a prega vestibular participava da sua composição. Em sete pacientes a fonte sonora vibrátil se localizava na região glótica. A análise acústica convencional revelou frequência fundamental média de 177,5 Hz, jitter médio de $1,11 \%$ e shimmer de $7,04 \%$. Pela escala GRBAS, um paciente (10\%) apresentou voz normal, 4 (40\%) foram classificados com disfonia discreta e os outros 50\% mostraram disfonia moderada (30\%) ou severa (20\%). Os autores concluíram que a reconstrução laríngea pós cordectomia realizada com o retalho da prega vestibular tornou possível emissão de voz normal (frequência fundamental $205 \mathrm{~Hz}$, jitter 0,13\% e shimmer 1,16\%), proporcionando coaptação completa em $30 \%$ dos casos, fonte sonora vibrátil na região glótica em $70 \%$ e participação do retalho como estrutura vibrátil em 90\%, além de preservar as funções laríngeas de respiração e proteção das vias aéreas durante a deglutição.

Dedivitis et al. (2008) realizaram a avaliação perceptivo-auditiva e acústica da voz em 20 pacientes submetidos a laringectomia frontolateral, sendo 18 do sexo masculino e 2 dos 
sexo feminino, com idade média de 61 anos. A avaliação perceptivo-auditiva foi realizada através da escala GIRBAS enquanto, a análise acústica foi feita pelo CSL modelo 4300B e pelo programa de análise vocal MDVP, Kay Elemetrics Corp. Os resultados da análise perceptivo-auditiva da voz revelaram que todos os pacientes apresentaram algum grau de disfonia. Nos resultados da avaliação acústica, 35\% dos pacientes submetidos à laringectomia fronto-lateral apresentaram voz classificada como disfonia severa, 35\% moderada e $25 \%$ leve. A instabilidade foi verificada, em grau leve, em $10 \%$ da amostra. A rugosidade foi observada em $35 \%$ com grau moderado e $35 \%$ severo. A soprosidade foi observada como ausente em metade dos sujeitos e em 25\% como grau leve e em 25\% moderado. Considerando os parâmetros acústicos, observou-se um importante incremento da frequência fundamental e os valores de todos os parâmetros apresentaram-se alterados. Concluíram que a análise perceptivo-auditiva da $\mathrm{voz}$ indicou que todos os pacientes submetidos à laringectomia frontolateral apresentaram algum grau de disfonia, caracterizada principalmente pela presença de rugosidade e tensão. A análise acústica da voz mostrou incremento da frequência fundamental e medidas acústicas alteradas.

Wiskirska-Woźnica et al. (2011) pesquisaram um grupo de 20 pacientes com idade entre 52-82 anos, com idade média de 66,5 anos, consistindo de 3 pacientes do sexo feminino e 17 do sexo masculino, submetidos à cirurgia de laringectomia parcial para a retirada do cancer de laringe, com as seguintes técnicas cirúrgicas: laringectomia parcial supracricóide (SCPL) em quatro casos (T3NOM0), Técnica de Calearo em 11 casos (T2NOM0), Sedlacek em três casos (T2N0M0) e laringectomia supraglótica em dois casos (T2N0M0). Os pacientes não foram submetidos a radioterapia. Os métodos utilizados na investigação foram: (1) avaliação perceptivo-auditiva da voz pela escala GRBAS; (2) videolaringoestroboscopia; (3) análise acústica da voz, (4) tempo máximo de fonação e (5) avaliação da qualidade de vida pelo protocolo IDV. A F0, o tempo máximo de fonação, e as medições de intensidade máxima de fonação não foram significativamente diferente nos 2 grupos. Não houve também nenhuma diferença significativa com a pontução média do IDV. De acordo com a escala GRBAS, em geral a qualidade da voz foi alterada moderadamente em ambos os grupos. A estimativa perceptivo-auditiva da voz (GRBAS) durante conversa espontânea revelou uma boa fonação em apenas três casos após o uso de cirurgia com o Método Calearo. As vozes eram levemente rouca, áspera e tensa. As vozes de outros oito pacientes, após diversos tipos de laringectomia parcial, principalmente após a CHEP, foi classificada como grave, rouca e áspera, e até mesmo muito fraco em um caso. Os nove pacientes restantes apresentaram disfonia leve na escala GRBAS. O tempo máximo de fonação (TMF) em todos os pacientes variou de 2 a $21 \mathrm{~s}$ 
(média 10s). Os melhores resultados de TMF foram observados após cirurgia reconstrutiva com a Método Calearo. A auto-avaliação da voz utilizando a escala do IDV refletiu entre graus severo e graus leves de deficiência voz (respectivamente 5 a 25 pontos) em 10 pacientes, e 26 a 40 pontos em 2 pacientes (máxima pontuação 120, resultados de escala abaixo de Jacobson 60 pontos voz handicap). Apenas um paciente que avaliou a sua voz como quase normal, marcou 104 pontos na escala de IDV. Quando se compara os resultados médios de IDV para os tipos de laringectomia parcial, a pior pontuação (27) foi obtida após a cirurgia de Sedlacek, 31 após a cirurgia com o método Calearo (31) e após a CHEP (46). Os resultados de achados videolaringoestroboscópicos são relativos as formas de fechamento da neoglote e fonação. Os melhores resultados da análise acústica, particularmente de perturbação, da frequência e amplitude, foram observados após Sedlacek, mas, inversamente, a estimativa perceptiva da voz e da voz auto-avaliação foram piores nesse grupo de pacientes. 
5 Materíaís e $\mathcal{M}$ Métodos 


\section{MATERIAIS E MÉTODOS}

\subsection{Consideração Ética}

Para o desenvolvimento deste trabalho foram respeitados todos os princípios éticos contidos no Art. $29^{\circ}$ do código de ética do fonoaudiólogo e resoluções 196/96 e 257/97 sobre ética em pesquisa com seres humanos. Este projeto foi submetido e aprovado pelo Comitê de Ética em Pesquisas da Fundação Hospital Amaral Carvalho, sob o processo de nº133/11 em 25/11/2011 e 17/01/2014 (ANEXOS A e B).

\subsection{Casuística}

Foram analisados os sinais das vozes de 31 pacientes adultos, de ambos os sexos, sendo 29 homens (94\%) e 2 mulheres (6\%), com faixa etaria entre 45 e 81 anos ( $\bar{X}=63,48$ anos DP $=9$,95anos) e submetidos a laringectomia parcial vertical aqui denominado grupo de pacientes (GP). Estes sinais de vozes analisados pertencem ao banco de vozes coletado na dissertação de mestrado intitulada: "O impacto da alteração de voz na qualidade de vida de pacientes submetidos a laringectomia parcial vertical” (2006 - Bioengenharia - EESC-USP São Carlos) de autoria de Renata Furia Sanchez com aprovação do Comitê de Ética em Pesquisas da Fundação Hospital Amaral Carvalho, em 14/06/2005.

Foram analisados também os sinais de vozes sem alterações vocais e laríngeas de 31 homens de faixa etária compreendida entre 20 e 40 anos (média 30 anos $\pm 5,54$ anos) aqui denominado grupo controle (GC) coletados do banco de vozes na dissertação de mestrado intitulada: "Análise acústica não linear dos padrões visuais de dinâmica vocal (PVDV) de homens adultos” (2012 - Bioengenharia - EESC-USP - São Carlos) de autoria de Debora Godoy Galdino.

\subsubsection{Banco de Dados dos Sinais de Voz}

No estudo de Sanchez (2006) os indivíduos do GP foram selecionados por meio dos prontuários eletrônicos submetidos a laringectomia parcial vertical, entre fevereiro de 1993 e 
abril de 2005, no Departamento de Cabeça e Pescoço do Hospital Amaral Carvalho. Dos 94 pacientes encontrados 6 que moravam fora do estado de São Paulo e 25 que não estavam com seus dados para contato atualizados no prontuário, foram excluídos da pesquisa. Portanto, 63 pacientes foram contatados por telefone para participar deste estudo, sendo que: 3 estavam doentes e impossibilitados de comparecer a entrevista, 3 faltaram a entrevista e 26 foram a óbito.

A gravação digital das vozes foram realizadas com os pacientes em posição sentada, com um microfone de cabeça posicionado lateralmente a $3 \mathrm{~cm}$ (em um ângulo de 90 graus) à boca do indivíduo. O programa utilizado para gravação foi o Sound Forge 7.0 com a seguinte amostra:

a) fala encadeada:

- automática (números de 1 a 20 e dias da semana),

- conversa espontânea (aproximadamente 60 segundos) onde o mesmo relatava o seu problema vocal.

b) vogal sustentada /a/ (mínimo de 5 segundos).

Segundo Galdino (2012) os critérios para exclusão dos participantes do GC foram: ter queixas de voz ou audição, histórico de cirurgia laríngea, ser cantor, ser fumante, fazer uso de álcool diário e não apresentar bom estado de saúde geral. Para esta seleção os indivíduos primeiramente participaram de uma entrevista fonoaudiológica com levantamento dos dados pessoais, vocais e de saúde geral. As gravações das vozes dos indivíduos participantes foram realizadas em sala acusticamente tratada do Laboratório de voz da Clínica de Fonoaudiologia da Faculdade de Odontologia de Bauru - Universidade de São Paulo.

A postura adotada para a gravação foi o indivíduo sentado, tronco reto, costas apoiadas no encosto da cadeira, braços e mãos relaxados sobre as pernas. Para gravação e edição de áudio, foi utilizado o programa profissional Sound Forge 10.0 da Sony Pictures Digital Inc. Os sinais foram gravados a uma taxa de amostragem de $44.100 \mathrm{~Hz}, 16$ bits e com um canal (mono). O microfone de cabeça, modelo AKG C444, conectado a um préamplificador estéreo da KAY PENTAX, foi ajustado a uma distância de aproximadamente três centímetros da comissura lateral da boca.

Para a gravação dos sinais de voz, foram solicitadas ao indivíduo as seguintes emissões contidas no protocolo CAPE-V: vogal sustentada /a/ de 3 a 5 segundos, trecho de fala espontânea com o conteúdo "Diga-me o que acha de sua voz" e "Fale-me um pouco 
sobre sua profissão ou como foi seu dia”, e a leitura das sentenças "Érica tomou suco de pêra e amora", "Sonia sabe sambar sozinha", "Olha lá o avião azul”, "Agora é hora de acabar", "Minha mãe namorou um anjo", "Papai trouxe pipoca quente".

\subsection{Procedimentos}

Os sinais de vozes utilizados foram analisados pelo método ANL, baseado na técnica dos Padrões Visuais da Dinâmica Vocal (PVDV), utlizando a escala de classificação L-IE desenvolvida neste estudo e pela avaliação perceptivo-auditiva utilizando a escala GRBAS.

\subsubsection{Análise dos Padrões Visuais da Dinâmica Vocal - escala L-IE}

A análise qualitativa dos padrões visuais de dinâmica vocal (PVDV) é uma das técnicas de análise não linear da voz e foi desenvolvida a partir do método de reconstrução do espaço de fase. Este método representa a vibração das pregas vocais em um gráfico bidimensional (GALDINO, 2012).

A partir dos sinais de voz da vogal /a/ foram gerados os gráficos bidimensionais por meio da rotina computacional desenvolvida e implementada no MatLab ${ }^{\circledR} 10.0$ a partir do pacote TISEAN (DAJER, 2006; HEGGER et al., 1999) pela fonoaudióloga do Laboratório de Processamentos de Sinais do SEL-EESC-USP.

Este estudo contribuiu com uma nova proposta de classificação dos parâmetros dos PVDV pelo método da ANL: a escala L-IE. O desenvolvimento desta escala surgiu pela necessidade de maior especificação na classificação dos parâmetros dos PVDV, uma vez que as apresentadas em estudos anteriores (DAJER et al., 2009; DAJER, 2010; GALDINO, 2012) não permitiram uma descrição adequada das vozes com grande quantidade de ruído, como as vozes pós LPV. Após muitas reuniões e discussões com um grupo de fonoaudiólogas pesquisadoras da ANL da Universidade de São Paulo foi possível a sua elaboração, que possibilitou uma interpretação mais precisa e com menor subjetividade dos gráficos bidimensionais dos sinais de vozes.

A avaliação visual qualitativa dos gráficos bidimensionais por meio da escala L-IE (Laços - Irregularidade e Espaçamento) desenvolvida neste estudo, em que L se relaciona as características do trato vocal e I e E ao ciclo vibratório das estruturas remanescentes, foi baseada na classificação proposta da análise dos padrões visuais da dinâmica vocal (PVDV) 
descrita por Dajer (2010) e Galdino (2012). A proposta de Dajer (2010) descreveu os três parâmetros de avaliação dos gráficos bidimensionais: número de laços (loops); regularidade e convergência dos traçados das órbitas avaliados em uma escala de 0 a 4 , da pior para a melhor configuração dos traçados, respectivamente (DAJER et al., 2011). O estudo de Galdino (2012), renomeou o parâmetro convergência para espaçamento dos traçados e na escala considerou não apenas o número de ocorrência das irregularidades, mas também o grau de severidade. Na escala L-IE do presente estudo a denominação regularidade foi substituída por irregularidade. A escala de classificação L-IE, utiliza para a avaliação do número de laços das órbitas uma escala de 0 a 4, crescente de acordo com o número de laços (Tabela1) e para a irregularidade e espaçamento dos traçados uma escala de 1 a 7 crescente de acordo com o aumento do grau da alteração (Tabelas 2 e 3).

Tabela 1 - Classificação do número de laços da escala L-IE, considerando a quantidade de laços das órbitas

\begin{tabular}{ll}
\hline & \multicolumn{1}{c}{ NÚMERO DE LAÇOS (L) } \\
\hline $\mathbf{0}$ & Indefinição total das órbitas dos traçados \\
$\mathbf{1}$ & Um laço visualizável \\
$\mathbf{2}$ & Dois laços visualizáveis \\
$\mathbf{3}$ & Três laços visualizáveis \\
$\mathbf{4}$ & Quatro ou mais laços visualizáveis \\
\hline
\end{tabular}

As Figuras de 3 a 7 ilustram a classificação do número de laços do gráfico bidimensional pela escala L-IE.

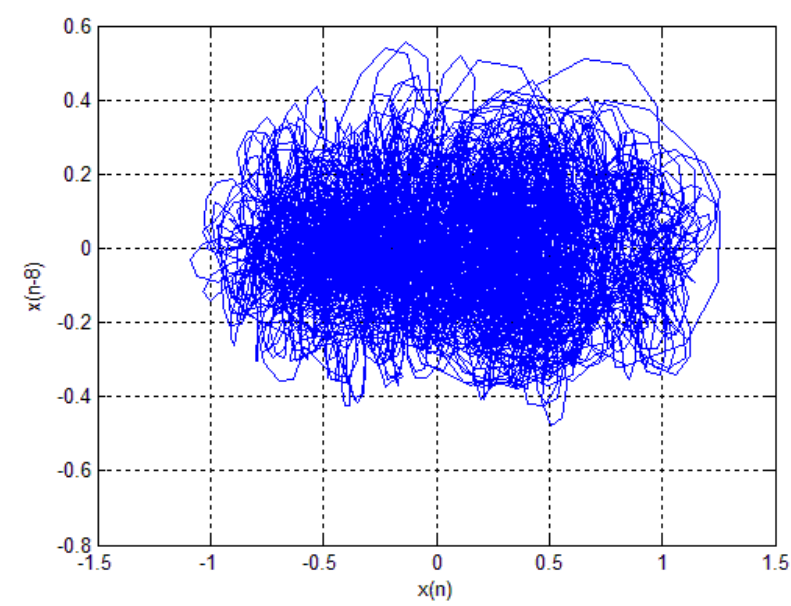

Figura 3 - Gráfico bidimensional com classificação do parâmetro do número de laços igual a 0 de um indivíduo do presente estudo 


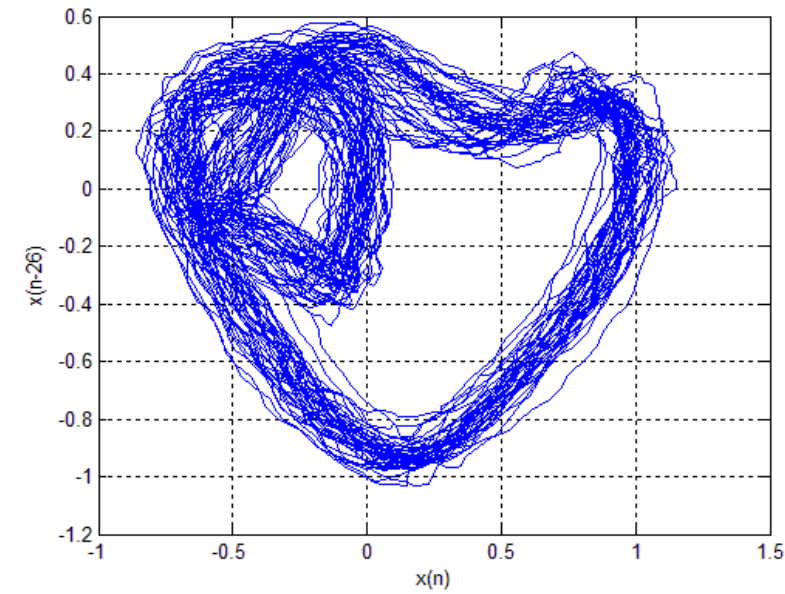

Figura 4 - Gráfico bidimensional com classificação do parâmetro do número de laços igual a 1 de um indivíduo do presente estudo

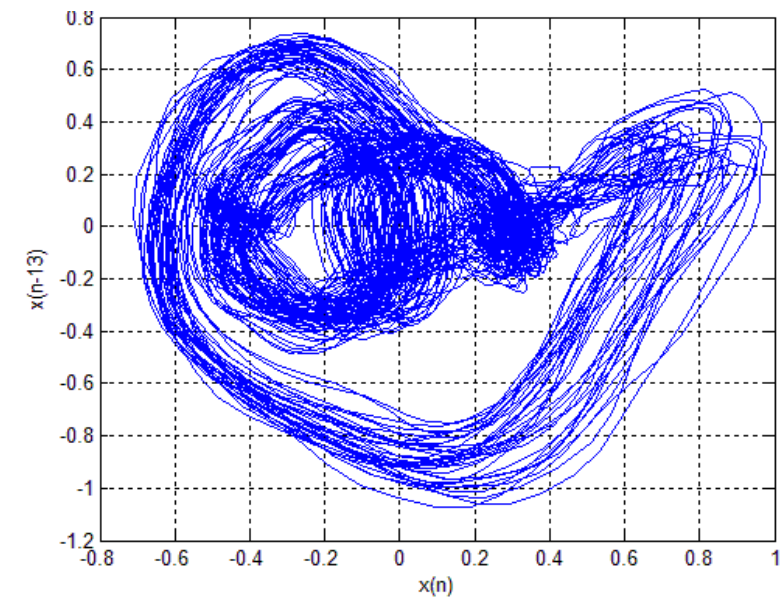

Figura 5 - Gráfico bidimensional com classificação do parâmetro do número de laços igual a 2 de um indivíduo do presente estudo

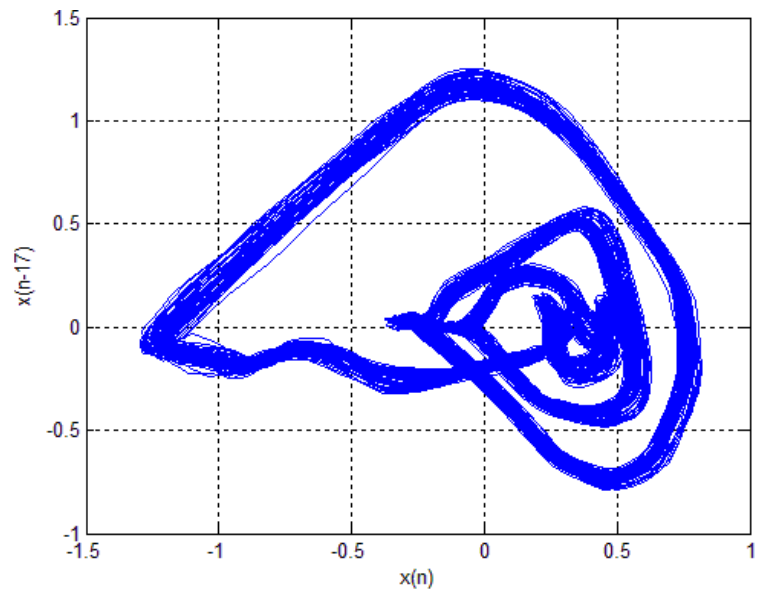

Figura 6 - Gráfico bidimensional com classificação do parâmetro do número de laços igual a 3 de um indivíduo do presente estudo 


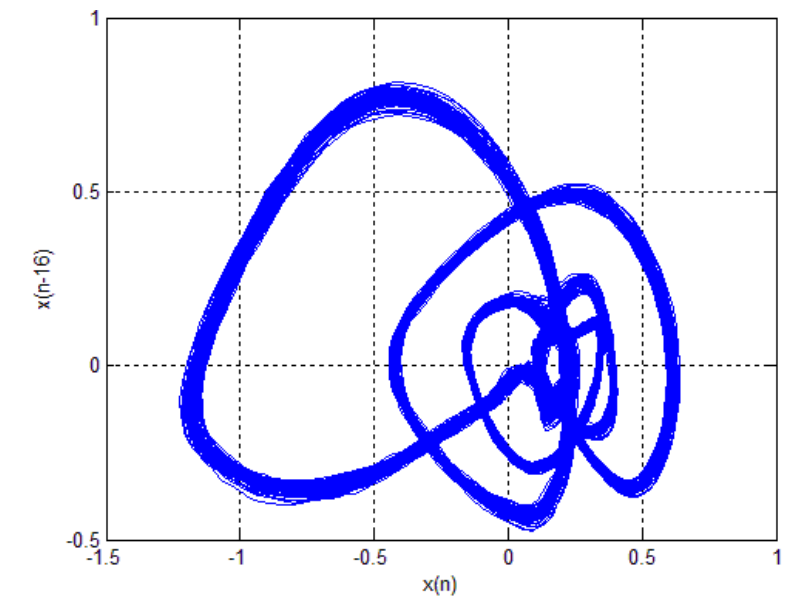

Figura 7 - Gráfico bidimensional com classificação do parâmetro do número de laços igual a 4 ou mais de um indivíduo do presente estudo

Tabela 2 - Classificação dos graus do parâmetro irregularidade (I) dos traçados segundo a escala L-IE

\begin{tabular}{cl}
\hline GRAU & \multicolumn{1}{c}{ IRREGULARIDADE (I) } \\
\hline $\mathbf{1}$ & Discreta com ocorrência única ou menos de 50\% \\
$\mathbf{2}$ & Discreta com ocorrência de mais de $50 \%$ \\
$\mathbf{3}$ & Moderada com ocorrência única ou menos de $50 \%$ \\
$\mathbf{4}$ & Moderada com ocorrência de mais de $50 \%$ \\
$\mathbf{5}$ & Severa com ocorrência única ou menos de $50 \%$ \\
$\mathbf{6}$ & Severa com ocorrência de mais de $50 \%$ \\
$\mathbf{7}$ & Não mensurável \\
\hline
\end{tabular}

As Figuras de 8 a 14 ilustram a classificação em graus do parâmetro da irregularidade do gráfico bidimensional pela escala L-IE.

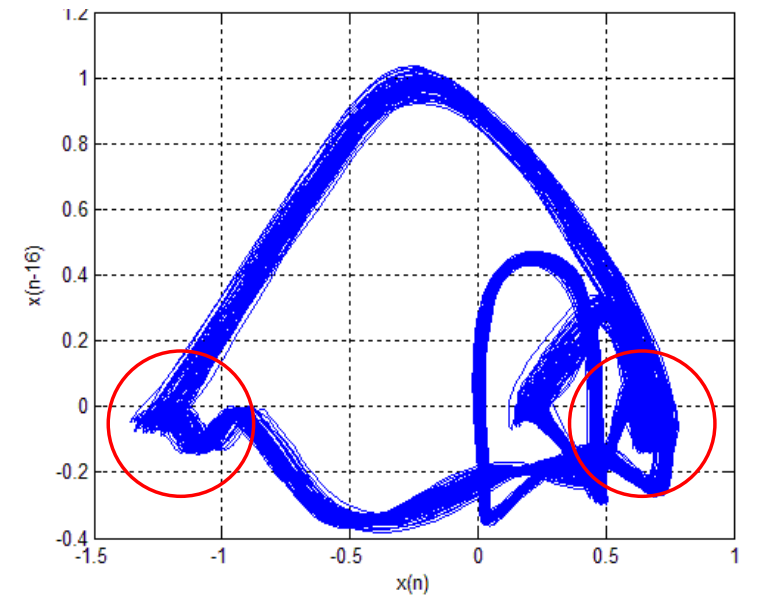

Figura 8 - Gráfico bidimensional com classificação do parâmetro da irregualaridade igual a 1 de um indivíduo do presente estudo 


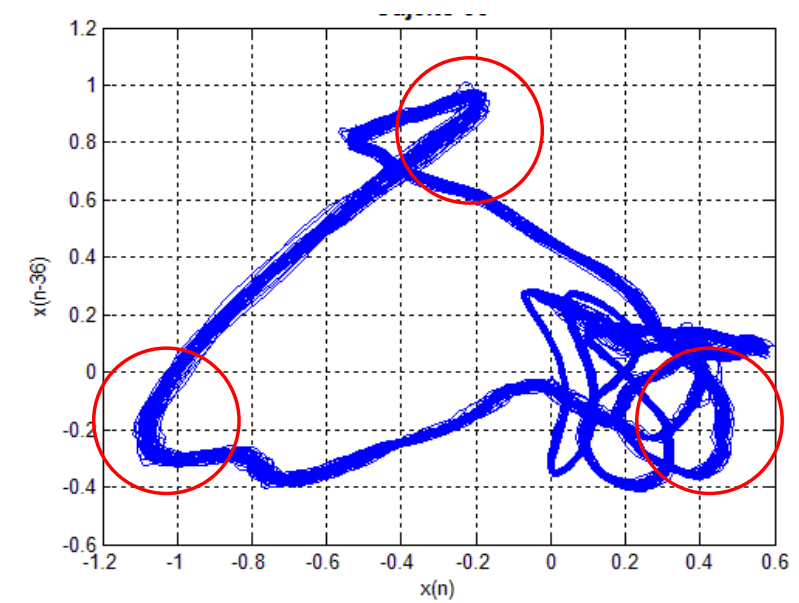

Figura 9 - Gráfico bidimensional com classificação do parâmetro da irregularidade igual a 2 de um indivíduo do presente estudo

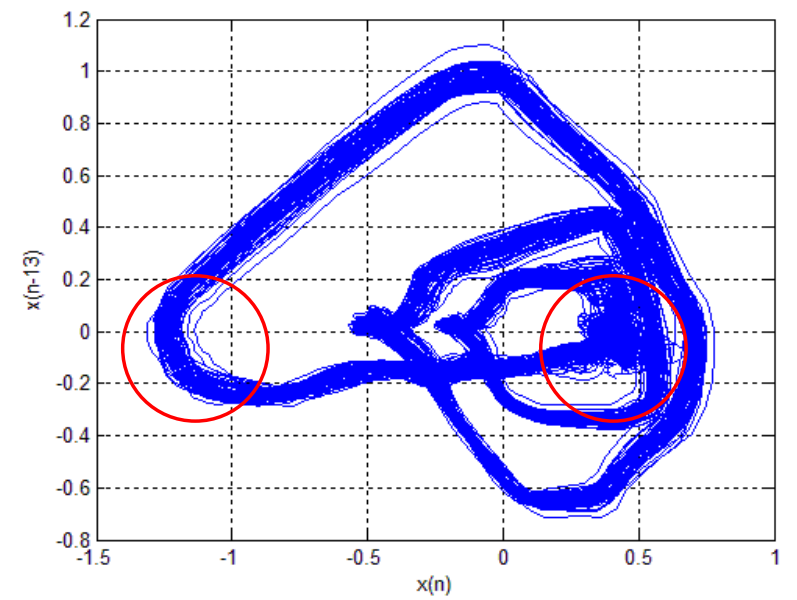

Figura 10 - Gráfico bidimensional com classificação do parâmetro da irregularidade igual a 3 de um indivíduo do presente estudo

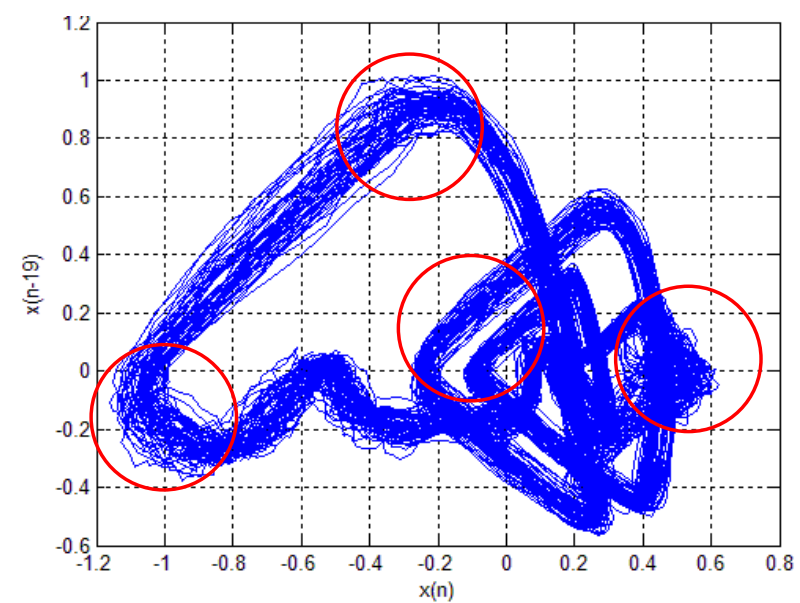

Figura 11 - Gráfico bidimensional com classificação do parâmetro da irregularidade igual a 4 de um indivíduo do presente estudo 


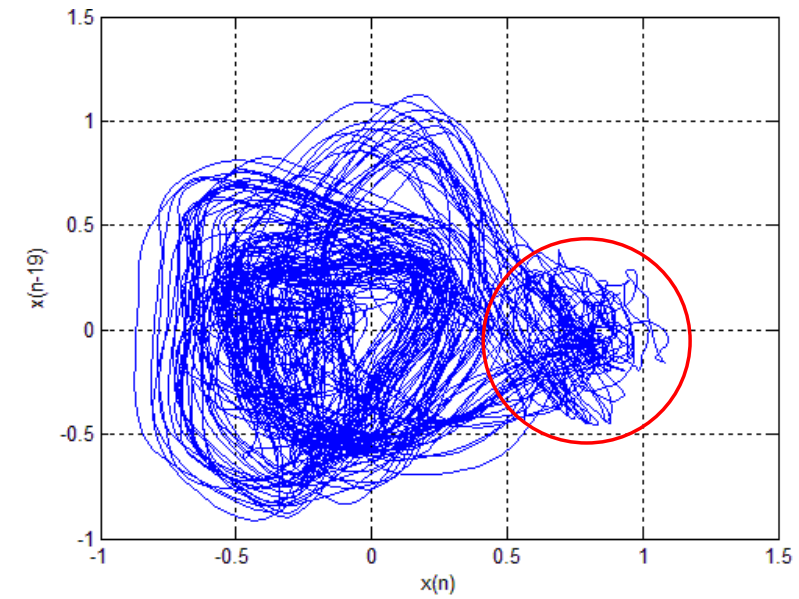

Figura 12 - Gráfico bidimensional com classificação do parâmetro da irregularidade igual a 5 de um indivíduo do presente estudo

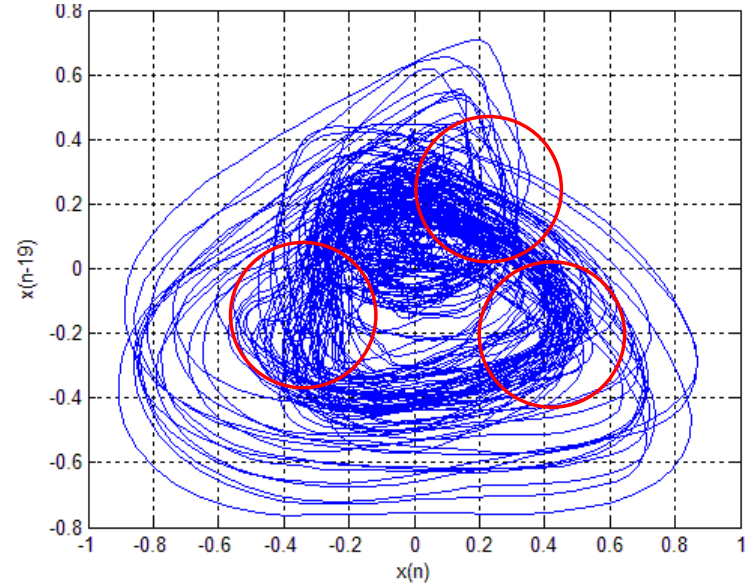

Figura 13 - Gráfico bidimensional com classificação do parâmetro da irregularidade igual a 6 de um indivíduo do presente estudo

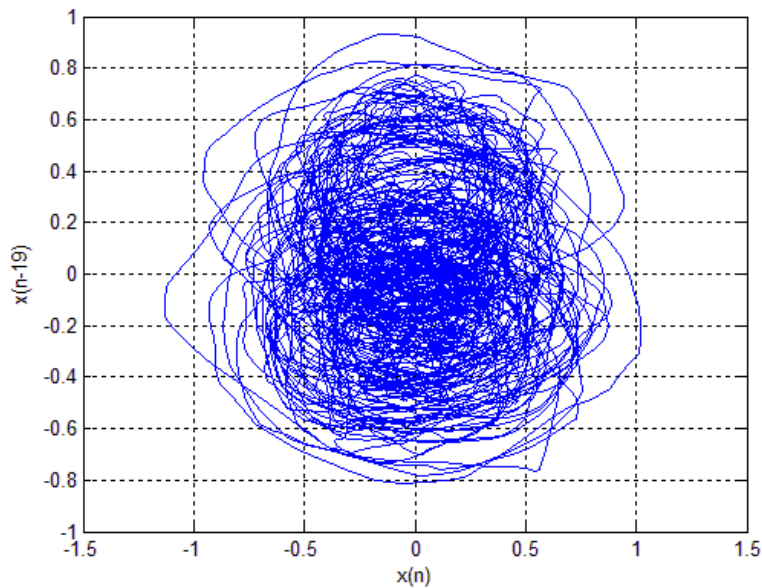

Figura 14 - Gráfico bidimensional com classificação do parâmetro da irregularidade igual a 7 de um indivíduo do presente estudo 
Tabela 3 - Classificação dos graus do parâmetro espaçamento (E) dos traçados segundo a escala L-IE

\begin{tabular}{cl}
\hline GRAU & \multicolumn{1}{c}{ ESPAÇAMENTO (E) } \\
\hline $\mathbf{1}$ & Discreto com ocorrência única ou menos de 50\% \\
$\mathbf{2}$ & Discreto com ocorrência de mais de 50\% \\
$\mathbf{3}$ & Moderado com ocorrência única ou menos de 50\% \\
$\mathbf{4}$ & Moderado com ocorrência de mais de 50\% \\
$\mathbf{5}$ & Severo com ocorrência única ou menos de 50\% \\
$\mathbf{6}$ & Severo com ocorrência de mais de 50\% \\
$\mathbf{7}$ & Não mensurável \\
\hline
\end{tabular}

As Figuras 15 a 21 ilustram a classificação do grau de espaçamento do gráfico bidimensional pela escala L-IE.

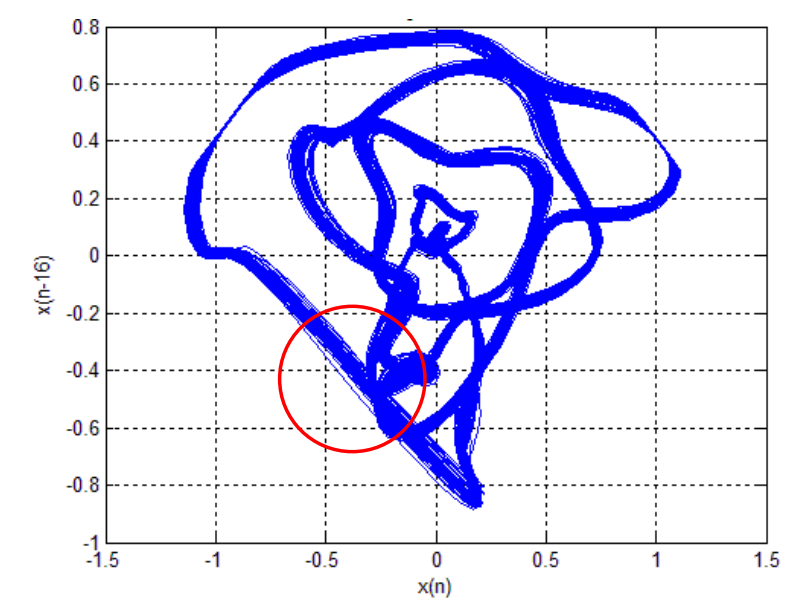

Figura 15 - Gráfico bidimensional com classificação do parâmetro do espaçamento igual a 1 de um indivíduo do presente estudo

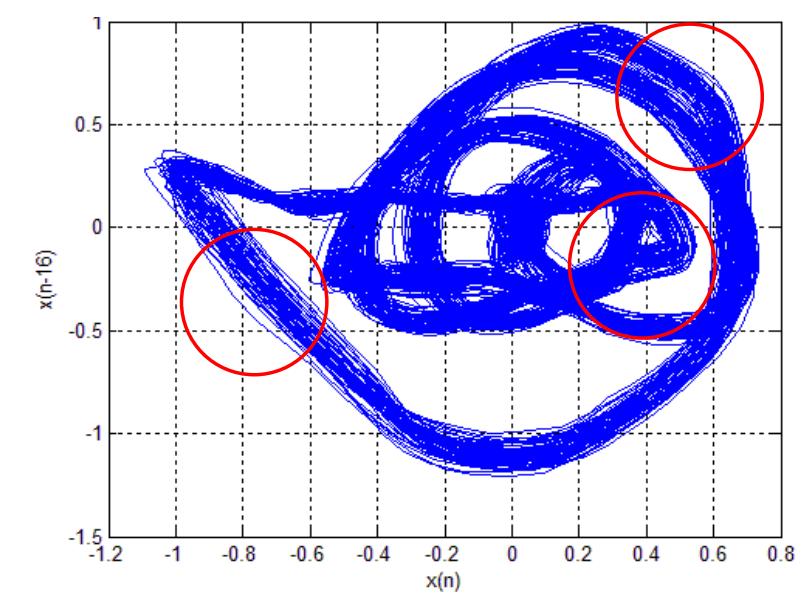

Figura 16 - Gráfico bidimensional com classificação do parâmetro do espaçamento igual a 2 de um indivíduo do presente estudo 


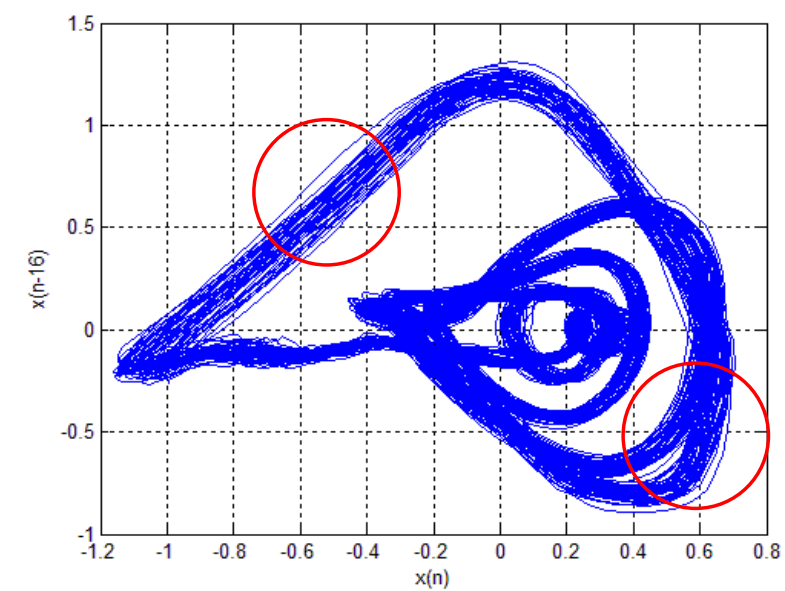

Figura 17 - Gráfico bidimensional com classificação do parâmetro do espaçamento igual a 3 de um indivíduo do presente estudo

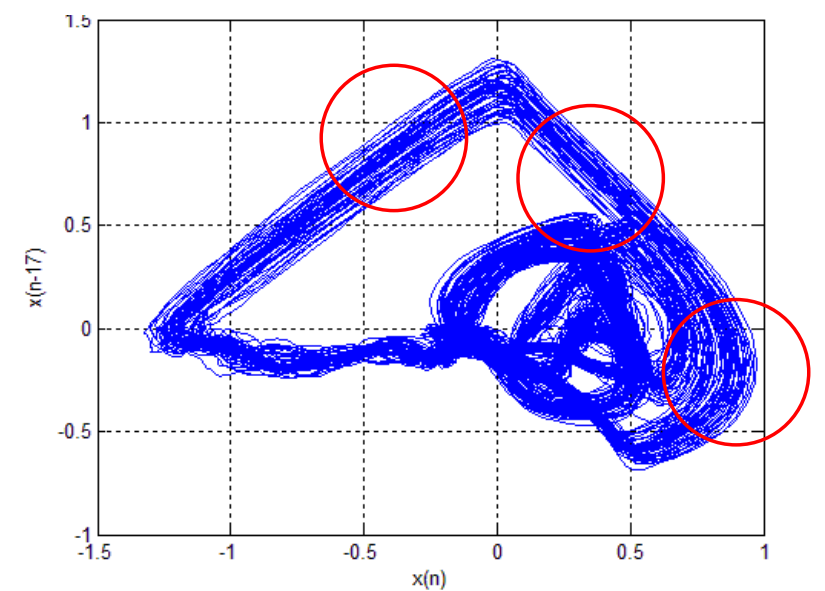

Figura 18 - Gráfico bidimensional com classificação do parâmetro do espaçamento igual a 4 de um indivíduo do presente estudo

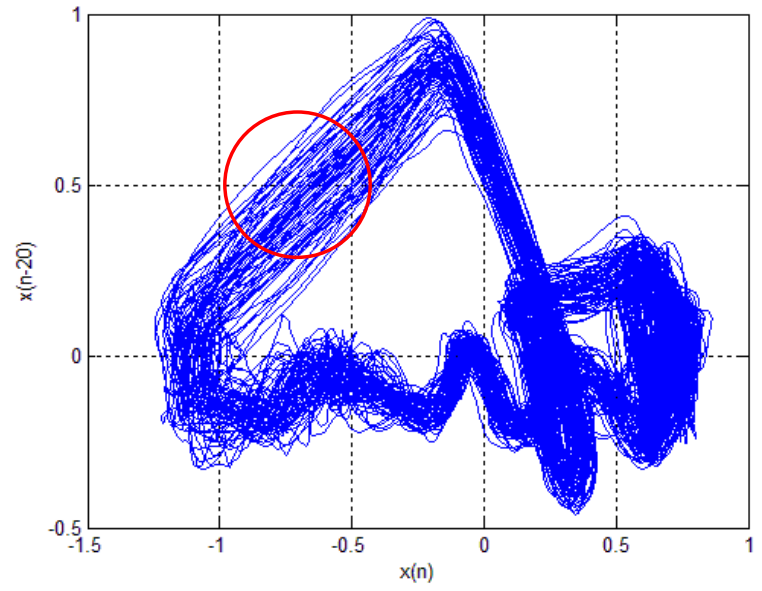

Figura 19 - Gráfico bidimensional com classificação do parâmetro do espaçamento igual a 5 de um indivíduo do presente estudo 


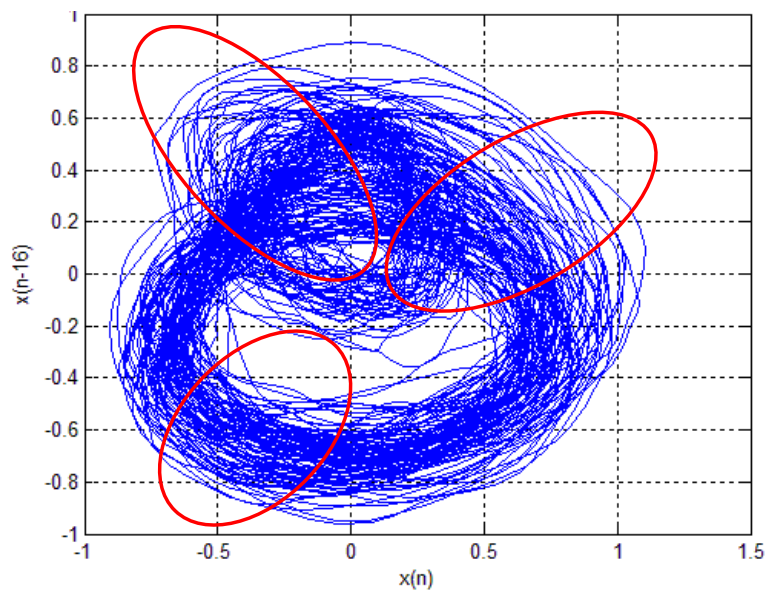

Figura 20 - Gráfico bidimensional com classificação do parâmetro do espaçamento igual a 6 de um indivíduo do presente estudo

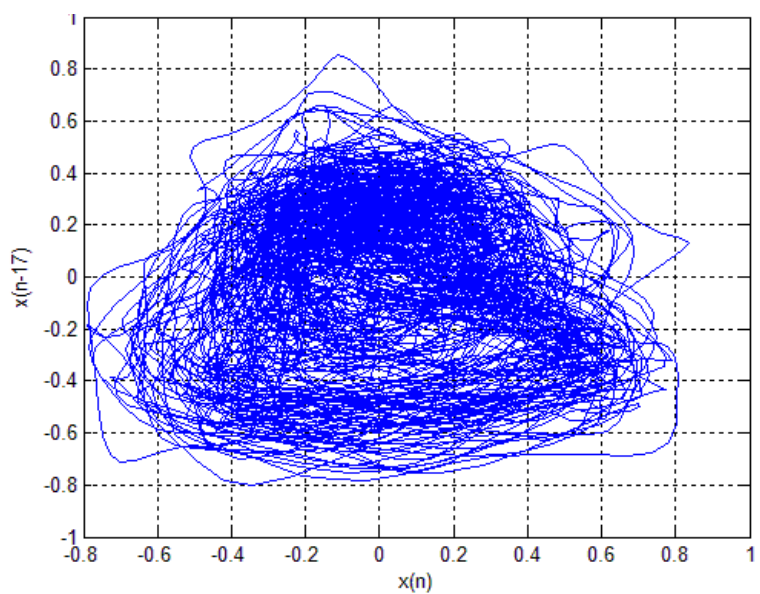

Figura 21 - Gráfico bidimensional com classificação do parâmetro do espaçamento igual a 7 de um indivíduo do presente estudo

A análise visual qualitativa dos gráficos bidimensionais de acordo com os parâmetros da escala L-IE foi realizada por quatro fonoaudiólogas em consenso entre elas. Foram projetadas de forma aleatória as imagens dos gráficos dos grupos GP e GC e para a análise da reprodutibilidade foram acrescentados doze gráficos, sendo seis de cada grupo, totalizando $20 \%$ da amostra.

\subsubsection{Avaliação perceptivo-auditiva da voz - escala GRBAS}

Para avaliação clínica perceptivo-auditiva da voz foi utilizada a escala GRBAS. Esta escala é baseada nos trabalhos de Isshiki et al. (1966) e desenvolvida pelo Comitê da Sociedade Japonesa de Logopedia e Foniatria (BODT et al., 1997). A escala GRBAS é um 
método simples de avaliação do grau global da disfonia, representado pelo "G" (grade of hoarseness) pela identificação de quatro parâmetros vocais independentes: a rugosidade, representada pelo "R" (roughness); a soprosidade, pelo "B" (breathiness); a fraqueza, pelo "A" (asthenic) e a tensão, pelo "S" (strained). Os termos rugosidade e soprosidade são usados na literatura para descrever alterações na qualidade vocal. Rugosidade corresponde a um ruído associado à voz causado pela falta de sincronia da vibração entre as pregas vocais e soprosidade corresponde à presença de um ruído de fundo, audível, resultante de um escape de ar, em geral, devido a um fechamento glótico incompleto durante a fonação. Os termos fraqueza e tensão vocal são parâmetros que evidenciam falha na habilidade de sustentar a vibração das pregas vocais durante a fonação, baseado no sistema mioelástico da laringe e nas forças aerodinâmicas da corrente pulmonar. Fraqueza indica falta de sustentação muscular à passagem do fluxo aéreo glótico, dando a sensação de perda de intensidade e tensão, ao contrário da fraqueza, indica excesso de força muscular, caracterizando esforço à fonação. A escala GRBAS pontua o grau de desvio do "G" e de cada parâmetro avaliado de 0 a 3 a saber: “0” corresponde à ausência do aspecto avaliado (isto é, a normalidade); “1” à alteração discreta, (quando a alteração não é identificada imediatamente pelo ouvinte, sendo necessário uma maior atenção para percebê-la); "2" à alteração moderada (quando a alteração foi facilmente percebida) e "3" à alteração severa (quando, além de facilmente percebida, a alteração chama a atenção e/ou incomoda o ouvinte) (TELES-MAGALHÃES, 2002).

A avaliação perceptivo-auditiva das vozes do GP foi realizada por uma fonoaudióloga com experiência em avaliação vocal. Os dados da GRBAS foram coletados no estudo de Sanchez (2006).

\subsection{Análise dos resultados}

Os dados deste estudo foram apresentados de forma descritiva pela porcentagem, pela média e desvio padrão.

A comparação dos resultados da Escala L-IE entre os grupos GP e GC foi feita pelo teste de Mann-Whitney.

A correlação entre os parâmetros da Escala L-IE foi realizada pelo teste da Correlação de Spearman com os resultados obtidos dos grupos $(\mathrm{GP}+\mathrm{GN})$ e isoladamente com os do grupo GP. 
Foi realizada a correlação entre os parâmetros da Escala L-IE e os parâmetros da Escala GRBAS pelo teste da Correlação de Spearman com os resultados do GP.

Para a reprodutibilidade da avaliação da Escala L-IE foi realizada a comparação estatítca e a correlação por meio do teste da Correlação de Spearman dos $20 \%$ da amostra reavaliada. 
6 Resultados 


\section{RESULTADOS}

\subsection{Resultados da análise dos padrões visuais da dinâmica vocal - escala L-IE}

Os resultados dos gráficos bidimensionais quanto ao número de laços e dos parâmetros irregularidade e espaçamento da escala L-IE dos grupos GP e GC estão apresentados nas Figuras 22, 23 e 24 e na Tabela 4.

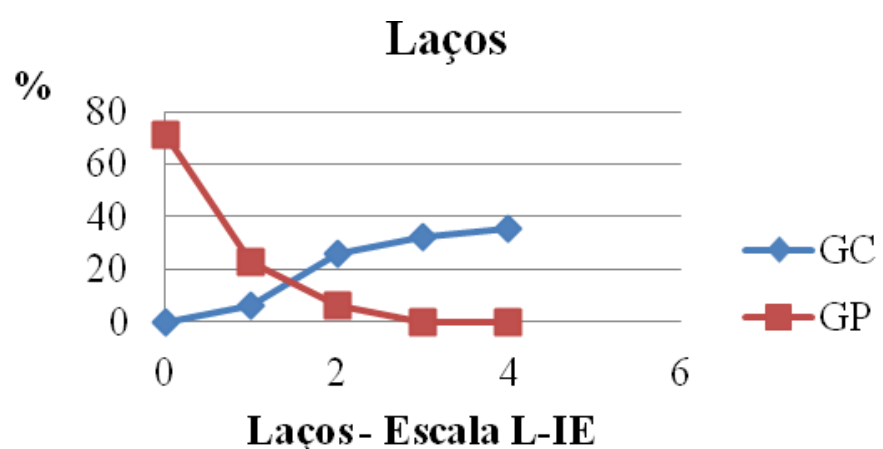

Figura 22 - Porcentagem do número de laços da escala L-IE dos grupos GP e GC deste estudo

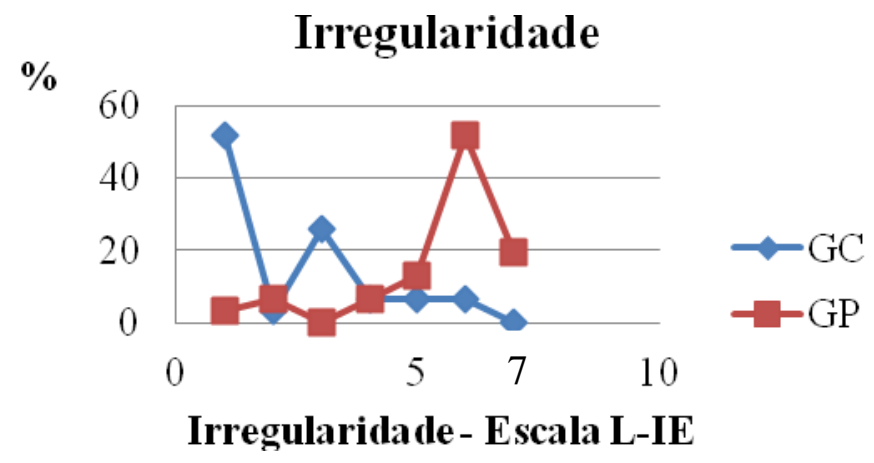

Figura 23 - Porcentagem do parâmetro irregularidade da escala L-IE dos grupos GP e GC deste estudo

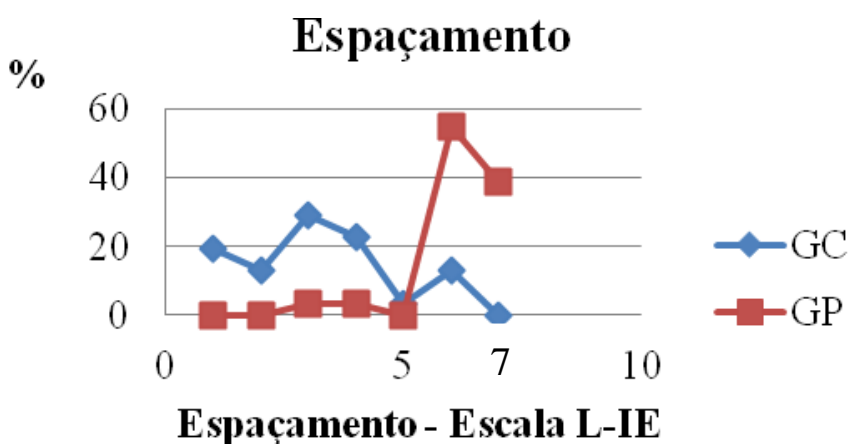

Figura 24 - Porcentagem do parâmetro espaçamento da escala L-IE dos grupos GP e GC deste estudo 
Tabela 4- Média, desvio padrão, valores máximos e mínimos e os percentis do número de laços (L) e dos parâmetros irregularidade (I) e espaçamento (E) da Escala L-IE dos grupos GP e GC e o resultado da comparação estatística entre os grupos

\begin{tabular}{|c|c|c|c|c|c|c|c|c|c|c|c|}
\hline \multirow[b]{2}{*}{$\begin{array}{c}\text { Escala } \\
\text { L-IE }\end{array}$} & \multirow[b]{2}{*}{ Grupo } & \multirow[b]{2}{*}{$\mathbf{n}$} & \multirow[b]{2}{*}{ Média } & \multirow[b]{2}{*}{ DP } & \multirow[b]{2}{*}{$\begin{array}{c}\text { Mi } \\
\text { n. }\end{array}$} & \multirow[b]{2}{*}{ Max. } & \multicolumn{3}{|c|}{ Percentis } & \multirow{2}{*}{$\begin{array}{c}\text { Mann } \\
\text { Whitney } \\
\text { U }\end{array}$} & \multirow[b]{2}{*}{$\mathbf{P}$} \\
\hline & & & & & & & 25 & $\begin{array}{c}50 \\
\text { Mediana }\end{array}$ & 75 & & \\
\hline \multirow[b]{2}{*}{$\mathbf{L}$} & GC & 3 & 2,97 & 0,948 & 1 & 4 & 2,00 & 3,00 & 4,00 & \multirow[b]{2}{*}{19,000} & \multirow[b]{2}{*}{0,000} \\
\hline & GP & $\begin{array}{l}1 \\
3 \\
1\end{array}$ & 0,35 & 0,608 & 0 & 2 & 0,00 & 0,00 & 1,00 & & \\
\hline \multirow[b]{2}{*}{ I } & GC & 3 & 2,29 & 1,657 & 0 & 6 & 1,00 & 1,00 & 3,00 & \multirow[b]{2}{*}{89,500} & \multirow[b]{2}{*}{0,000} \\
\hline & GP & $\begin{array}{l}1 \\
3 \\
1\end{array}$ & 5,52 & 1,503 & 1 & 7 & 5,00 & 6,00 & 6,00 & & \\
\hline \multirow[b]{2}{*}{$\mathbf{E}$} & $\mathrm{GC}$ & 3 & 3,16 & 1,573 & 1 & 6 & 2,00 & 3,00 & 4,00 & \multirow[b]{2}{*}{59,000} & \multirow[b]{2}{*}{0,000} \\
\hline & GP & $\begin{array}{l}1 \\
3 \\
1\end{array}$ & 6,23 & 0,884 & 3 & 7 & 6,00 & 6,00 & 7,00 & & \\
\hline
\end{tabular}

Houve correlação significativa $(\mathrm{p}<0,05)$ entre os três parâmetros da escala L-IE tanto para a análise total da amostra, grupos GP e GC, como para a análise do grupo GP separadamente (Tabela 5 e 6).

Tabela 5- Correlação entre os parâmetros da escala L-IE com dados de ambos os grupos GP e GC deste estudo

\begin{tabular}{clccc}
\hline \multicolumn{2}{c}{ Correlação Spearman } & $\mathbf{L}$ & $\mathbf{I}$ & $\mathbf{E}$ \\
\hline \multirow{4}{*}{$\mathbf{L}$} & $\mathrm{r}$ & 1,000 & $-0,766$ & $-0,772$ \\
& $\mathrm{p}$ & $\cdot$ & 0,000 & 0,000 \\
& $\mathrm{n}(\mathrm{GP}+\mathrm{GC})$ & 62 & 62 & 62 \\
\hline \multirow{4}{*}{$\mathbf{I}$} & $\mathrm{r}$ & $-0,766$ & 1,000 & 0,766 \\
& $\mathrm{p}$ & 0,000 & $\cdot$ & 0,000 \\
& $\mathrm{n}(\mathrm{GP}+\mathrm{GC})$ & 62 & 62 & 62 \\
\hline \multirow{4}{*}{$\mathbf{E}$} & $\mathrm{r}$ & $-0,772$ & 0,766 & 1,000 \\
& $\mathrm{p}$ & 0,000 & 0,000 & $\cdot$ \\
& $\mathrm{n}(\mathrm{GP}+\mathrm{GC})$ & 62 & 62 & 62 \\
\hline
\end{tabular}


Tabela 6- Correlação entre os parâmetros da escala L-IE com dados do grupo GP deste estudo

\begin{tabular}{|c|c|c|c|c|}
\hline \multicolumn{2}{|c|}{ Correlação } & $\mathbf{L}$ & I & $\mathbf{E}$ \\
\hline \multirow{3}{*}{$\mathbf{L}$} & $\mathrm{r}$ & 1,000 & $-0,516$ & $-0,476$ \\
\hline & $\mathrm{p}$ & . & 0,003 & 0,007 \\
\hline & $\mathrm{n}(\mathrm{GP})$ & 31 & 31 & 31 \\
\hline \multirow{3}{*}{ I } & $\mathrm{r}$ & $-0,516$ & 1,000 & 0,489 \\
\hline & $\mathrm{p}$ & 0,003 & . & 0,005 \\
\hline & $\mathrm{n}(\mathrm{GP})$ & 31 & 31 & 31 \\
\hline \multirow{3}{*}{$\mathbf{E}$} & $\mathrm{r}$ & $-0,476$ & 0,489 & 1,000 \\
\hline & $\mathrm{P}$ & 0,007 & 0,005 & . \\
\hline & $\mathrm{n}(\mathrm{GP})$ & 31 & 31 & 31 \\
\hline
\end{tabular}

$\mathrm{Na}$ análise da reprodutibilidade da avaliação dos parâmetros da escala L-IE não houve diferença significante entre a avaliação e o reteste e houve forte correlação entre eles (Tabela 7).

Tabela 7- Resultados da correlação de Spearman entre a avaliação e o reteste da avaliação da escala L-IE

\begin{tabular}{ccc}
\hline $\begin{array}{c}\text { Correlação de } \\
\text { Spearman }\end{array}$ & r & P \\
\hline L1 x L2 & 0,98 & 0,0000 \\
I1 x I2 & 0,93 & 0,0000 \\
E1 x E2 & 0,92 & 0,0000 \\
\hline
\end{tabular}

\subsection{Resultados da avaliação perceptivo-auditiva da escala GRBAS}

Os resultados da avaliação perceptivo-auditiva quanto aos parâmetros: grau global da disfonia $(\mathrm{G})$, rugosidade $(\mathrm{R})$, soprosidade (B), astenia (A) e tensão (S) da escala GRBAS estão descritos na Tabela 8. 
Tabela 8- Ocorrência do grau de desvio dos parâmetros da escala GRBAS para os pacientes do GP

\begin{tabular}{cccccc}
\hline Grau de desvio & $\mathbf{G}$ & $\mathbf{R}$ & $\mathbf{B}$ & $\mathbf{A}$ & $\mathbf{S}$ \\
& $\mathrm{n}(\%)$ & $\mathrm{n}(\%)$ & $\mathrm{n}(\%)$ & $\mathrm{n}(\%)$ & $\mathrm{n}(\%)$ \\
\hline $\mathbf{0}$ & $0(0)$ & $0(0)$ & $6(19,35)$ & $16(51,61)$ & $12(38,71)$ \\
$\mathbf{1}$ & $3(9,68)$ & $11(35,48)$ & $4(12,90)$ & $12(38,71)$ & $11(35,48)$ \\
$\mathbf{2}$ & $9(29,03)$ & $17(54,83)$ & $16(51,61)$ & $2(6,45)$ & $4(12,90)$ \\
$\mathbf{3}$ & $19(61,29)$ & $3(9,68)$ & $5(16,13)$ & $1(3,23)$ & $4(12,90)$ \\
\hline Total (GP) & $31(100)$ & $31(100)$ & $31(100)$ & $31(100)$ & $31(100)$ \\
\hline
\end{tabular}

\subsection{Correlação entre a escala L-IE e a escala GRBAS}

A análise da correlação entre os dados do grupo GP da avaliação dos padrões visuais da dinâmica vocal com escala L-IE e a avaliação perceptivo-auditiva com escala GRBAS indicou forte correlação $(\mathrm{p}<0,05)$ entre o número de laços e os parâmetros grau global da disfonia e soprosidade e entre o parâmetro irregularidade e a soprosidade (Tabela 9).

Tabela 9- Resultados do teste de correlação de Spearman entre as escalas L-IE e GRBAS dos dados dos pacientes do grupo GP

\begin{tabular}{ccccccc}
\hline \multicolumn{2}{c}{$\begin{array}{l}\text { Correlação } \\
\text { Spearman }\end{array}$} & $\mathbf{G}$ & $\mathbf{R}$ & $\mathbf{B}$ & $\mathbf{A}$ & $\mathbf{S}$ \\
\hline \multirow{4}{*}{$\mathbf{L}$} & $\mathrm{R}$ & $-0,364$ & $-0,134$ & $-0,401$ & $-0,247$ & $-0,178$ \\
& $\mathrm{p}$ & 0,044 & 0,472 & 0,025 & 0,180 & 0,339 \\
& $\mathrm{n}(\mathrm{GP})$ & 31 & 31 & 31 & 31 & 31 \\
\hline & $\mathrm{R}$ & 0,245 & $-0,266$ & 0,553 & 0,302 & 0,199 \\
$\mathbf{I}$ & $\mathrm{p}$ & 0,185 & 0,148 & 0,001 & 0,098 & 0,284 \\
& $\mathrm{n}(\mathrm{GP})$ & 31 & 31 & 31 & 31 & 31 \\
\hline & $\mathrm{R}$ & 0,170 & $-0,233$ & 0,320 & 0,007 & $-0,156$ \\
$\mathbf{E}$ & $\mathrm{p}$ & 0,361 & 0,207 & 0,080 & 0,969 & 0,403 \\
& $\mathrm{n}(\mathrm{GP})$ & 31 & 31 & 31 & 31 & 31 \\
\hline
\end{tabular}


7 Díscussão 


\section{DISCUSSÃO}

A análise acústica convencional não apresenta confiabilidade para sinais de voz com grande quantidade de ruído, classificados como Tipo 3 (TITZE, 1995) considerados caóticos por Gama e Behlau (2009), como os dos pacientes submetidos a LPV. Para a caracterização acústica desse tipo de sinal de voz o uso da análise dinâmica não linear tem sido sugerida como preferencial (DAJER, 2006; 2010; DAJER et al., 2005; 2011; HENRÍQUEZ et al., 2009; JIANG et al., 2001; LITTLE et al., 2007; 2011; MAC CALLUM et al., 2009; MARRARA, 2010; SANCHEZ et al., 2012; YAN et al., 2013). Neste estudo o uso do método da ANL possibilitou uma caracterização acústica confiável dos sinais de vozes de pacientes pós LPV para complementar a avaliação vocal perceptivo-auditiva.

Os resultados da ANL, por meio da análise visual dos gráficos bidimensionais da vogal /a/ na comparação entre os dois grupos GP e GC relacionados aos três parâmetros da escala L-IE, mostrou uma diferença estatisticamente significante entre os grupos, em que indivíduos do GP apresentaram valores inversamente proporcionais aos obtidos pelos do GC. O GP se distinguiu pela não visualização do número de laços, traçados com grau severo de irregularidade e de espaçamento, enquanto o GC evidenciou a presença de 4 ou mais laços e traçados com grau discreto de irregularidade e espaçamento, dados esses de normalidade corroboram o estudo de Scalassara et al. (2009) que relacionaram a presença de muito laços, regularidade e convergência dos traçados no gráfico de vozes saudáveis. Resultado semelhantes foram descritos por Galdino (2012) que classificou vozes normais com número de laços, regularidade dos traçados e espaçamento dos traçados com grau 4.

Os gráficos bidimensionais do sinal de voz da vogal /a/ dos indivíduos do GP se caracterizaram pela ausência de laços visualizáveis (71\%) e quando presentes os laços apresentaram-se em número reduzido, sendo dois, o maior número de laços encontrado. A não visualização dos laços impossibilita a discriminação do traçado das órbitas dos ciclos vibratórios das estruturas remanescentes, assim os gráficos dos sinais de vozes caóticas caracterizam-se por um padrão da imagem indefinido. Este achado é semelhante ao encontrado no estudo de MacCallum et al. (2009) que pesquisaram vozes esofágicas com a ANL, e apresentaram gráficos bidimensionais com traçado das órbitas indefinidos e sem a possibilidade de visualização do número de laços. Esse dado concorda com o resultado descrito no estudo de caso com paciente LPV de Sanchez et al. (2012) que registrou dois laços visualizáveis. Pode-se inferir que este dado esteja relacionado à alteração no trato vocal 
decorrente da mutilação cirúrgica que acontece nas laringectomias parciais para remoção do tumor da laringe. A diminuição do número de laços nos gráficos bidimensionais dos sinais de voz do GP demonstra a redução da amplitude das frequências harmônicas decorrente das alterações anatômicas no trato vocal pós LPV. Segundo Dajer (2010), as características da configuração de laços (loops) encontram-se relacionadas com a quantidade de formantes e suas respectivas amplitudes. Para Marrara (2010), o menor número de laços (loops) evidencia menor complexidade do sinal de voz.

O aumento do grau de irregularidade dos traçados no GP comparado ao GC pode ser justificado pelo aumento de ruído no sinal de voz desses pacientes decorrente da redução da coaptação das estruturas remanescentes da laringe. Tal dado foi evidenciado por Sanchez et al. (2012) que relataram aumento do grau de irregularidade em estudo de caso com paciente pós LPV. Marrara (2010) observou aumento na irregularidade evidenciada nos PVDV de vozes com rugosidade, soprosidade, tensão ou instabilidade. Scalassara et al. (2009) justificaram o aumento da irregularidade pela presença de fenda glótica, turbulência do fluxo de ar e vibração assimétrica.

O grau severo de espaçamento dos traçados encontrado no GP corrbora os estudos de Dajer (2010), Marrara (2010), Sanchez et al., (2012) e Scalassara (2009) que relataram o aumento do grau do espaçamento dos traçados dos gráficos bidimensionais na análise dos PVDV em vozes alteradas. Esse resultado pode ser justificado uma vez que o grau de espaçamento evidencia a aperiodicidade da voz como citado nos estudos com a ANL de MacCallum et al. (2009), Dajer (2010) e Marrara (2010). Em seu estudo Scalassara et al. (2009) correlacionaram o grau de espaçamento a mudanças de volume do fluxo aéreo e variação da onda da mucosa.

Com relação à avaliação perceptivo-auditiva da voz por meio da escala GRBAS, os parâmetros com maior grau de alteração no GP foi a rugosidade e a soprosidade. Essas características vocais estão de acordo com as citadas por Carrara-De Angelis e Barros (2000) que descreveram as vozes de pacientes pós laringectomia parcial com presença de ruído intenso caracterizado pela rouquidão, aspereza (denominadas como rugosidade) e pela soprosidade.

Quanto ao grau global da disfonia (G) o GP teve a maioria de suas vozes avaliada com grau severo, seguido do moderado. Esses resultados são semelhantes aos da literatura que classificou a maioria das vozes de pacientes pós laringectomias parciais pela escala GRBAS com graus de disfonia moderado e severo (DEDIVITIS et al., 2008; RICZ et al., 2004; WISKIRSKA-WOŹNICA et al., 2011). No entanto, no estudo de Ricz et al. (2004) e 
Wiskirska-Woźnica et al. (2011) a ocorrência do grau global de disfonia em grau moderado foi maior do que a de grau severo e para Dedivitis et al. (2008) a porcentagem para ambos os graus de disfonia, severo e moderado, foi a mesma. A severidade do grau de disfonia, severo ou moderado, pode variar de acordo com a sequela cirúrgica realizada para a retirada do tumor de laringe. Infelizmente, no presente estudo as informações das características anatomofuncionais da laringe pós LPV não estavam disponíveis nos prontuários dos pacientes investigados. No entanto, é evidente a presença da disfonia como principal sequela cirúrgica nesses pacientes, tanto em graus moderado como severo em todos os estudos.

O presente estudo classificou o parâmetro da rugosidade para a maioria da amostra com graus entre moderado e severo. Resultados semelhantes foram descritos por Dedivitis et al. (2008) e Wiskirska-Woźnica et al. (2011), enquanto Ricz et al. (2004) relatou graus de rugosidade entre moderado e severo para $40 \%$ da amostra. A ocorrência do grau moderado de rugosidade no presente estudo foi maior do que a do grau severo. Esses dados estão de acordo com os de Ricz et al. (2004) e Wiskirska-Woźnica et al. (2011). O estudo de Dedivitis et al. (2008) apresentou a mesma proporção entre os graus moderado e severo de rugosidade. A rugosidade evidencia a irregularidade vibratória e pode estar presente nas vozes pós LPV, dessa forma tão evidente, pela falta de estruturas vibrantes e pela rigidez da mucosa decorrentes do tecido cicatricial, além das possíveis reconstruções cirúrgicas.

Para o parâmetro da soprosidade, o presente estudo apresentou a maioria dos graus entre moderado e severo, que se diferencia dos estudos de Ricz et al. (2004); Dedivitis et al. (2008) e Wiskirska-Woźnica et al. (2011) que apresentaram graus moderado e severo de 40\%, $35 \%$ e $25 \%$, respectivamente. A ocorrência do grau moderado foi maior do que a do severo no presente estudo, este dado concorda com os descritos nos estudos de Dedivitis et al. (2008); Ricz et al. (2004) e Wiskirska-Woźnica et al. (2011). A soprosidade presente no sinal de voz de pacientes submetidos à LPV se justifica pela presença de ar não sonorizado que gera ruído audível, decorrente da fenda glótica. O grau de severidade da soprosidade correlaciona-se ao grau de coaptação glótica.

O parâmetro da astenia no GP deste estudo foi classificado com graus entre moderado e severo em apenas $10 \%$ da amostra. Este dado é semelhante aos descritos na literatura que também aponta baixa ocorrência, entre $0 \%$ e $20 \%$, de graus moderado e severo para a astenia (DEDIVITIS et al., 2008; RICZ et al., 2004; WISKIRSKA-WOŹNICA et al., 2011). A pequena ocorrência de astenia em vozes de pacientes submetidos à LPV é esperada uma vez que a astenia relaciona-se a fraqueza do fluxo aéreo e a diminuição da firmeza glótica na fonação, mais comuns em disfonias neurológicas ou psicogênicas. 
Quanto ao parâmetro da tensão, houve no GP baixa ocorrência (26\%) entre os graus moderado e severo. Este dado foi maior do que o descrito por Ricz et al. (2004) e menor do que os descritos por Dedivitis et al. (2008) e Wiskirska-Woźnica et al. (2011). Ressalta-se a divergência da ocorrência dos graus de tensão moderado e severo entre os estudos da literatura, que variaram de 0\% a 60\% (DEDIVITIS et al., 2008; RICZ et al., 2004; WISKIRSKA-WOŹNICA et al., 2011). A tensão está relacionada ao aumento do esforço gerado no trato vocal para a adução glótica no momento da fonação. Esse comportamento vocal varia de indivíduo para indivíduo, o que pode explicar a divergência dos dados nos estudos.

A aplicação do teste de Correlação de Spearman entre a avaliação visual dos gráficos bidimensionais por meio da escala L-IE e a avaliação perceptivo-auditiva pela escala GRBAS mostrou forte correlação entre o número de laços (L) da escala L-IE e os parâmetros grau global da disfonia $(\mathrm{G})$ e soprosidade (B) da escala GRBAS. A redução do número de laços indicou vozes com maior grau global de disfonia e de soprosidade. Esses resultados estão de acordo com os estudos de Dajer (2010), que encontrou correlação entre número de laços e a soprosidade.

No presente estudo também houve forte correlação entre o parâmetro de irregularidade (I) da escala L-IE e o grau de soprosidade (B) da escala GRBAS. Os traçados com maior grau de irregularidade indicam maior grau de soprosidade na voz. Este dado corrobora com o resultado descrito por Dajer (2010) que também correlacionou o aumento do grau da irregularidade com a soprosidade da voz. Yan et al. (2013) também correlacionaram a piora da qualidade vocal, na avaliação perceptivo-auditiva, com os piores resultados da ANL.

Tais correlações permitiram uma análise mais precisa sobre os dados obtidos na ANL com o uso da escala L-IE, pois possibilitaram uma melhor interpretação das vozes a partir da análise visual dos gráficos bidimensionais do sinal de voz.

Neste estudo não foi possível obter a descrição cirúrgica dos tipos de LPV, pois esses dados não estavam descritos na maioria dos prontuários dos pacientes, o que impossibilitou a correlação deste dado com os resultados da ANL.

A rotina computacional desenvolvida e implementada no MatLab ${ }^{\circledR} 10.0$ que gerou gráficos bidimensionais dos sinais de voz do presente estudo não foi disponibilizado aos pesquisadores. Fato este que prejudicou a padronização do tempo ou do número de ciclos glóticos selecionados para a obtenção dos gráficos e impossibilitou a obtenção de novos gráficos em períodos de ciclos diferentes para a mesma voz quando necessário. A falta de acesso ao programa limitou ainda as possibilidades de novas análises, uma vez que o referido 
programa gera também gráficos em 3D, que permitiria a interpretação do sinal de voz de forma mais ampla.

No entanto, ressalta-se a dificuldade na interpretação dos gráficos para a classificação dos parâmetros por se tratar de uma análise visual qualitativa e ainda nova na avaliação acústica vocal. Sugere-se, que para a aplicação da escala L-IE haja treinamento visual do avaliador, como acontece com a análise perceptivo-auditiva da voz que necessita treinamento auditivo para identificação dos parâmetros vocais.

Este estudo demonstrou a eficiência deste método na avaliação acústica de vozes ruidosas, como uma ferramenta visual tanto para o controle terapêutico como para fins de pesquisas em voz.

Ainda são poucos os estudos encontrados na literatura com o uso da ANL em vozes de pacientes submetidos à laringectomia. Portanto, a principal contribuição deste estudo a comunidade científica foi a caracterização dos sinais de vozes de pacientes pós LPV com o uso do método da ANL por meio da análise visual dos gráficos bidimensionais. 
8 Conclusão 


\section{CONCLUSÃO}

O método da ANL pela análise dos PVDV com uso da escala L-IE, se mostrou eficiênte na avaliação das vozes dos pacientes subemtidos a LPV com presença de ruído intenso.

Os sinais de voz dos pacientes submetidos a LPV investigados por meio do método da ANL com base na técnica dos Padrões Visuais da Dinâmica Vocal (PVDV) com o uso da escala L-IE, se caracterizaram quanto ao número de laços pela total indefinição das órbitas e pelo grau severo para os parâmetros da irregularidade e do espaçamento dos traçados. 
Referêncías 


\section{REFERÊECIAS ${ }^{1}$}

A VOZ e as cordas vocais. 2004.2 Disponível em:<http://www.rc.unesp.br/pef/2003_projetos/Pedro/cordas_vocais.htm>. Acesso em: 22/07/2013.

ABRAHÃO, M.; SANTOS, R.O.; CERVANTES, O. Laringectomias parcias. In: A Atuação da fonoaudiologia no câncer de cabeça e pescoço. São Paulo: Lovise, 2000. p.105-112.

ANDRADE SOBRINHO, F.A. Medida da dispersão da periodicidade de um sinal de voz normal e voz patológica através da seção de Poincaré. 2011. Dissertação (Mestrado em Processamento de Sinais de Instrumentação) - Escola de Engenharia de São Carlos, Universidade de São Paulo, São Carlos, 2011. Disponível em: <http://www.teses.usp.br/teses/disponiveis/18/18152/tde-08062011-151518/>. Acesso em: 23 jan. 2012.

ARAUJO, S.A. et al. Normatização de medidas acústicas da voz normal. Revista Brasileira de Otorrinolaringologia, São Paulo, v.68, n.4, ago. 2002. Disponível em: $<$ http://www.scielo.br/scielo.php?script=sci_arttext\&pid=S003472992002000400014\&lng $=$ pt\&nrm=iso $>$. Acesso em: 14 maio 2012.

BODT, M.S.D. et al. Test-retest study of the GRBAS scale: influence of experience and professional background on perceptual rating of voice quality. Journal of Voice, v.11, n.1, p.74-80, Mar. 1997.

BUTTE, C. J. et al. Perturbation and nonlinear dynamic analysis of different singing styles. Journal of Voice, v.23, n.6, p.647-652, Nov. 2009. DOI: 10.1016/j.jvoice.2008.02.004.

CAMARGO, Z. Avaliação objetiva da voz. In: A ATUAÇÃO da fonoaudiologia no câncer de cabeça e pescoço. São Paulo: Lovise, 2000. p.175-194.

CARRARA-DE ANGELIS, E.; BARROS, A.P.B. Reabilitação fonoaudiológica nas laringectomias parciais. In: A ATUAÇÃO da fonoaudiologia no câncer de cabeça e pescoço. São Paulo: Lovise, 2000. p.221-225.

CHAI, L. et al. Perturbation and nonlinear dynamic analysis of adult male smokers. Journal of Voice, v.25, n.3, p.342-347, May 2010.

CHOI, S. H. et al. Nonlinear dynamic-based analysis of severe dysphonia in patients with vocal fold scar and sulcus vocalis. Journal of Voice, v.26, n.5, p.566-576, Apr. 2012.

CHUN, R.Y.S. A Voz do professor: estudo de grupos de saúde vocal em unidade básica de saúde. INTERÂMBIO, v.7, p.167-176, 1998.

\footnotetext{
${ }^{1}$ De acordo com a Associação Brasileira de Normas Técnicas. NBR 6023/2002
} 
COSTA, W. C. A. et al. Classificação de sinais de vozes saudáveis e patológicas por meio da combinação entre medidas da análise dinâmica não linear e codificação preditiva linear. Revista Brasileira de Engenharia Biomédica, v.29, n.1, p.3-14, jan./mar. 2013.

DAJER, M.E. Padrões visuais de sinais de voz através de técnica de análise não linear. 2006. Dissertação (Mestrado em Bioengenharia) - Escola de Engenharia de São Carlos, Universidade de São Paulo, São Carlos, $2006 . \quad$ Disponível em: <http://www.teses.usp.br/teses/disponiveis/82/82131/tde-16052006-095323/>. Acesso em: 20 maio 2012.

Análise de sinais de voz por padrões visuais de dinâmica vocal. 2010. p.154. Tese (Doutorado) - Escola de Engenharia de São Carlos, Universidade de São Paulo, São Carlos, 2010.

DAJER, M., PEREIRA, J.; MACIEL, C. Chaos tool implementation for non-singer and singer voice comparison (preliminary study). Journal of Physics: conference series. V.90, n.1, p.012082, Nov. 2007.

Nonlinear dinamical analysis of normal voices. In: IEEE INTERNATIONAL SYMPOSIUM ON MULTIMIDEA, 7., 2005, Irvine. Proceedings... NewYork: IEEE Computer Society. p.767-771.

DAJER, M. E. et al. Vocal dynamic visual pattern for voice characterization. Journal of Physics: conference series. v.332, n.1, p.012026, Dec. 2011.

DEDIVITIS R.A. et al. Achados perceptivo-auditivos e acústicos em pacientes submetidos à laringectomia fronto-lateral. Revista Brasileira de Cirurgia da Cabeça e do Pescoço, v.37, n.3, p.163-165, jul./set. 2008.

FRASER, A.M.; SWINNEY, H.L. Independent coordinates for strange attractors from mutual information. Physical Review Letters, v.33, p.1134-1140, 1986.

FUKUYAMA, E.E. Análise acústica da voz captada na faringe próximo à fonte glótica através de microfone acoplado ao fibrolaringoscópio. Revista Brasileira de Otorrinolaringologia, São Paulo, v.67, n.6, nov. 2001. Disponível em: $<$ http://www.scielo.br/scielo.php?script=sci_arttext\&pid=S0034-

$72992001000600005 \& \operatorname{lng}=\mathrm{en} \& \mathrm{nrm}=\mathrm{iso}>$. Accesso em: 14 maio 2012.

GALDINO, Debora Godoy. Análise acústica não linear dos padrões visuais de dinâmica vocal (PVDV) de homens adultos. 2012. Dissertação (Mestrado em Bioengenharia) Escola de Engenharia de São Carlos, Universidade de São Paulo, São Carlos, 2012. Disponível em:<http://www.teses.usp.br/teses/disponiveis/82/82131/tde-29112013-095147/>. Acesso em: 27 jan. 2014.

GAMA A.C.C.; BEHLAU M.S. Estudo da constância de medidas acústicas de vogais prolongadas e consecutivas em mulheres sem queixa de voz e em mulheres com disfonia. Revista da Sociedade Brasileira de Fonoaudiologia, v.14, n.1, p.8-14, 2009. 
GAMA, A.C.C. et al. Estudo do efeito do apoio visual do traçado espectrográfico na confiabilidade da análise perceptivo-auditiva. Revista CEFAC, São Paulo, v.13, n.2, p.314 321, mar./abr. 2010.

HEGGER, R.; KANTZ, H.; SCHREIBER, T. Practical implementation of nonlinear time series methods: The TISEAN package. Chaos, v.9, n.2, p.413-435, 1999.

HENRÍQUEZ, P. et al. Characterization of healthy and pathological voice through measures based on nonlinear dynamics. IEEE Transactions on Audio, Speech, and Language Processing, v.17, n.6, p.1186-1195, Aug. 2009.

INSTITUTO NACIONAL DO CÂNCER. Tipos de câncer - laringe. Rio de Janeiro, 2013.

ISSHIKI, N.; YANAGIHARA, N.; MORIMOTO, M. Aproach to the objective diagnoses of hoarseness. Folia Phoniatr, v.18, p.393-400, 1966.

JIANG, J.J.; ZHANG, Y.; STERN, J. Modeling of chaotic vibrations in symmetric vocal folds. Journal of the Acoustical Society of America, v.110, n.4, p.2120-2128, Oct.

KENT, R.D.; READ, C. The Acoustic analysis of speech. San Diego: Singular, 1992.

LEE, V.S. et al. Perturbation and nonlinear dynamic analysis of acoustic phonatory signal in parkinsonian patients receiving deep brain stimulation. Journal of Communication Disorders, v.41, n.6, p.485-500, 2008. DOI:10.1016/j.jcomdis.2008.02.001.

LITTLE, M.A.; COSTELLO, D.A.E.; HARRIES, M.L. Objective dysphonia quantification in vocal fold paralysis:comparing nonlinear with classical measures. Journal of Voice, v.25, n.1, p.21-31, Jan. 2011.

LITTLE M.A., M.C. et al. Exploiting nonlinear recurrence and fractal scaling properties for voice disorder detection. BioMedical Engineering OnLine, v.6, art.23, 2007. DOI: 10.1186/1475-925X-6-23. Disponível em: $<$ http://www.biomedical-engineeringonline.com/content/6/1/23>. Acesso em: 14/01/2012.

MACCALLUM, J. K.; ZHANG, Y.; JIANG, J. J. Vowel selection and its effects on perturbation and nonlinear dynamic measures. Folia Phoniatrica et Logopaedica, v.63, n.2, p.88-97, 2010.

MACCALLUM J.K. et al. Acoustic analysis of aperiodic voice: perturbation and nonlinear dynamic properties in esophageal phonation. Journal of Voice, v.23, n.3, p.283-290, May 2009.

MALUCELli, A.V. Doenças da laringe, traquéia e brônquios. 2013. Disponível em: <http://www.drmalucelli.com.br/Laringe-Traqueia-

Bronquios/conteudo.php?cat=5\&pg=024>. Acesso em: 22/07/2013. 
MARRARA, J.L. Padrões visuais da dinâmica vocal como instrumento para o diagnóstico da disfagia em pacientes com alterações neurológicas. 2010. Dissertação (Mestrado em Processamento de Sinais de Instrumentação) - Escola de Engenharia de São Carlos, Universidade de São Paulo, São Carlos, $2010 . \quad$ Disponível $\mathrm{em}:<\mathrm{http}: / /$ www.teses.usp.br/teses/disponiveis/18/18152/tde-06052010-160149/>. Acesso em: 20 maio 2012.

MATOS, B.J. Laringectomias parciais. In: FONOAUDIOLOGIA em cancerologia. São Paulo: Fundação Oncocentro de São Paulo; Comitê de Fonoaudiologia em Cancerologia, 2000. p.8-47.

MEREDITH, M.L. et al. Describing pediatric dysphonia with nonlinear dynamic parameters. International Journal of Pediatric Otorhinolaryngology, v.72, n.12, p.1829-1836, Dec. DOI:10.1016/j.ijporl.2008.09.004.

MONTAGNOLI, A. N. nálise residual do sinal da voz. 1998. 66p. Dissertação (Mestrado) - Escola de Engenharia de São Carlos, Universidade de São Paulo, São Carlos, 1998.

RICZ, H.; MAMEDE, R.C.M.; AGUIAR-RICZ, L. Análise funcional da laringe póscordectomia, reconstruída com retalho de prega vestibular. Revista Brasileira de Otorrinolaringologia, v.70, n.6, p.727-733, nov./dez. 2004.

SANCHEZ, R. F. O Impacto da alteração de voz na qualidade de vida de pacientes submetidos a laringectomia parcial vertical. 2006. Dissertação (Mestrado) - Programa de Pós-Graduação Interunidades em Bioengenharia, Escola de engenharia de São Carlos, Faculdade de Medicina de Ribeirão Preto, Instituto de Química de São Carlos, Universidade de São Paulo, São Carlos, 2006.

SANCHEZ, R.F. et al. (2012). Application of nonlinear acoustic analysis of voice in patients submitted to vertical partial laryngectomy: a case report. International Archives of Otorhinolaryngoly, v.16, Suppl.1, p.29, 2012.

SCALASSARA, P. R. Relative entropy measures applied to healthy and pathological voice characterization. Applied Mathematics and Computation, v.207, n.1, p.95-108, 2009.

SOUZA, L.M. Detecção inteligente de patologias na laringe baseada em máquinas de vetores de suporte e na transformada wavelet. 2011. Dissertação (Mestrado em Física Aplicada) - Instituto de Física de São Carlos, Universidade de São Paulo, São Carlos, 2011. Disponível em:<http://www.teses.usp.br/teses/disponiveis/76/76132/tde-13042011-112203/>. Acesso em: 23 jan. 2012.

STORY, B.H.; TITZE, I.R. Voice simulation with a body-cover model of the vocal folds. Journal of the Acoustical Society of America, v.97, n.2, p.1249-1260, 1995.

TELES-MAGALHÃES, L. C. Análise dos parâmetros acústicos vocais de pacientes com disfunção velofaríngea com e sem articulação compensatória. Bauru: [s.n.], 2002. p.163. 
TITZE, I.R.; BAKEN, R.J.; HERZEL, H. Evidences of chaos in vocal fold vibration. In: TITZE, I.R. (Ed.). Vocal fold physiology: frontiers in basic science. San Diego: Singular, 1993. p.143-188.

TITZE IR. Workshop on acoustic analysis. Summary statement. Iowa City:

National Center for Voice and Speech, USA; 1995.p. 26-30.

TSANAS, A. et al. Nonlinear speech analysis algorithms mapped to a standard metric achieve clinically useful quantification of average Parkinson's disease symptom severity. Journal Royal Society Interface, v.8, p.842-855, 2011. DOI:10.1098/rsif.2010.0456.

TUMA, J. et al. Configuração das pregas vestibulares em laringes de pacientes com nódulo vocal. Revista Brasileira de Otorrinolaringolia, v.71, n.5, p.576-581, 2005.

WISKIRSKA-WOŹNICA, B.et al. Voice estimation in patients after reconstructive subtotal laryngectomy. Head \& Neck Oncology, v.3, p.46, 2011. Disponível em: <http://www.headandneckoncology.org/content/3/1/46>. Acesso em: 23/07/2013.

YAN, N. et al. Nonlinear dynamical analysis of laryngeal, esophageal, and tracheoesophageal speech of cantonese. Journal of Voice, v.27, n.1, p.101-110, Jan. DOI: 10.1016/j.jvoice.2012.06.009.

ZHANG, Y.; JIANG, J.J. Chaotic vibrations of a vocal fold model with a unilateral polyp. Journal of the Acoustical Society of America, v.115, p.1266, 2004. Disponível em:<http://dx.doi.org/10.1121/1.1648974>. Acesso em: 29/10/2011. 
APÊNDICE A - GRÁFICOS BDIDMENSIONAIS DOS PVDV DOS 31PACIENTES DO GP CLASSIFICADOS COM A ESCALA L-IE

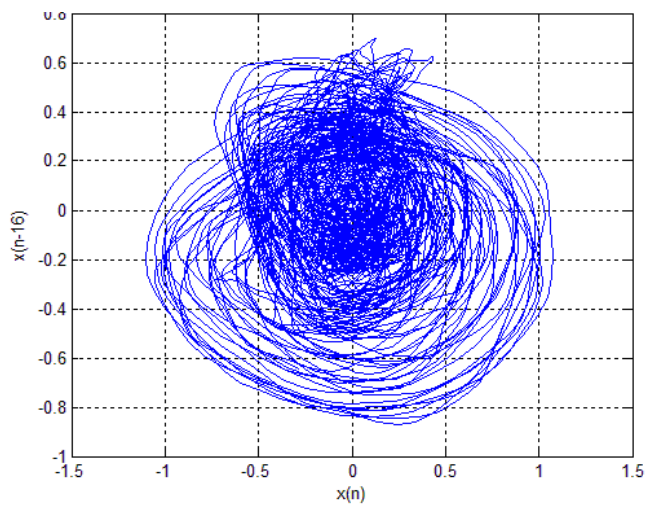

$\mathrm{L}_{0} \mathrm{I}_{5} \mathrm{E}_{6}$

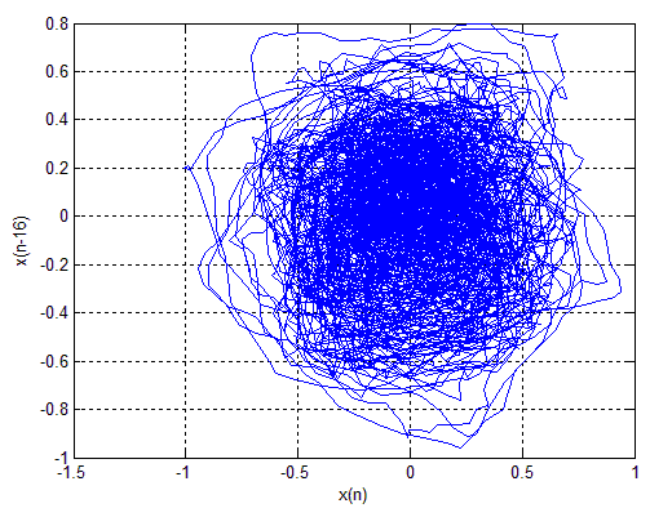

$\mathrm{L}_{0} \mathrm{I}_{6} \mathrm{E}_{7}$

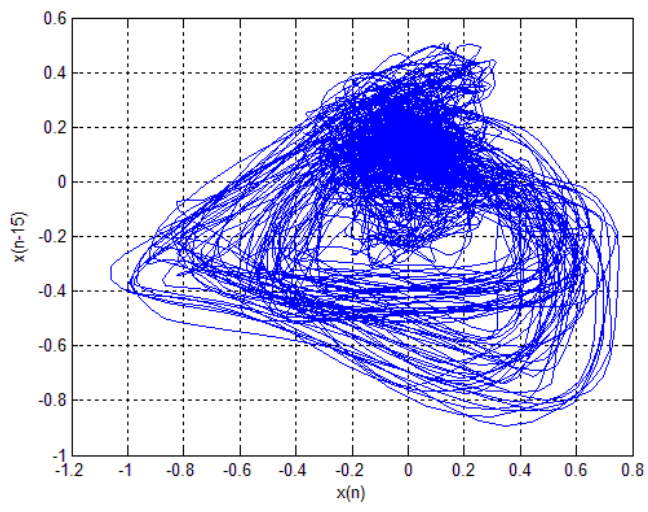

$\mathrm{L}_{1} \mathrm{I}_{1} \mathrm{E}_{6}$

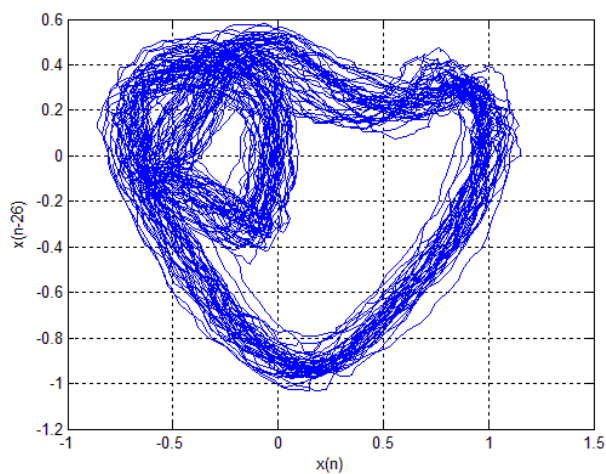

$\mathrm{L}_{1} \mathrm{I}_{4} \mathrm{E}_{4}$
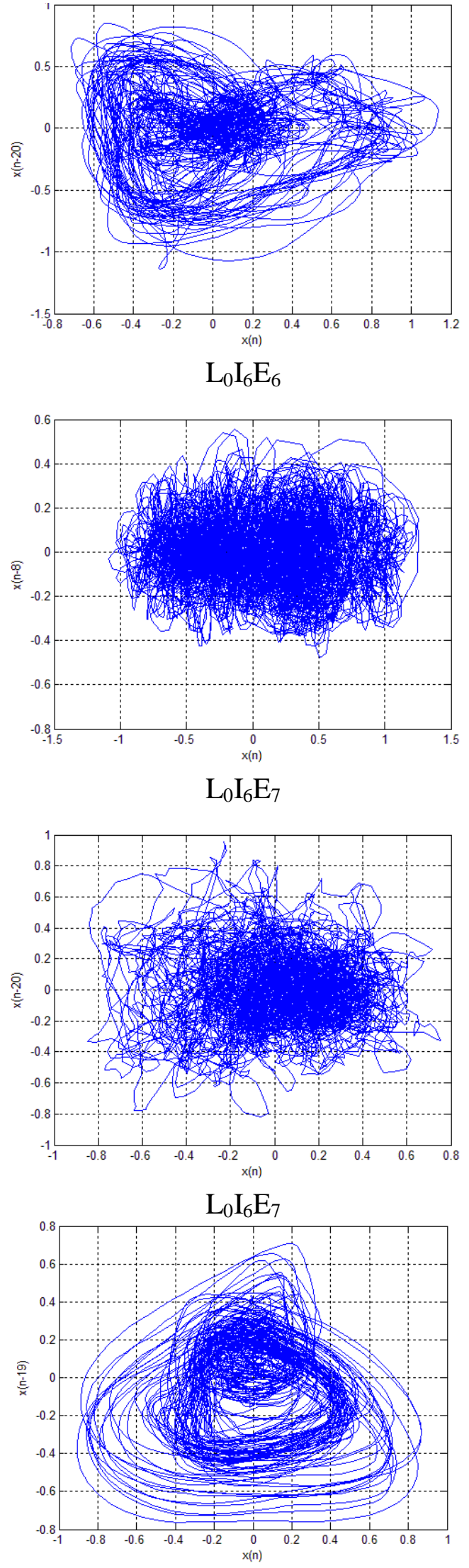

$\mathrm{L}_{1} \mathrm{I}_{2} \mathrm{E}_{6}$ 


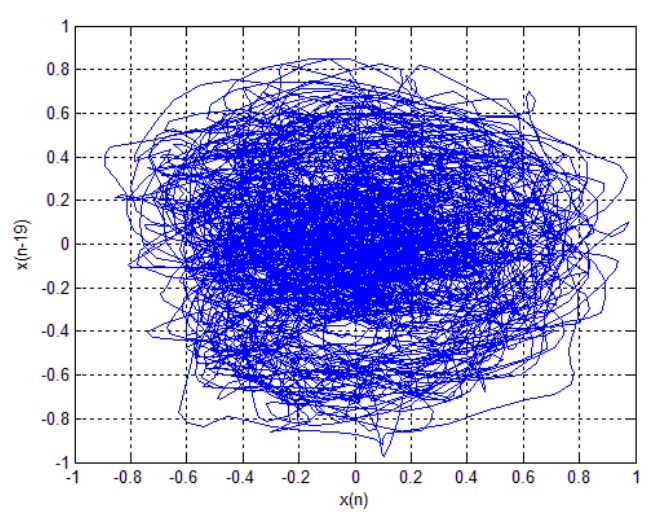

$\mathrm{L}_{0} \mathrm{I}_{6} \mathrm{E}_{7}$

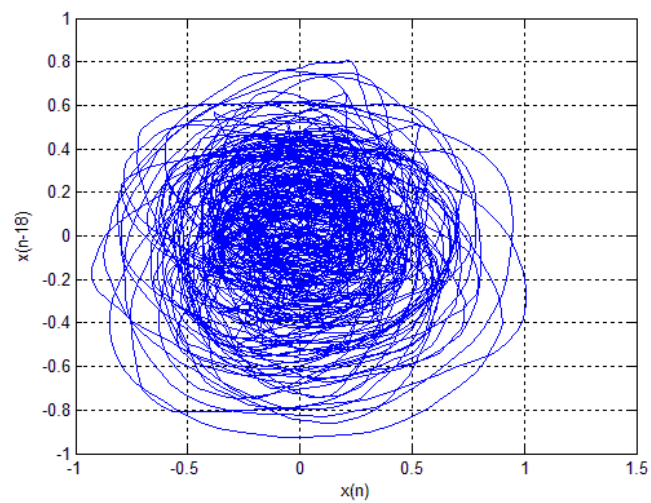

$\mathrm{L}_{0} \mathrm{I}_{7} \mathrm{E}_{6}$

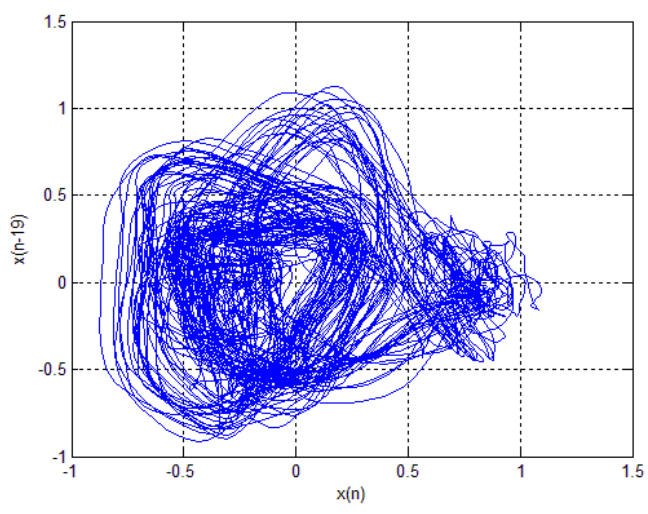

$\mathrm{L}_{2} \mathrm{I}_{5} \mathrm{E}_{6}$

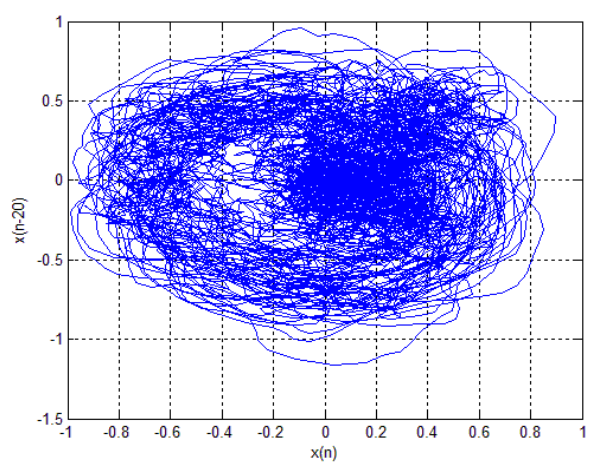

$\mathrm{L}_{0} \mathrm{I}_{6} \mathrm{E}_{3}$
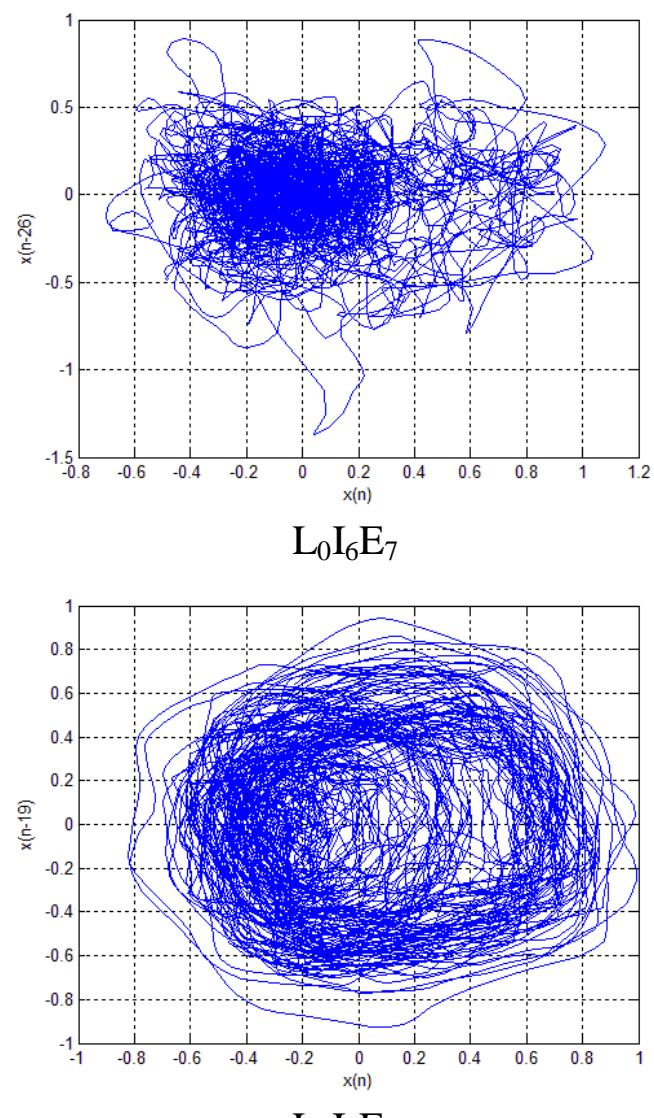

$\mathrm{L}_{0} \mathrm{I}_{6} \mathrm{E}_{6}$
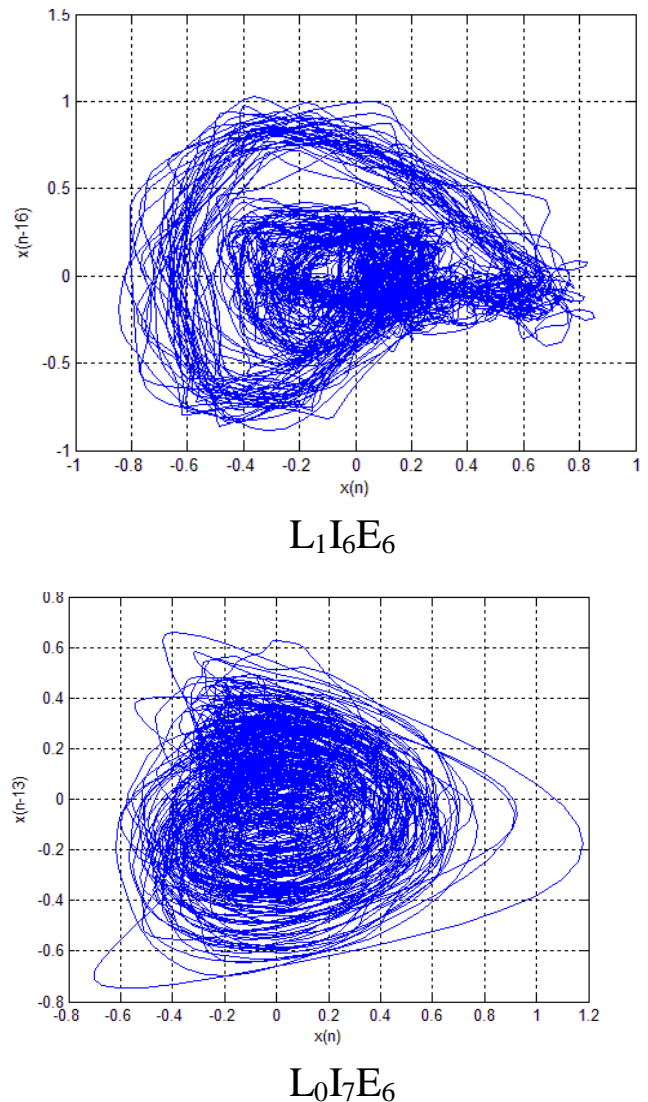


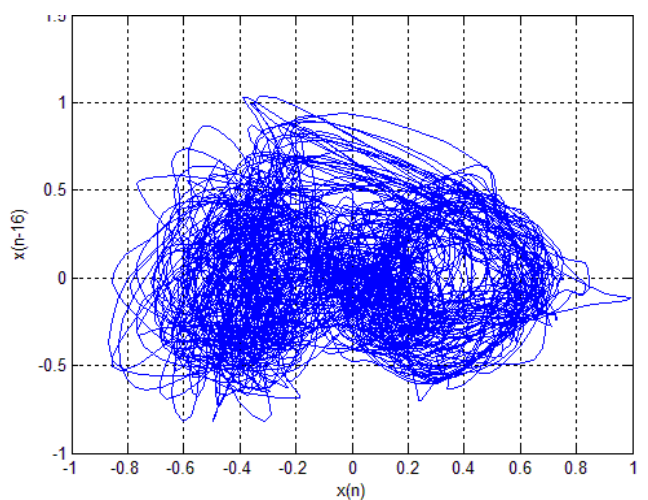

$\mathrm{L}_{0} \mathrm{I}_{6} \mathrm{E}_{7}$

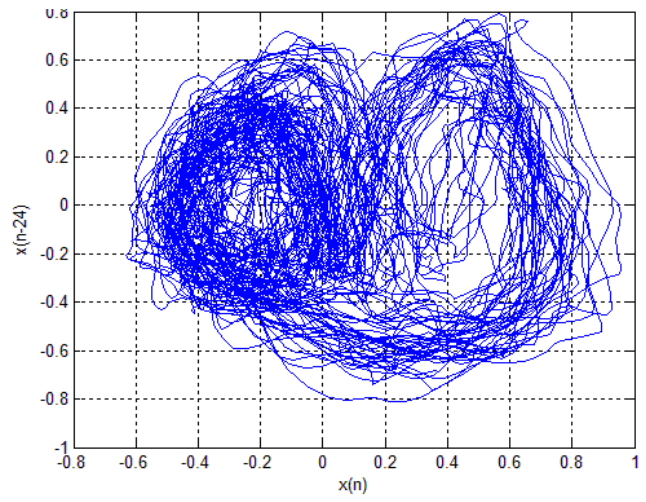

$\mathrm{L}_{1} \mathrm{I}_{6} \mathrm{E}_{6}$

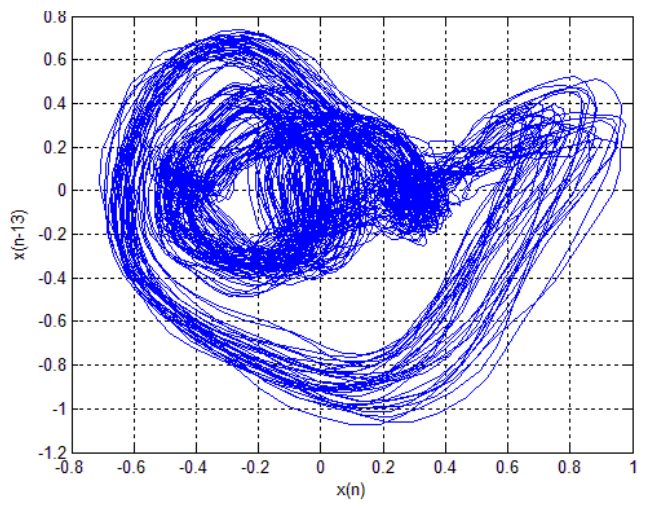

$\mathrm{L}_{2} \mathrm{I}_{5} \mathrm{E}_{6}$

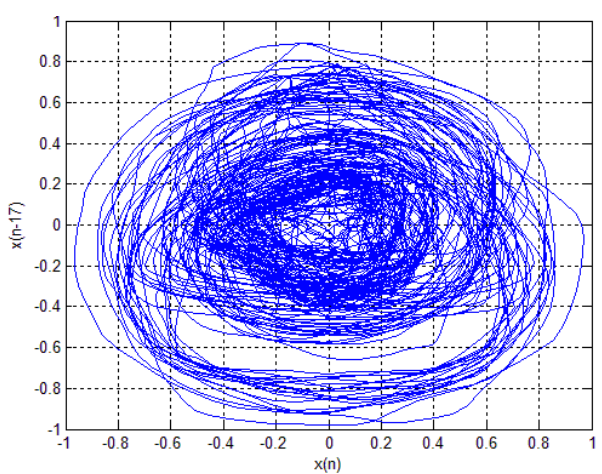

$\mathrm{L}_{0} \mathrm{I}_{4} \mathrm{E}_{6}$
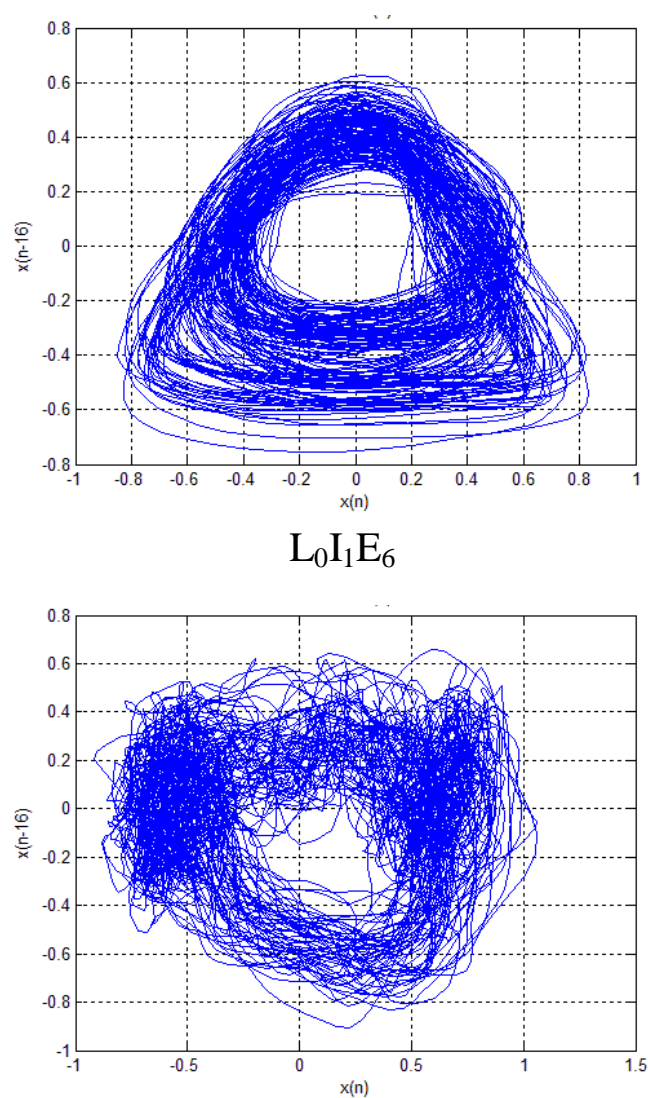

$\mathrm{L}_{0} \mathrm{I}_{6} \mathrm{E}_{6}$

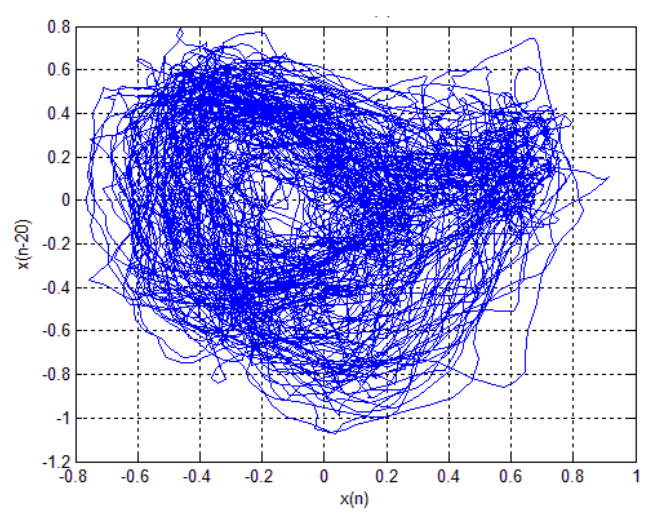

$\mathrm{L}_{0} \mathrm{I}_{6} \mathrm{E}_{6}$

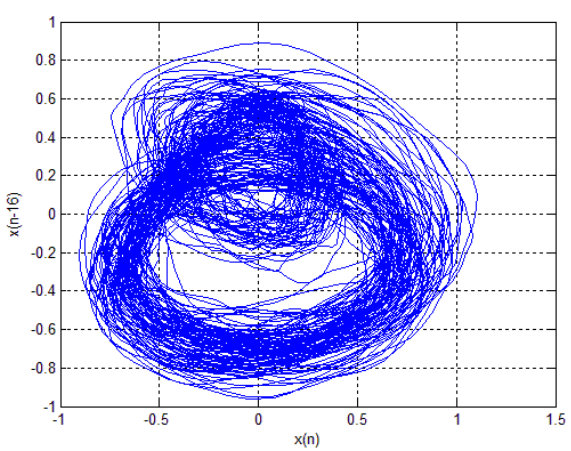

$\mathrm{L}_{0} \mathrm{I}_{6} \mathrm{E}_{6}$ 


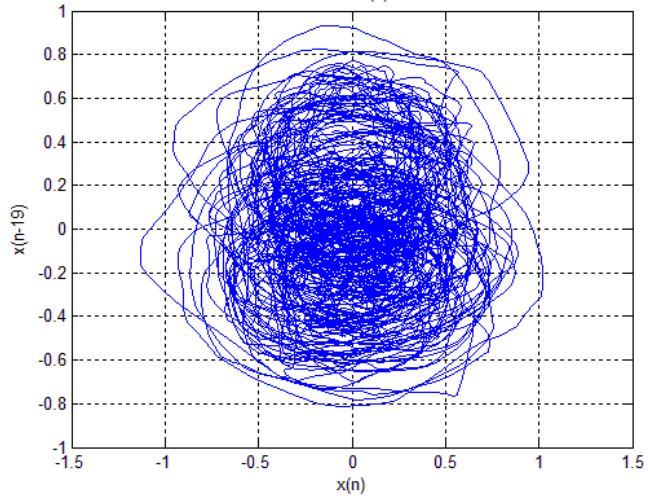

$\mathrm{L}_{0} \mathrm{I}_{7} \mathrm{E}_{7}$

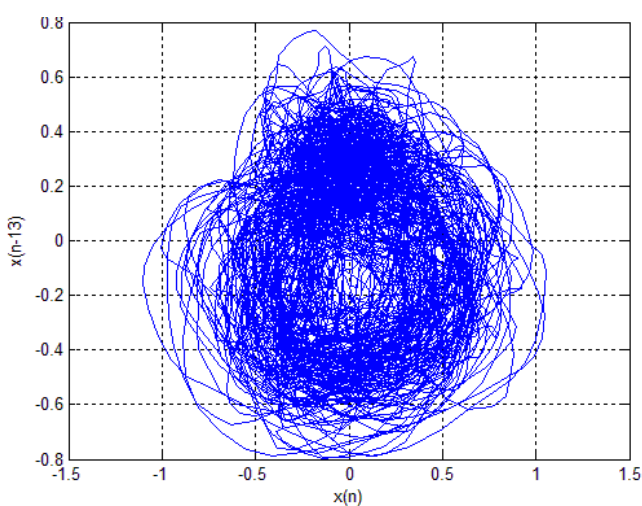

$\mathrm{L}_{0} \mathrm{I}_{7} \mathrm{E}_{7}$

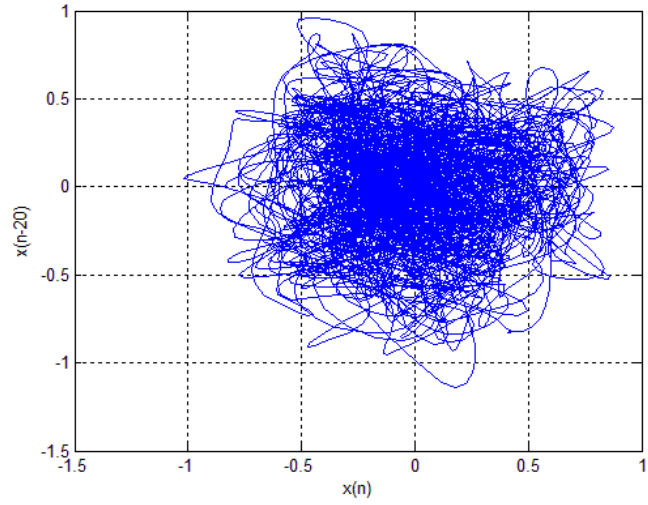

$\mathrm{L}_{0} \mathrm{I}_{6} \mathrm{E}_{7}$

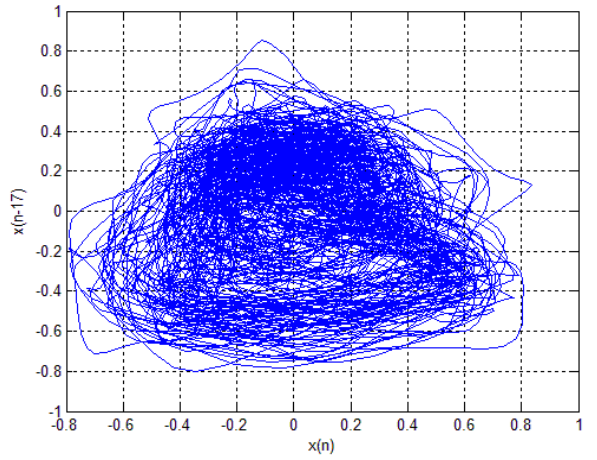

$\mathrm{L}_{0} \mathrm{I}_{7} \mathrm{E}_{7}$

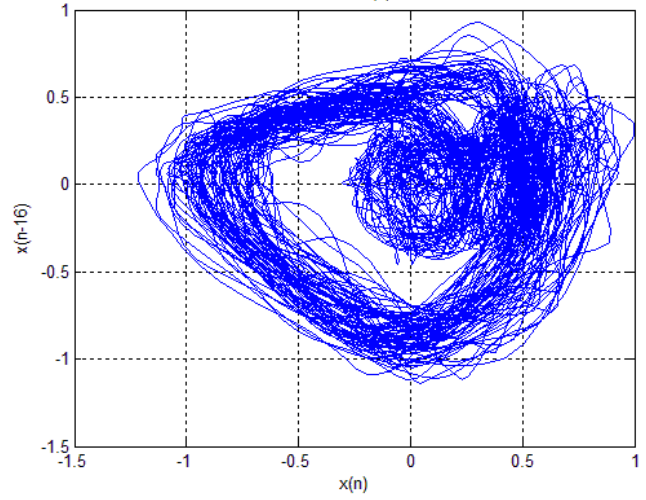

$\mathrm{L}_{1} \mathrm{I}_{6} \mathrm{E}_{6}$

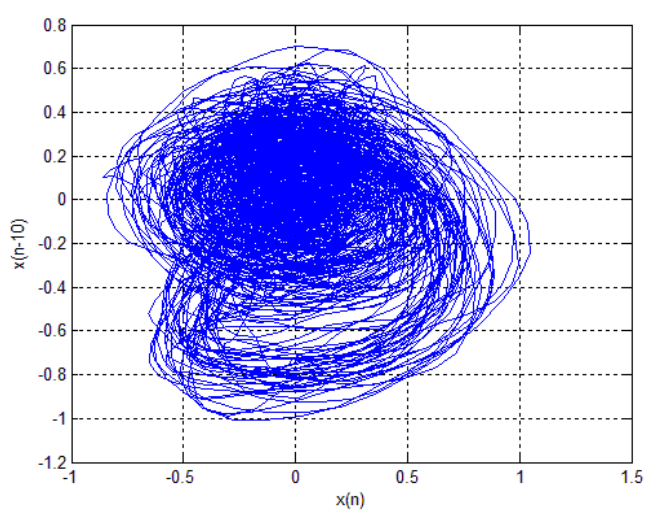

$\mathrm{L}_{0} \mathrm{I}_{7} \mathrm{E}_{7}$

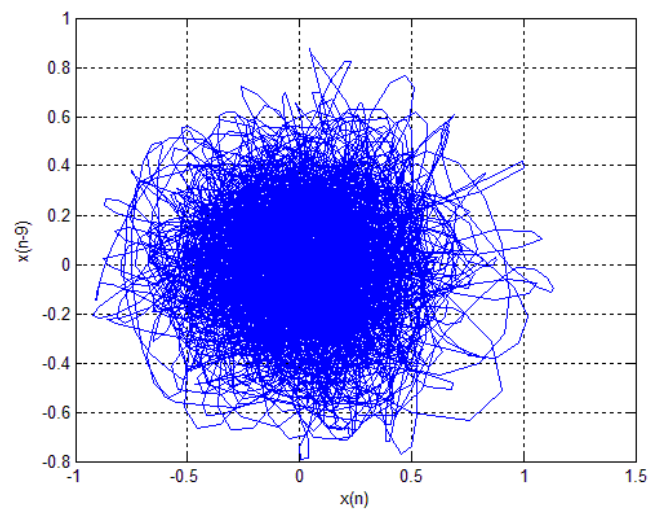

$\mathrm{L}_{0} \mathrm{I}_{6} \mathrm{E}_{7}$ 
APÊNDICE B - GRÁFICOS BDIDMENSIONAIS DOS PVDV DA SUJEITO DO GC CLASSIFICADOS COM A ESCALA L-IE

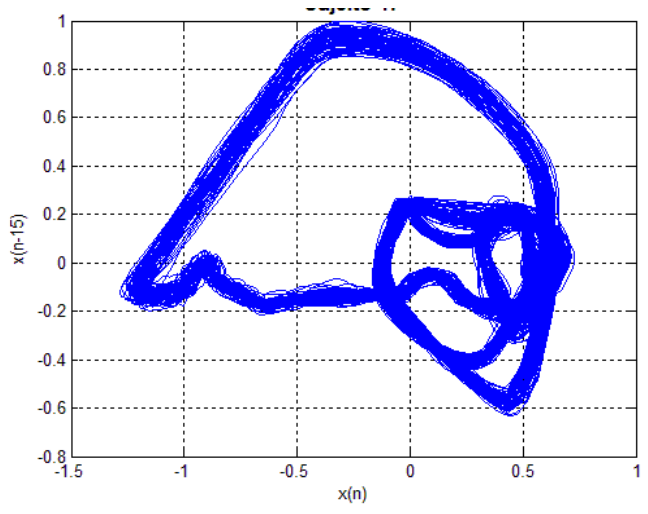

$\mathrm{L}_{3} \mathrm{I}_{1} \mathrm{E}_{2}$

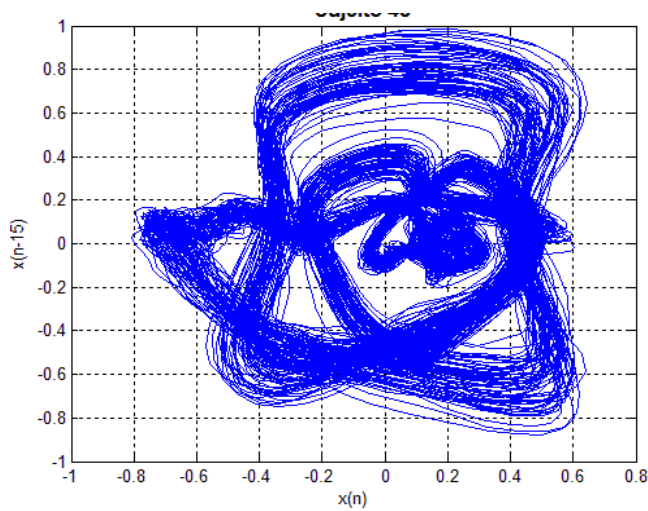

$\mathrm{L}_{4} \mathrm{I}_{1} \mathrm{E}_{6}$

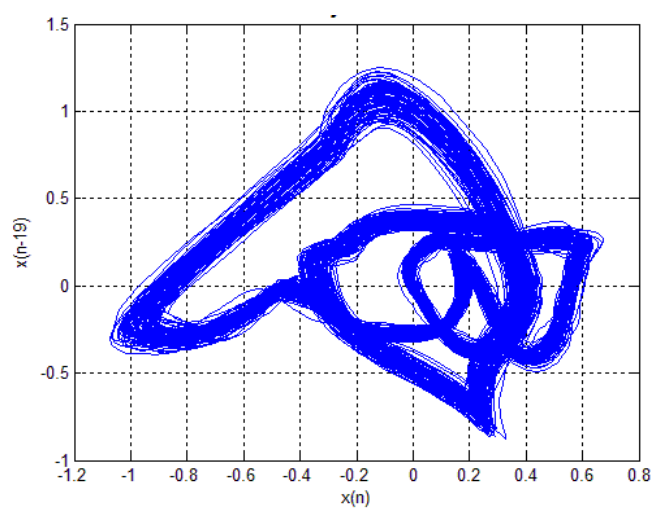

$\mathrm{L}_{2} \mathrm{I}_{1} \mathrm{E}_{3}$

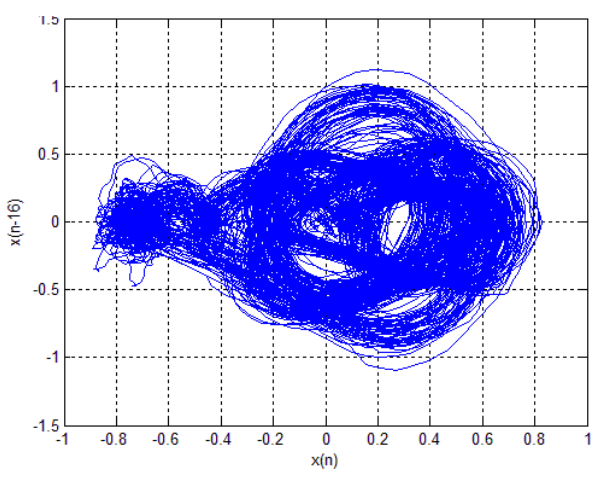

$\mathrm{L}_{2} \mathrm{I}_{5} \mathrm{E}_{6}$

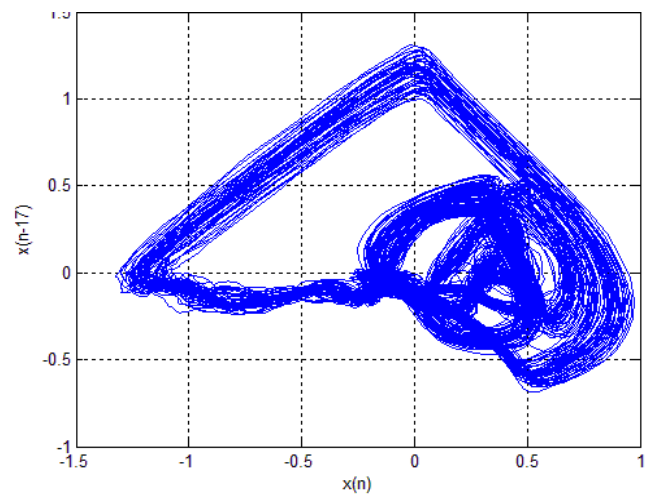

$\mathrm{L}_{3} \mathrm{I}_{3} \mathrm{E}_{4}$

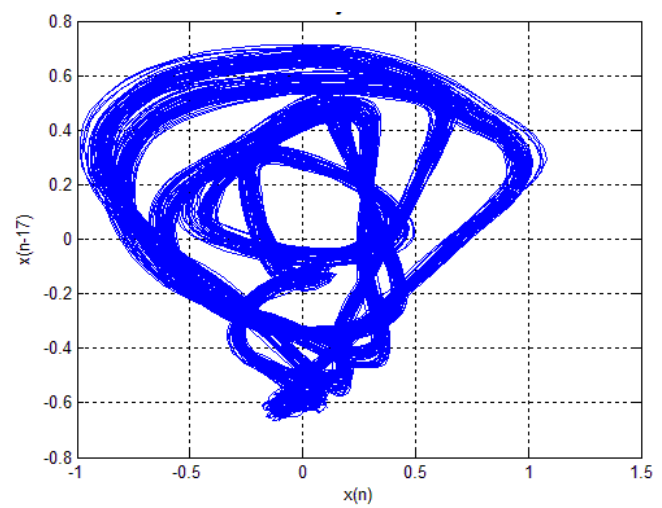

$\mathrm{L}_{4} \mathrm{I}_{1} \mathrm{E}_{3}$

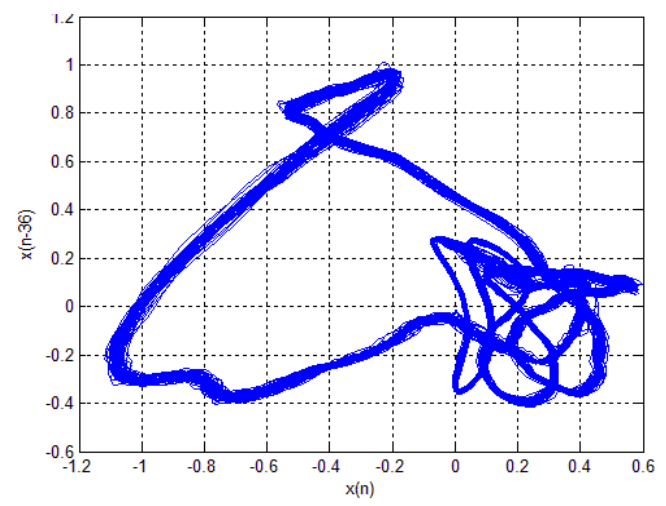

$\mathrm{L}_{4} \mathrm{I}_{2} \mathrm{E}_{1}$

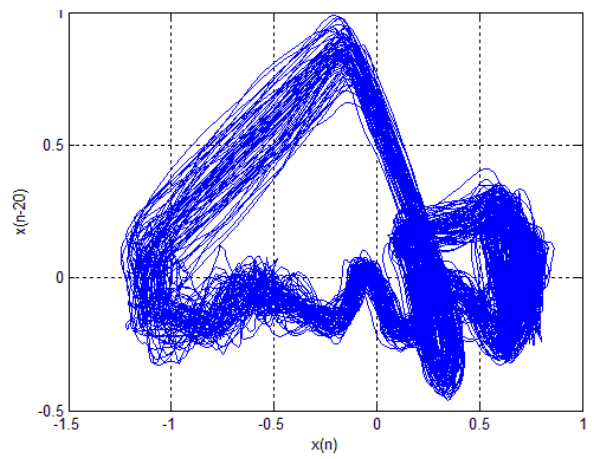

$\mathrm{L}_{1} \mathrm{I}_{5} \mathrm{E}_{5}$ 


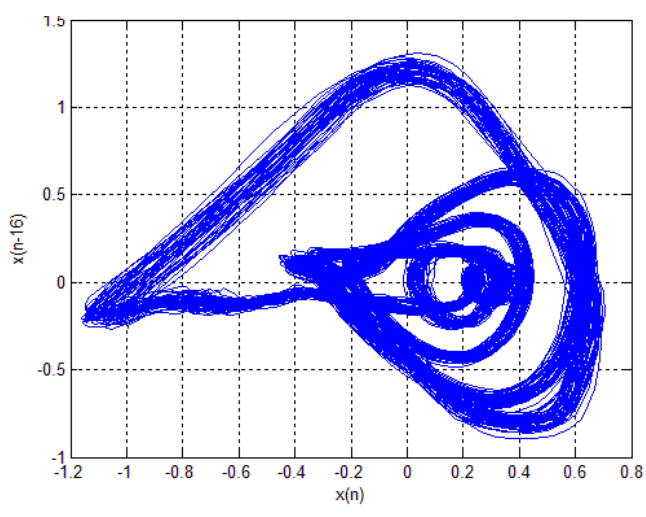

$\mathrm{L}_{4} \mathrm{I}_{1} \mathrm{E}_{3}$

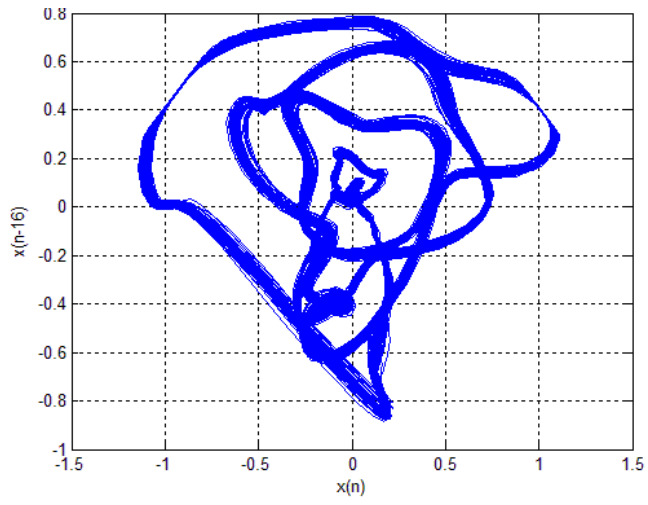

$\mathrm{L}_{4} \mathrm{I}_{1} \mathrm{E}_{1}$

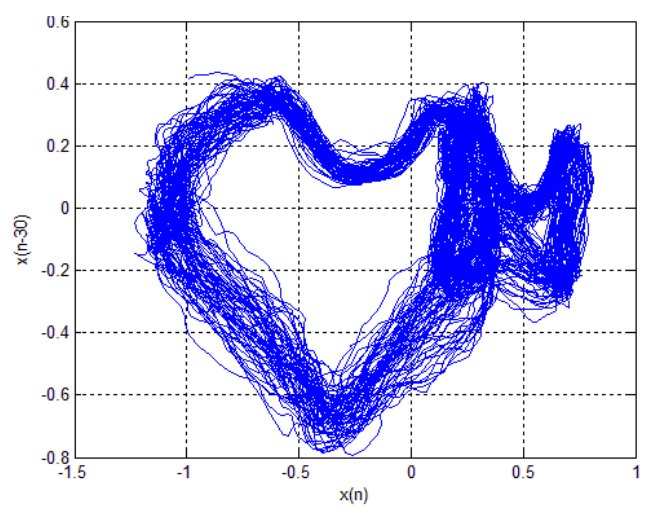

$\mathrm{L}_{1} \mathrm{I}_{6} \mathrm{E}_{6}$

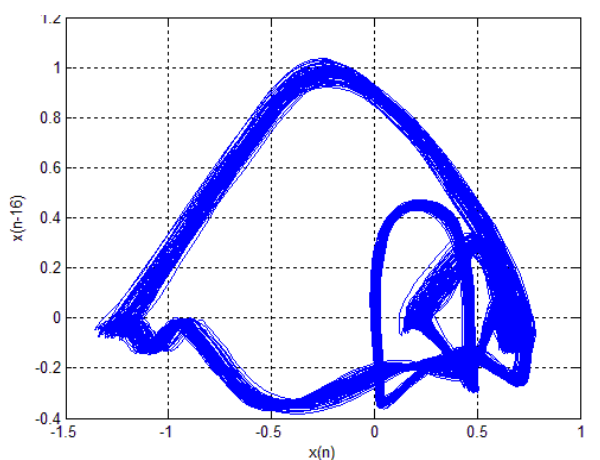

$\mathrm{L}_{2} \mathrm{I}_{1} \mathrm{E}_{1}$

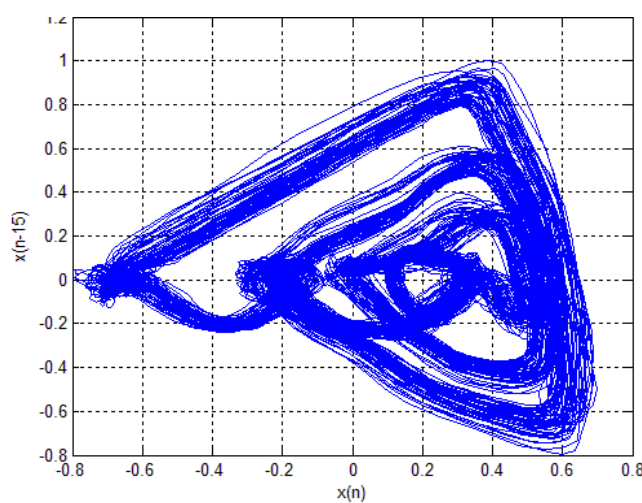

$\mathrm{L}_{4} \mathrm{I}_{3} \mathrm{E}_{4}$

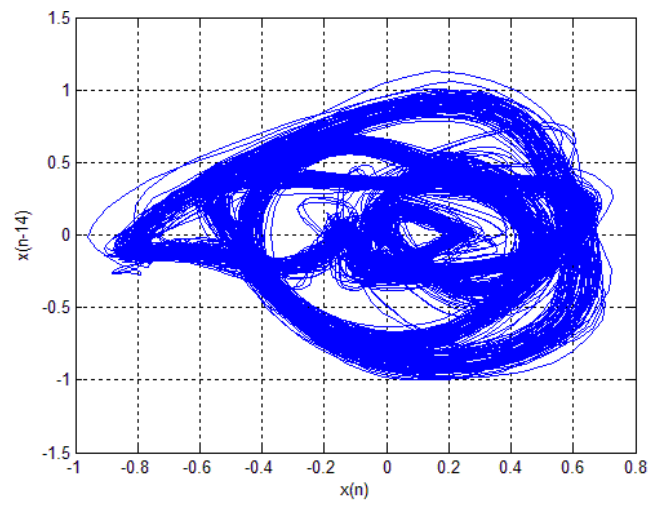

$\mathrm{L}_{4} \mathrm{I}_{3} \mathrm{E}_{4}$

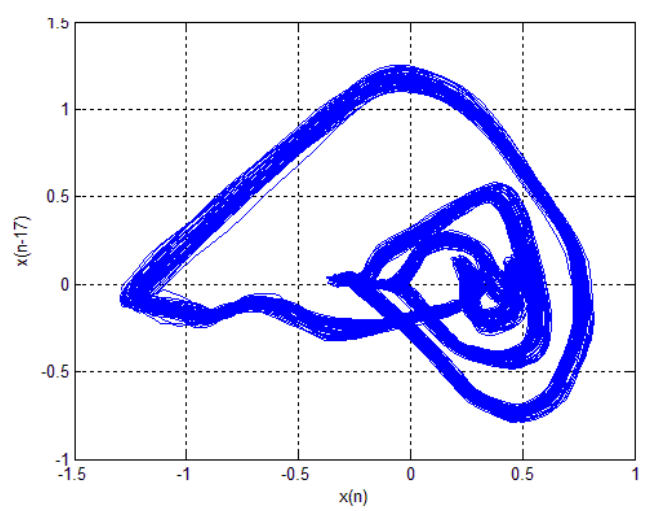

$\mathrm{L}_{3} \mathrm{I}_{1} \mathrm{E}_{1}$

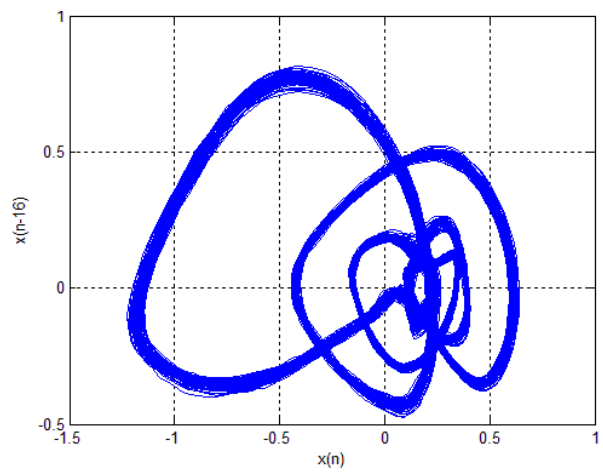

$\mathrm{L}_{4} \mathrm{I}_{1} \mathrm{E}_{1}$ 


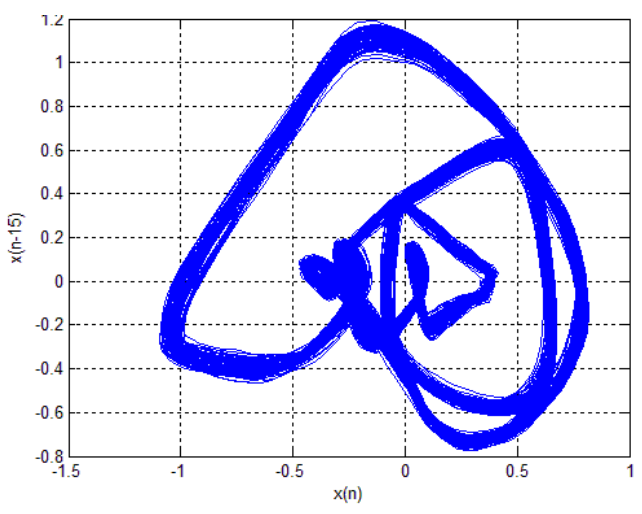

$\mathrm{L}_{4} \mathrm{I}_{1} \mathrm{E}_{2}$

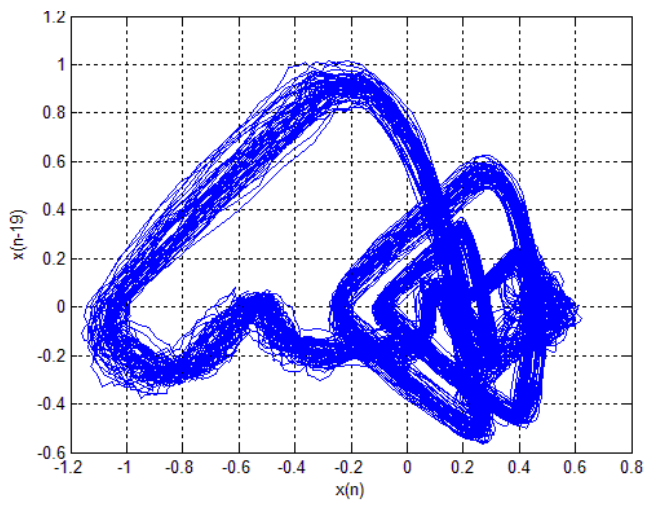

$\mathrm{L}_{3} \mathrm{I}_{4} \mathrm{E}_{4}$

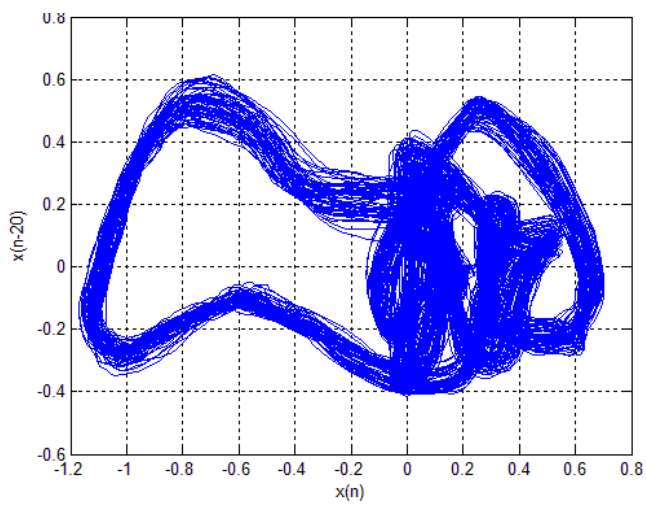

$\mathrm{L}_{3} \mathrm{I}_{1} \mathrm{E}_{3}$

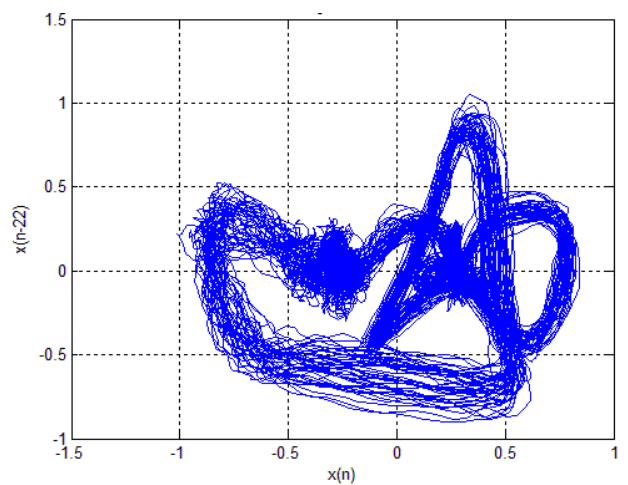

$\mathrm{L}_{2} \mathrm{I}_{6} \mathrm{E}_{4}$

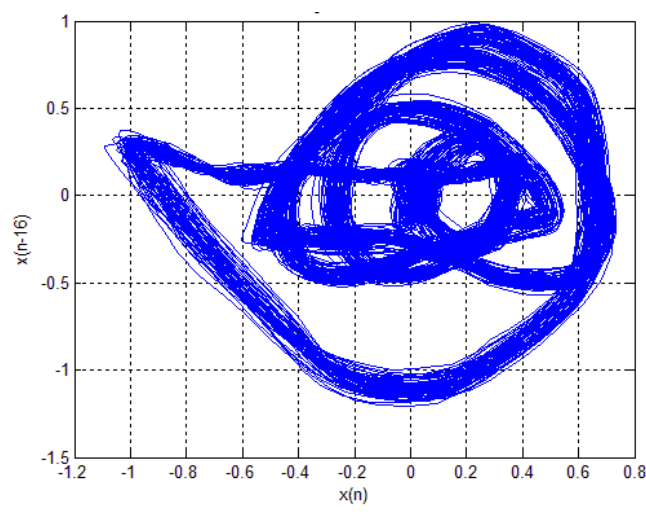

$\mathrm{L}_{3} \mathrm{I}_{1} \mathrm{E}_{2}$

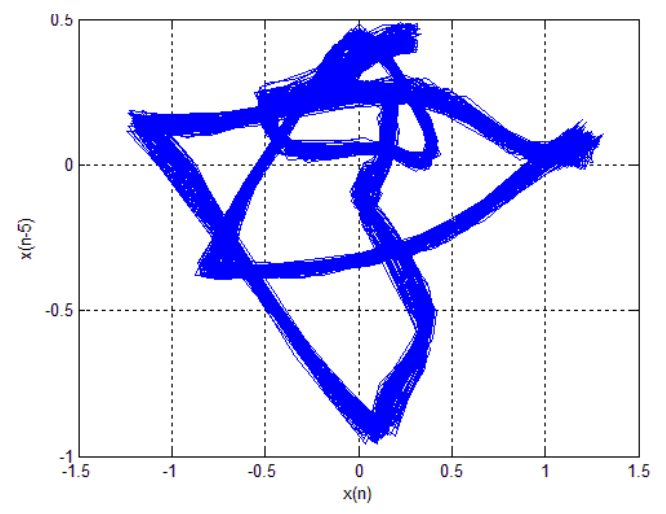

$\mathrm{L}_{2} \mathrm{I}_{1} \mathrm{E}_{1}$

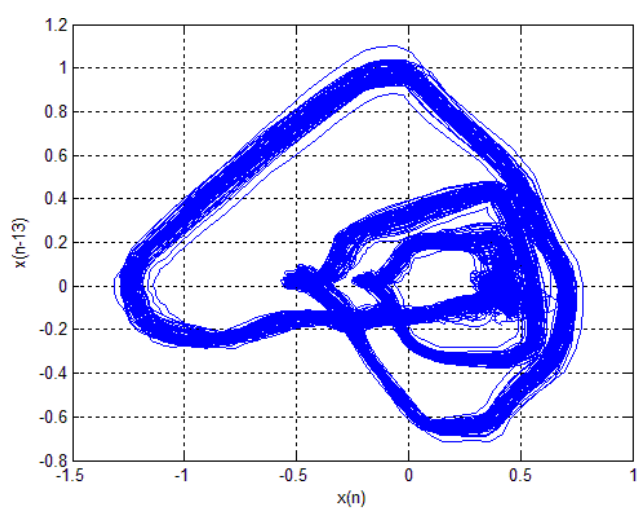

$\mathrm{L}_{2} \mathrm{I}_{3} \mathrm{E}_{2}$

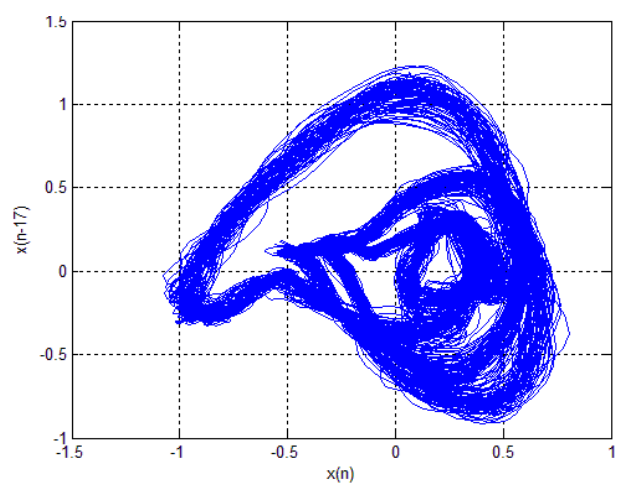

$\mathrm{L}_{3} \mathrm{I}_{4} \mathrm{E}_{4}$ 


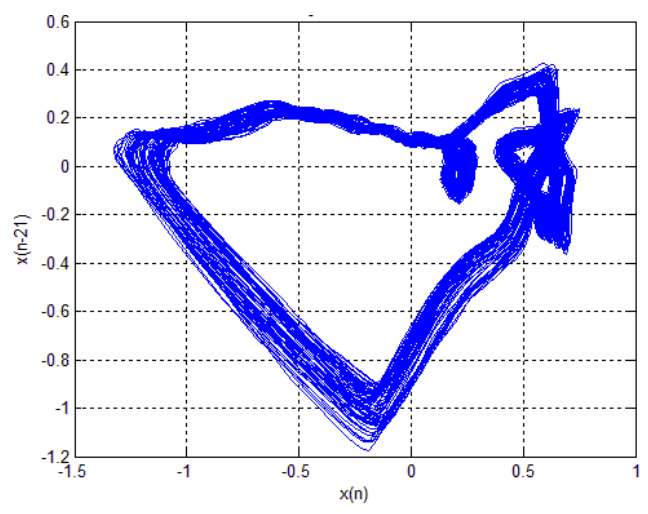

$\mathrm{L}_{2} \mathrm{I}_{1} \mathrm{E}_{4}$

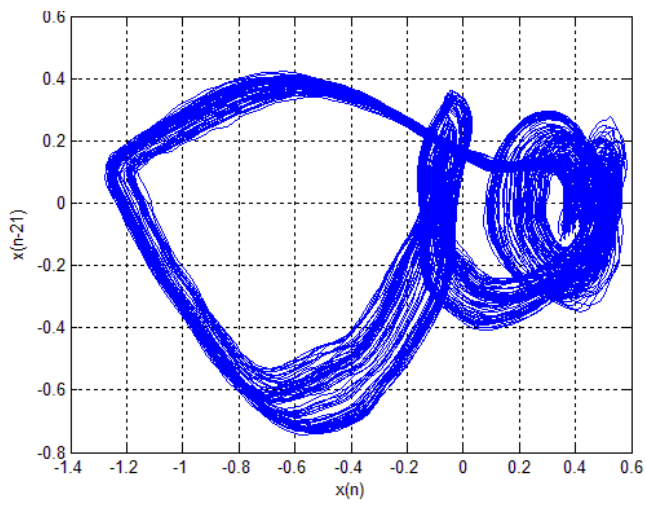

$\mathrm{L}_{3} \mathrm{I}_{1} \mathrm{E}_{6}$

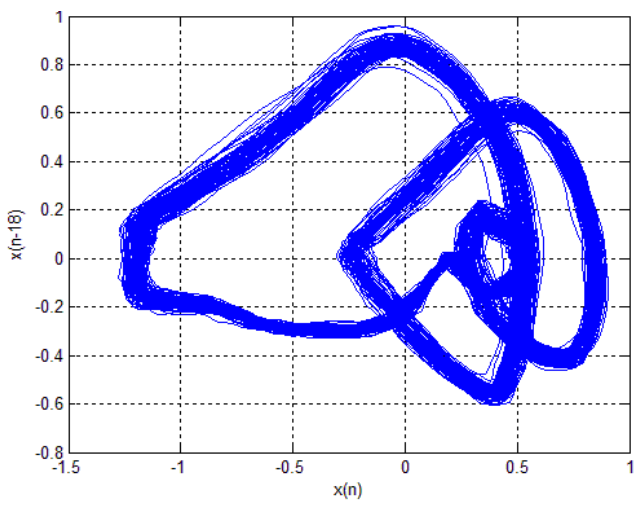

$\mathrm{L}_{2} \mathrm{I}_{1} \mathrm{E}_{3}$

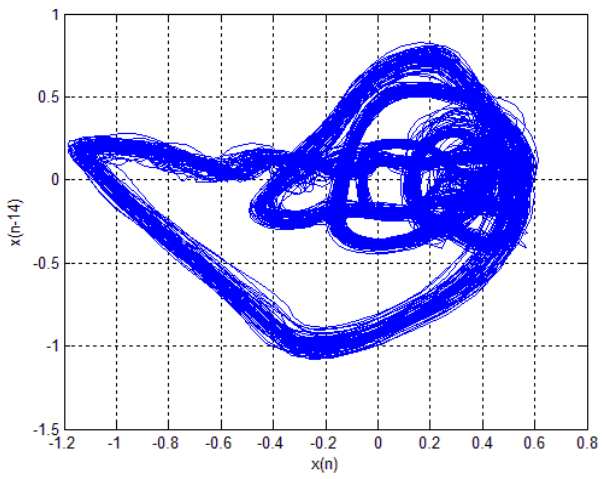

$\mathrm{L}_{4} \mathrm{I}_{3} \mathrm{E}_{3}$

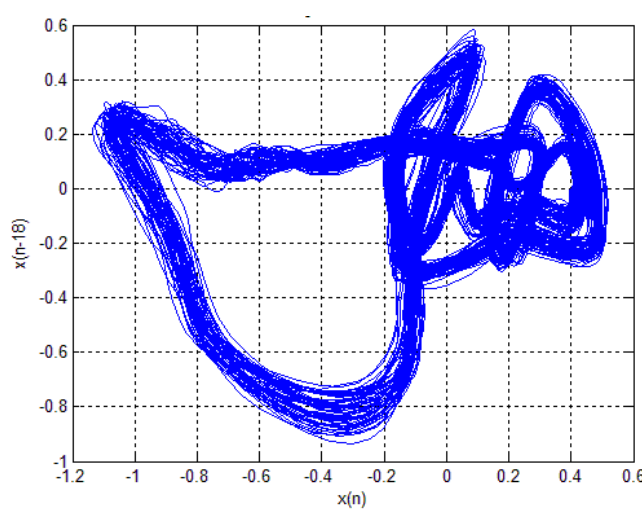

$\mathrm{L}_{4} \mathrm{I}_{3} \mathrm{E}_{3}$

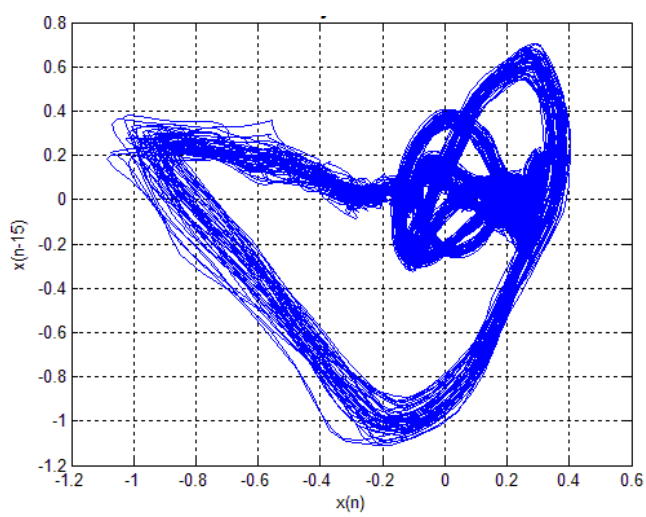

$\mathrm{L}_{3} \mathrm{I}_{3} \mathrm{E}_{3}$

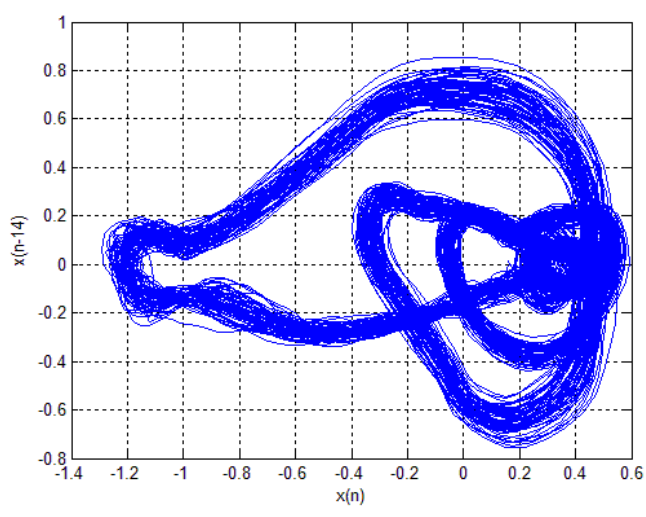

$\mathrm{L}_{3} \mathrm{I}_{3} \mathrm{E}_{3}$ 
Anexos 
ANEXO A

\section{APROVAÇÃO DO COMITÊ DE ÉTICA EM PESQUISA}

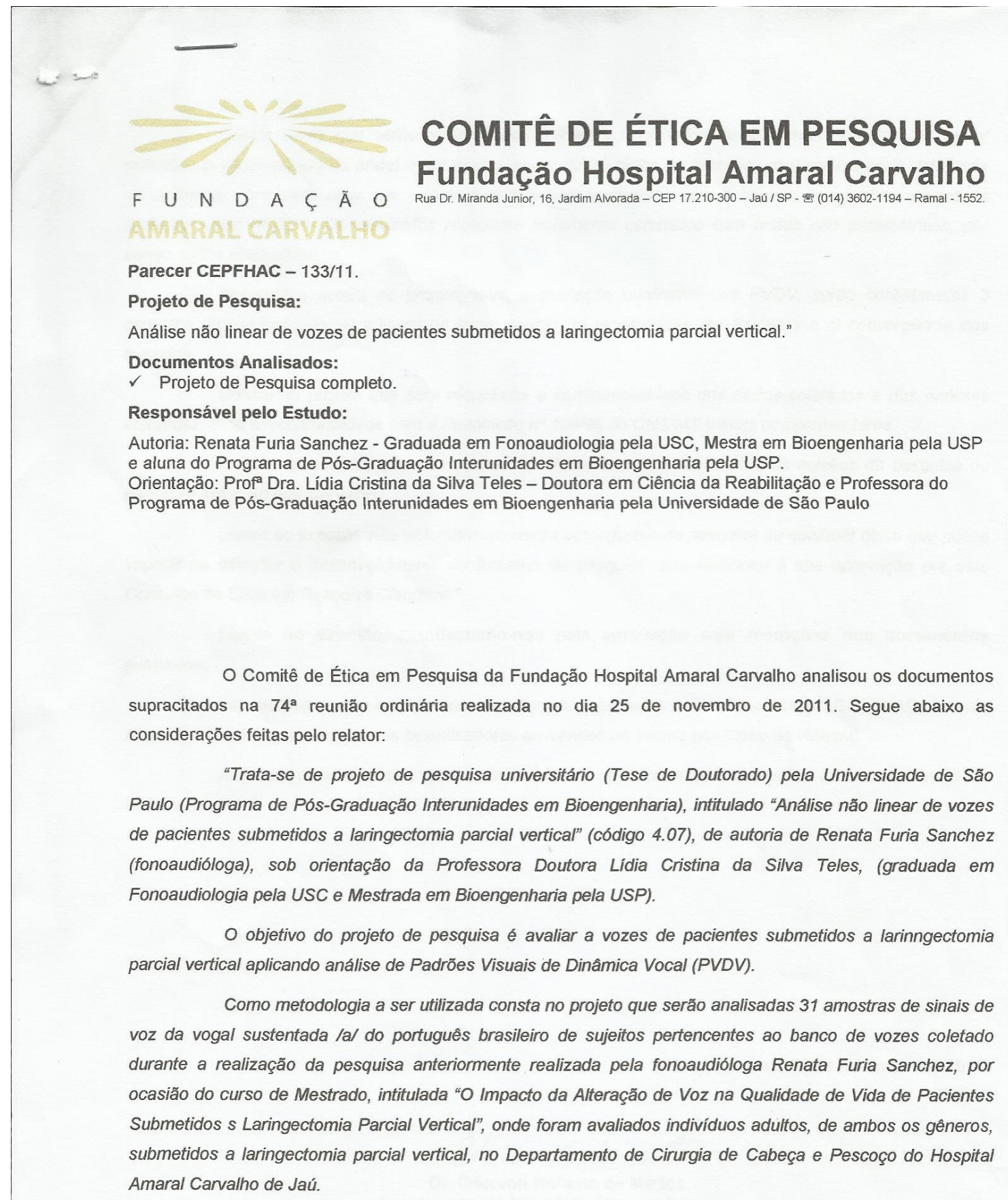


Consta ainda que serão selecionados trechos estacionários de 200 milissegundos (de maior estabilidade na amplitude da onda) e um trecho menor de 10 ciclos de duração, para análise mais detalhada na dinâmica, para cada uma das amostras para serem analisadas com a técnica de padrões visuais da dinâmica vocal (PVDV). Os resultados receberão tratamento estatístico com testes não paramétricos, por serem dados qualitativos.

Segundo a autora do projeto, para a avaliação qualitativa dos PVDV, serão considerados 3 aspectos da configuração: a) número de laços (loops), b) regularidade dos traçados e c) convergência dos traçados.

Consta no projeto que será respeitada a confidencialidade dos dados coletados e das análises efetuadas, tudo em conformidade com a Resolução $n^{\circ}$ 196/96 do CNS/MS e suas complementares.

Consta, finalmente, que não ocorrerá qualquer ônus financeiro para os sujeitos da pesquisa ou para o Hospital Amaral Carvalho.

Diante do exposto, não vis/umbrando riscos aos agentes da pesquisa ou qualquer óbice que possa impedir ou dificultar o desenvolvimento do trabalho de pesquisa, sou favorável à sua aprovação por este Conselho de Ética em Pesquisa Científica."

Diante do exposto, manifestamo-nos pela aprovação sem restrições dos documentos avaliados.

Informamos que os referidos documentos são rubricados pelo colaborador do CEPFHAC, Ricardo Augusto Sartori, e que nenhum dos pesquisadores envolvidos no estudo participou da votação.

Aproveito para recordar-lhe do compromisso de enviar relatórios semestrais referentes à evolução do estudo.

$$
\text { Clenw } \mu . d 6 \text { sutt }
$$

Dr. Éderson Roberto de Mattos 
PARECER CONSUBSTANCIADO

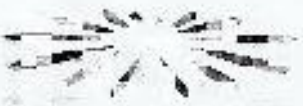

$H O S P$ H T A L

COMITÉ DE ÉTICA EM PESQUISA

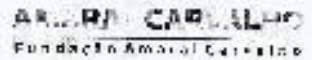

Fundação Hospital Amaral Carvalho

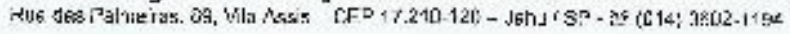

Harecer CEPTIAC: - 1)2il4

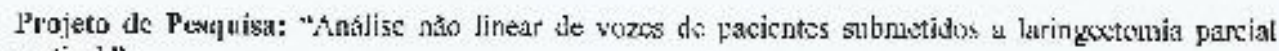
verlicel,"

Donumentos aunlikuling

$\checkmark$ Soljeiluçán de Altcrapăo do I'ltulo der Privjetor;

Rexponsivel pelo Fistuite: Rensta r uria Sanchect

\section{PARTCTR CONSUBSTANCIADO}

O Cumits de Ética em l'esquicu da Fundapân Hospital Amaral Carvalho analisou os

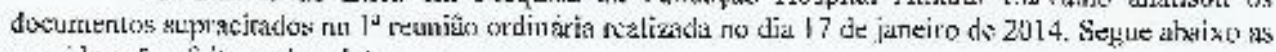
comsideraşos feitis jelo watator:

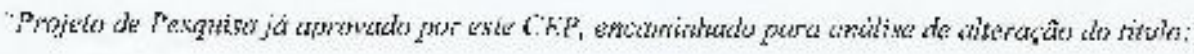

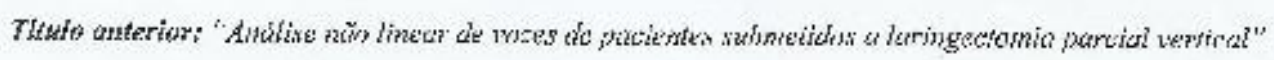

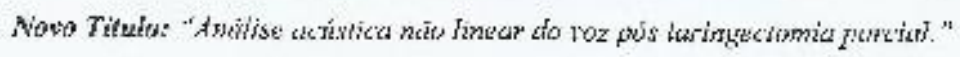

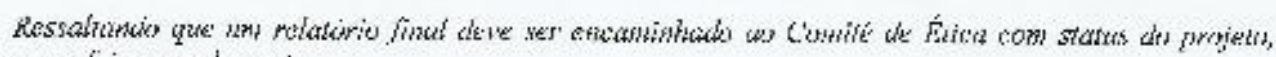
como fiot new andastentrs.

Sen enrater eticos."

Situaçăa: Aprơradı

Tnfonnamos yue us relizidos dacumentos stîn rubricudos pela colahoradora di: CIPFHAC;

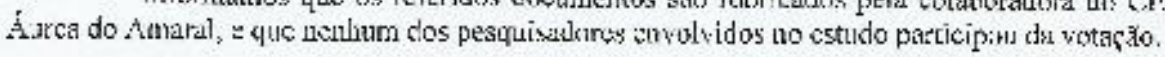

Aproycito para recordar-lhe do aumpromisso de ejyial relatirism scmestrais relerentus ì eหciluşĭ̄o to cstudo.

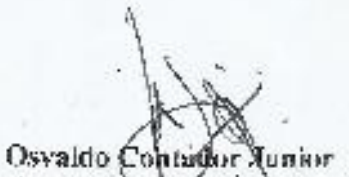

Jahu, 17 de joustro de 2014.

Coordenador do Cumnte de Titicy cm Pssquisa 